\title{
WestVirginiaUniversity
}

THE RESEARCH REPOSITORY @ WVU

Graduate Theses, Dissertations, and Problem Reports

2001

\section{Rates of adoption in a university course management system}

\author{
David Russell Feeney \\ West Virginia University
}

Follow this and additional works at: https://researchrepository.wvu.edu/etd

\section{Recommended Citation}

Feeney, David Russell, "Rates of adoption in a university course management system" (2001). Graduate Theses, Dissertations, and Problem Reports. 2390.

https://researchrepository.wvu.edu/etd/2390

This Dissertation is protected by copyright and/or related rights. It has been brought to you by the The Research Repository @ WVU with permission from the rights-holder(s). You are free to use this Dissertation in any way that is permitted by the copyright and related rights legislation that applies to your use. For other uses you must obtain permission from the rights-holder(s) directly, unless additional rights are indicated by a Creative Commons license in the record and/ or on the work itself. This Dissertation has been accepted for inclusion in WVU Graduate Theses, Dissertations, and Problem Reports collection by an authorized administrator of The Research Repository @ WVU.

For more information, please contact researchrepository@mail.wvu.edu. 


\title{
RATES OF ADOPTION IN A UNIVERSITY COURSE MANAGEMENT SYSTEM
}

\author{
David R. Feeney \\ Dissertation submitted to the College of Human Resources and Education \\ at West Virginia University \\ in partial fulfillment of the requirements \\ for the degree of \\ Doctor of Education \\ in \\ Educational Psychology
Dan Hursh, Ph.D., Committee Chairperson Andy Katayama, Ph.D. Neal Shambaugh, Ph.D. Roy Moxley, Ph.D. Stephen Ledoux, Ph.D. John Eshleman, Ed.D. \\ Department of Advanced Educational Studies \\ Morgantown, West Virginia \\ 2001
}

Keywords: innovation diffusion, educational technology, course management system Copyright 2001 David R. Feeney 


\section{Abstract \\ RATES OF ADOPTION IN A UNIVERSITY \\ COURSE MANAGEMENT SYSTEM}

David R. Feeney

This research focuses on diffusion of an education innovation in a large, traditional University. In March 1999, the Blackboard digital course management system was installed for enterprise-wide availability at Temple University, the 39th largest university in the United States. The web-enabled database of Temple Blackboard logs the adoption date, course ID, and course title for every Blackboard course, unobtrusively, twenty-four hours a day. Temple Blackboard serves as a digital approximation of the cumulative recorder pioneered by B. F. Skinner, recording more than 2800 course adoptions across 30 months, in real time. Temple Blackboard course records provide unprecedented quantity and quality of objective measures of innovation diffusion in a large education organization. The whole population of digital cumulative records may be analyzed, making statistical sampling optional. Digital cumulative recording of Temple Blackboard course adoption facilitates comparisons with other Temple course management systems, while reducing pro-innovation bias. Blackboard rates of adoption for Temple University as a whole, per college, per department, and per faculty may be visualized, compared, ranked, and analyzed, answering pressing questions about educational technology diffusion with precision and economy. 


\section{Dedication}

The author wishes to dedicate this document to his wife Mary, who was there. 


\section{Acknowledgments}

The author wishes to acknowledge The International Behaviorology Institute, http://www.behaviorology.org, for its long-term support of my research in effective digital education. 


\section{Table of Contents}

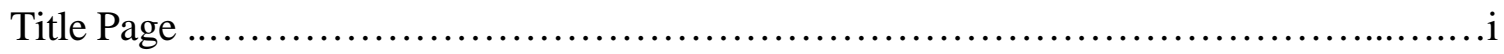

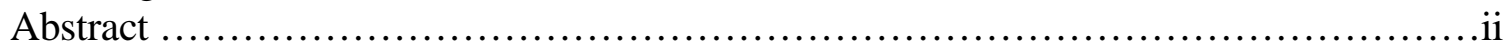

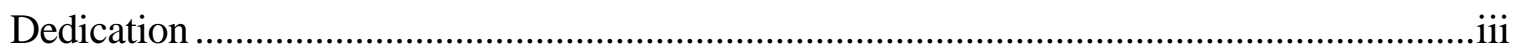

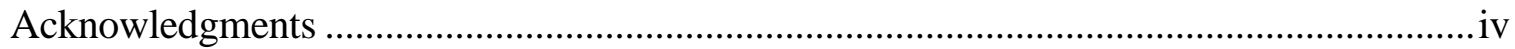

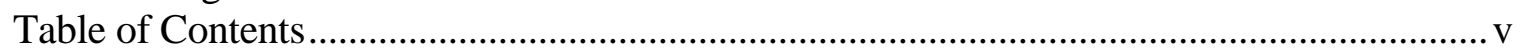

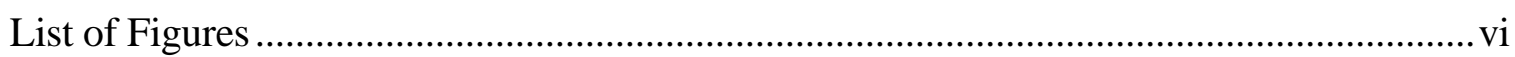

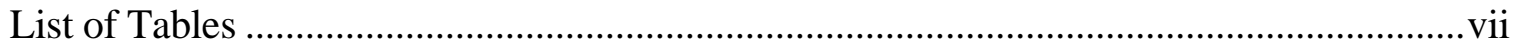

List of Nomenclature ................................................................................................ vii

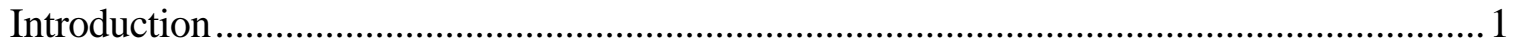

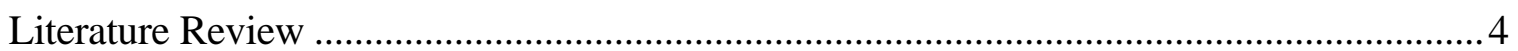

Online Courses: The Gold Rush .............................................................................. 4

Measuring Rate: The Reciprocal Values of B. F. Skinner and Everett Rogers.............. 20

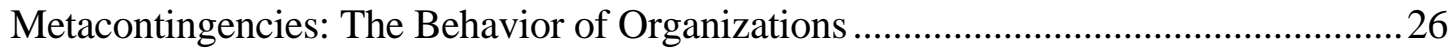

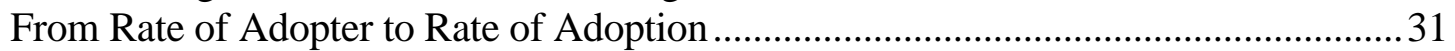

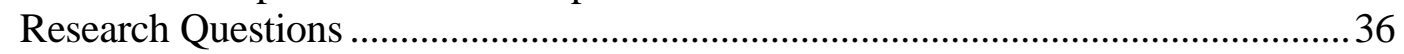

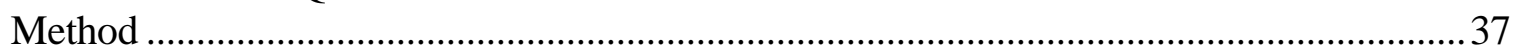

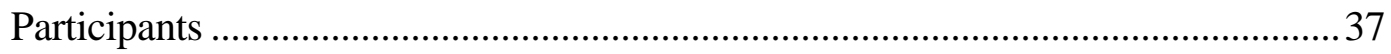

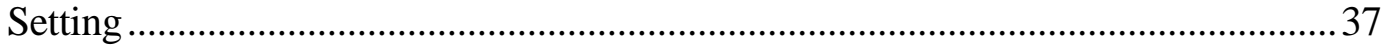

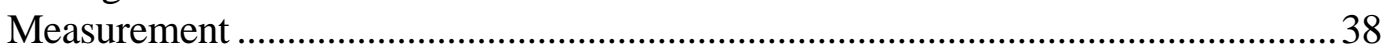

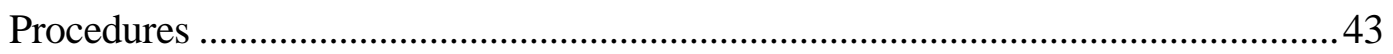

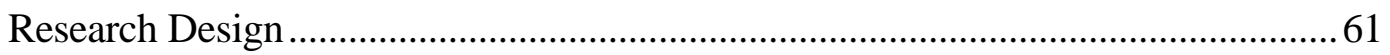

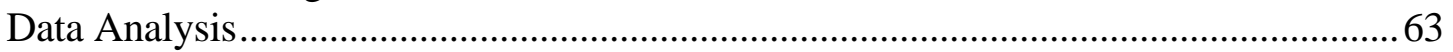

Charting Rate of Adoption as Cumulative Records ..............................................6 64

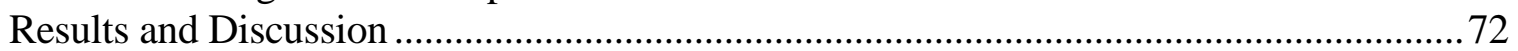

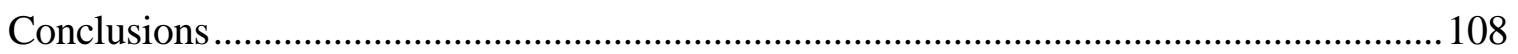

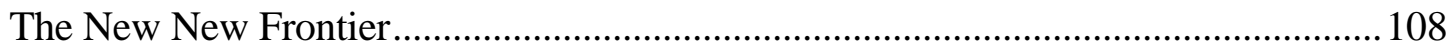

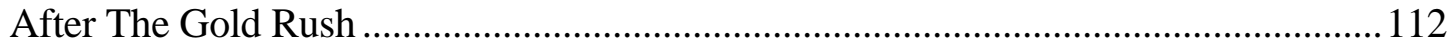

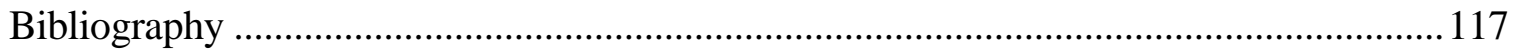

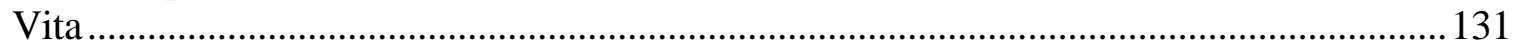

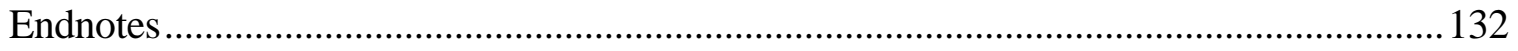




\section{List of Figures}

FIGURE 1: Temple Blackboard Course Catalog, preparing to search for STAT402..........51

FIGURE 2: Temple Blackboard Course Catalog search results for STAT402 ....................52

FIGURE 3: Temple Directory before and after searching for FEENEY .............................56

FIGURE 4: Using CREATION datestamps and CUMULATIVE NUMBERS, Excel will chart all 2,839 Temple Blackboard courses per day as a cumulative record. ........................65 FIGURE 5: Cumulative records of rates of adoption by Temple On-Line Learning Program, Temple Blackboard, Blackboard colleges, the Fox School, Fox School departments, and Fox School faculties.............................................................................6

FIGURE 6: Temple Blackboard course request web forms from phases B1 and B2-B3....70 FIGURE 7: Rate of adoption for On-Line Learning Program with Blackboard phases. .....73 FIGURE 8: Rate of adoption for Temple Blackboard, showing B1, B2, and B3 phases. ...75 FIGURE 9: Exponential trendline applied to Temple Blackboard cumulative curve...........77 FIGURE 10: The Temple Blackboard chart, and its inverse. ...............................................79 FIGURE 11: Cumulative records of rates of adoption for Temple colleges and

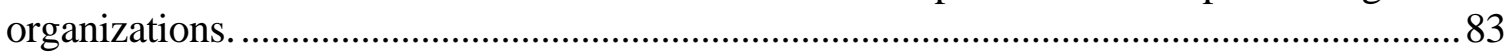

FIGURE 12: Cumulative records of rates of adoption for Temple colleges and

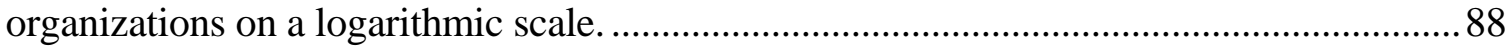

FIGURE 13: Fox School percentage of Temple Blackboard courses. .................................90 FIGURE 14: 872 Fox School Blackboard courses and constituent departmental ROAs. ...92 FIGURE 15: Fox Departmental rates of adoption per full-time faculty..............................95

FIGURE 16: The Fox Departments chart, and its inverse....................................................98

FIGURE 17: Fox Departmental rates of adoption per all faculty. ………...........................100 FIGURE 18: All-faculty rates of adoption 20 points before and after onset of B2 phase.. 104 FIGURE 19: All-faculty rates of adoption 20 points before and after onset of B3 phase.. 107 


\section{List of Tables}

Table 1: A basic On-Line Learning Program course record, constructed by the author......39

Table 2: A basic Temple Blackboard course record, tracked mechanically...........................41

Table 3: Basic On-Line Learning Program course record, as created by author................... 43

Table 4: On-Line Learning Program course records, listing FACULTY NAME and

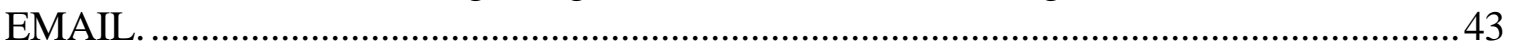

Table 5: On-Line Learning Program course records, with extra columns..............................45

TABLE 6: Temple Blackboard course records arranged and sorted by date. ........................46

TABLE 7: Temple Blackboard course records with TU and COL columns.........................47

TABLE 8: Temple Blackboard course records sorted by COLLEGE CODE. ...................... 48

TABLE 9: The 26 code groups by which all 2,839 Temple Blackboard course records were

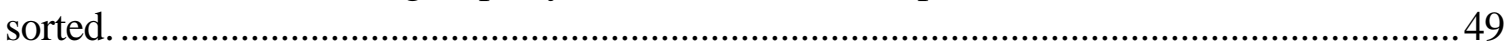

TABLE 10: 872 Fox Blackboard course records were coded by Fox department................58

TABLE 11: 872 Fox Blackboard course records were placed in 17 code groups.................59

TABLE 12: Blackboard courses and rates of adoption per Temple college and organization, ranked from highest to lowest. .......................................................................................... 82

TABLE 13: Fox Blackboard courses and rates of adoption per Fox department and organization, ranked from highest to lowest....................................................................94

TABLE 14: Temple University vs. Fox School rates of adoption.........................................97

TABLE 15: Slope calculations for Temple Blackboard and its three phases...................... 102 


\section{List of Nomenclature}

1. Blackboard: The brand name of course management system installed at Temple University. See http://foxonline.temple.edu/drf/evidence/bbcompany/

2. Course Management System (CMS): A course management system allows easy exchange of text, multimedia documents, and live conversations between faculty, students, staff, and the public via a World Wide Web browser, a web-enabled database, and commercial course management system software. See http://webopedia.internet.com/TERM/d/distance_learning.html; Blackboard, http://www.blackboard.com; WebCT, http://www.webct.com; Princeton University CREN Seminar, http://www.cren.net/know/techtalk/events/cms.html

3. Diffusion: In physical science, the flow of energy or matter from a higher concentration to a lower concentration, resulting in a homogeneous distribution. See http://encarta.msn.com/index/conciseindex/59/05947000.htm?z=1\&pg=2\&br=1, http://www.biologylessons.sdsu.edu/ta/classes/lab4/semnet/diffusion.htm, http://library.thinkquest.org/27819/ch2_10.shtml?tqskip=1

4. Database Management System (DBMS): Programs that enable you to store, modify, and extract information from a database. Most DBMSs include a report writer program that enables you to output data in the form of a report, and a graphics component that enables you to output information in the form of graphs and charts. See http://isp.webopedia.com/TERM/d/database_management_system_DBMS.html

5. Temple University Blackboard: The on-campus installation of the Blackboard CMS for use at Temple University in March, 1999. See http://blackboard.temple.edu

6. Temple University Blackboard System Administrator. Mr. Matt Palladinetti, computer services technician managing the Blackboard server and software application. See http://isc.temple.edu/isc/about/staff.html

7. Web Browser: a software application used to locate and display Web pages. The two most popular browsers are Netscape Navigator and Microsoft Internet Explorer. Both of these are graphical browsers, which means that they can display graphics as well as text. See http://isp.webopedia.com/TERM/b/browser.html 


\section{Introduction}

A course management system (CMS) allows easy exchange of text, multimedia documents, and live conversations between faculty, students, staff, and the public via the Internet. Using a World Wide Web browser, a web-enabled central server database, and commercial course management system software, teachers and learners may contact the materials and contingencies of instruction with or without face-to-face meetings.

Course management systems have been the focus of recent scholarly attention, provoking enthusiasm and condemnation, each leavened with uncertainty. While Joel Foreman and Joan Widmayer call course management systems "the inevitable future of education", they warn of a "new set of uncertainties" about how to teach with them (Foreman and Widmayer, 2000).

In a university context, a newly installed CMS offers widespread opportunity for organization members to adopt an educational innovation, a new digital teaching technology that must be selected, paid for, installed, maintained, and monitored. As integrating technology into higher education becomes an institutional imperative at schools across the United States (Cooper and Bull, 1997), adoption of digital courses in a new CMS becomes both an organizational goal, and a source of data upon which to evaluate performance.

When a new, previously unavailable course management system is implemented at a university, each actor in the educational scene is recast in the role of decision maker. To adopt, or not to adopt? That is the question. 
Hoping to profit from success while reducing uncertainty, CMS implementations at large Universities are watched closely by these new decision makers:

- Review committees, comparing various CMS products prior to institutional purchase;

- Faculty, whose adoption or nonadoption is now at issue;

- Department chairs, whose adoption of the CMS is a model for faculty;

- Deans, who lead colleges, provide resources, and monitor participation;

- Teacher-trainers, who work as change agents to diffuse selected innovations;

- CMS administrators, looking for data to predict demand on server resources;

- Vice Presidents, looking for data showing return on substantial investment;

- Presidents, looking for measures of institutional transformation;

- Students, for whom adoption is a pragmatic necessity.

Mere installation and availability of a course management system in a university is not a guarantee of a rate of adoption high enough to justify investment. Higher education organizations face persistent challenges in the adoption of technology (Falba, Strudler, and Bean, 1999; Olsen, 1999), with the course management system being the latest technology challenge (Foreman, 2001). With technology programs consistently ranking as a top priority in higher education (Carlson, 2000), new ways of measuring campus technology programs should prove generically useful (Brunner and McMillan, 
1994; Rai, 1998). In this study, Temple University's Blackboard CMS serves as a kind of Skinnerian cumulative recorder, logging a record of each Temple Blackboard course adoption in real time in its web-enabled database. The benefits of cumulative recording as a behavioral research strategy (Sidman, 1960; Skinner, 1938; Skinner, 1959) are extended via the World Wide Web to track rate of adoption of an education innovation on the part of any Temple faculty or staff among the 47,000 registered Temple Blackboard users. The adoption date, course ID, and course title of every Blackboard course is logged immediately, unobtrusively, and digitally, twenty-four hours a day. This digital approximation of B. F. Skinner's cumulative recorder provides direct, mechanical measurement of adoption of an innovation, while making feasible the analysis of thousands of digital records without statistical sampling. More than 30 months of course adoption records allow unprecedented quantification, charting, and visual inspection of rates of adoption in a university course management system. 


\section{Literature Review}

\section{Online Courses: The Gold Rush}

Mass adoption of computer and internet-based telecommunications technology has wreaked indelible changes across every sector of modern, industrialized societies. In 1962, the first recorded description of interconnected networking of computers were memoranda written by J. C. R. Licklider of Massachusetts Institute of Technology. Licklider described a "galactic network" of globally interconnected computers from which anyone could quickly access data and programs from any other computer, capturing the spirit of today's Internet. J. C. R. Licklider was the first head of the computer research program at Advanced Research Projects Agency (ARPA) in October 1962 (Leiner et al., 2000).

In the nearly 40 years since the verbal behavioral beginnings of the Internet, the decreasing costs of personal computers, amortized across the sunk costs of nearly ubiquitous telephone technology, has resulted in a brave, new world of increasingly affordable, adoptable online services, which inevitably will effect education at every level. Matthew Pittinsky, Chief Executive Officer of course management system company Blackboard, characterizes the reach and pace of Internet adoption, and its inevitable effect on education: "It took 2000 years for Roman Catholicism to reach 968 million, 350 years or so for the Harvard University charter to reach 1.4 million, and seven years for the commercial Internet to reach 250 million... American education is a 4 billion dollar a year business. If even $10 \%$ of that is shaken loose for the Internet, that's significant" (M. Pittinsky, personal communication, June 15, 2000). 
While the "digital divide" between those who can and cannot afford to adopt online services remains an enduring issue (Cross, 2001), the sweeping pace of adoption by the "haves" may be the best guarantee of access to "have-nots". Jakob Nielsen used public data samples compiled by web robots (programs that move from a web server to any other servers it links to) to estimate the number of web servers on the WWW in any given month. By January 1995, 18 months of data collection led Nielsen to estimate the growth rates of web servers at an annualized rate of about 12,000 percent, meaning that the number of web servers would double every 53 days (Nielsen, 1996). Wide citation of this explosive growth led Nielsen to publish further data in an attempt to "kill the 53 day meme", noting that

Of course, growth rates this fast cannot continue indefinitely, and now (March 1997), the same method provides an estimate of 333 percent annualized growth, corresponding to a doubling of the number of web servers every 173 days. The number of web servers is growing ever more rapidly in absolute terms, but the annualized growth rate will probably keep going down until at some point of time it approximates the growth rate of the Internet as a whole, which has been stable at about 100 percent per year ever since the Internet was founded (Nielsen, 1995, p. 2).

Recent demographic studies of America's expanding Internet populations are challenging the core presumptions of a digital divide: that young, technologically savvy white men dominate the Web. (Weiss, 2001). For example, a Harris Interactive study showed that the number of women logging on exceeded the number of men for the first 
time in May, 2000. Trends from several recent demographic studies show that people of different groups use the Internet in different ways (for example, affluent homes use the Internet as a tool of convenience, whereas working-class families use the Internet for entertainment) but that, owing to increasing adoption, the diverse characteristics of the online population increasingly represents the offline population.

Regardless of its real, imagined, or temporary status, allegations of a digital divide have prompted reactions from advocates and critics alike, equating "adoption of the internet in classrooms" with ending the digital divide. "We must not only close the gap... we must advocate and implement precollege experiences that provide quality technology and training for all our young people." (Cross, 2001, p. 1). Delores Cross cites current Secretary of Education Roderick Paige: "You have to know how to get wired in order to get hired" (Ibid, p. 2).

The most tangible advocate for increased classroom Internet adoption is the United States government. The "E-Rate" or Education Rate Program is a subsidy program targeting online service adoption in the classroom through significant discounts on the price of telecommunication services for schools and libraries. The Federal Communications Commission authorized the E-Rate program in May, 1997, part of the 1996 revisions to the Telecommunications Act. ${ }^{\mathrm{i}}$ Since 1998, the Schools and Libraries Program within the FCC has overseen the allocation of need-based discounts on online services to more than 1 million schools and libraries - discounts that range from 20 to 90 percent. The cost of E-Rate subsidies is passed through phone companies to consumers as "universal service" charges on their regular phone bill (Rogers and Oder, 2001). In 1998, then Secretary of Education Richard. W. Riley equated E-Rate with eliminating the 
digital divide, by getting "useful technology into every classroom" with additional initiatives focusing on "giving teachers support and training to use technology... to lead this information revolution" (Riley, 1998). The E-Rate program has a 2001 budget of $\$ 5.78$ billion, which equals nearly the total spending in the last three years. Regardless of the reality of the digital divide, federal support for adoption of online services in education is substantial.

Even skeptics of computing in the classroom have become adopters of online services in education, mainly to support skeptics of the classroom itself: homeschoolers. Former Secretary of Education William Bennett states "So far, there is no good evidence that most uses of computers significantly improve learning", yet in $2001 \mathrm{Mr}$. Bennett founded K12, an internet-based school for kindergarten through twelfth grade (Anonymous, 2001). K12 produces curricula for language arts, phonics, math, science, history, music, and art for delivery via the Internet, aimed at customers like public schools, private schools, and their primary audience: American homeschoolers. In 2001, there were an estimated 1.5 to 1.9 million children home schooled (Ray, 2001). Since 1993 (when home schooling became legal in all 50 states), the number of students being taught at home has tripled in consonance with increasing home-based internet adoption, bringing both educational content and socialization opportunities to homeschoolers (De Moll, 2000). By September 2000, internet media giant Amazon.com had created its own online store to bring internet content to home school families in America, Japan, Europe, and Canada (Billups, 2000).

"Knowing how to get wired" has also become an A-level issue in higher 
education. Since 1990, the annual Campus Computing Survey has become the largest continuing study of information technology in US higher education, surveying more than 600 colleges and universities about information technology in teaching and learning. Campus Computing Project surveys show that "faculty integration of technology into teaching" has been the top priority for academic computing administrators in 1999 and again in 2000 (Olsen, 1999; Carlson, 2000).

That priority is motivated in part by student challenges to faculty authority in terms of online technology skills acquired outside of class. "I think it's fair to say that many faculty members have ceded to their students the whole issue of technology skills," says Kenneth C. Green, founder of the Campus Computing Project. Citing "a new kind of Oedipal aggression in the classroom”, Green describes business students using superior skills to check The Wall Street Journal or Business Week websites before class and "going after their professors on content as well... and that's right at our hearts" (Olsen, 1999).

Faculty integration of computer technology into teaching has proven a resilient problem in classrooms of every kind. In 1996, Kenneth Green predicted "a coming ubiquity" of information technology like the Internet in college classrooms and boardrooms (Green, 1996). In a notable rejoinder to Kenneth Green's 1996 predictions, Everett Rogers concurred, suggesting that higher education had indeed crossed 
"the point of critical mass for instructional use of information technology... the rate of adoption is quite likely to continue to shoot upward over the next several years... in this instance, it creates still more demand for still more infrastructure and support as growing numbers of faculty across all disciplines and institutions adopt and adapt informational technologies in their instructional activities" (Rogers, Geoghegan, Marcus, and Johnson, 1996, p. 30$)$.

By 2000, however, the Campus Computing Project survey showed colleges lagging far behind in adoption of technology trends in society at large, such as ecommerce systems, wireless technology, and personal digital assistants. Commenting on year 2000 data, Kenneth Green suggests that technology integration in colleges may soon "reach a plateau", slowing considerably from its already slow pace (Carlson, 2000, p. A47).

In Green's "Oedipal aggression" scenario, both college faculty and students have access to the Internet on campus, if not in the classroom itself. It is the superior skills of students to use available technology which sets the stage for invidious comparison and, as Green relates, heartfelt challenges of faculty as subject-matter authorities. The distinction is between "technology in the classroom" and "integrating technology into teaching". Research has shown that the first does not cause the second.

According to the National Center for Education Statistics, only a fraction of U.S. students reported using available school computers, and even fewer reported any academic use during the 1992 school year (NCES, 1997a). While personal computers 
had been in public schools for more than 10 years (Becker, 1991), in 1992 fewer than half of high school students $(41.3 \%)$ used a computer for coursework once a week. More than half of students who did use a school computer in 1992 did so to play games or to practice computer-literacy skills like keyboarding, never using them for coursework (NCES, 1997b).

The U.S. Government's E-Rate subsidy program, which "bundles” teacher support and training initiatives with discounts on online services, acknowledges that adoption of online services and the Internet by schools is necessary, but not sufficient. William E. Kennard, Chairman of the Federal Communications Commission, placed the spotlight directly on classroom teachers:

As an EdLINC study found... 83\% of Americans believe that Internet access will improve educational opportunities for our children. Out in the field, we have to remember that the E-Rate program is not a turn-key program. Connectivity alone does not guarantee educational success. The skills you are called upon to use in introducing new technologies to the schools are demanding, but critically important. Your own conference paper states that if teachers are not trained in using computers, they can hardly be expected to use computers in training their students. Teaching effectively through computers cannot be done without connectivity, but E-Rate connectivity is just the first step in a larger process that you... have to contend with (Kennard, 2000, p. 3).

Research about pre-Internet computers in classrooms makes clear that using 
computers in coursework routinely challenges teachers, and teacher-educators. In a collective case study of changes in courses in a department of education, Falba, et al. incorporated interviews with education faculty who had experienced new teachereducation courses about Internet technology. Examination of subsequent education courses showed minimal changes, even after teacher-education, although the authors suggest that small observed changes in education faculty courses are valuable to the overall teacher education program as a whole. (Falba, Strudler, and Bean, 1999). In a larger study, Ndahi examined the use of online services by 79 industrial and technical teacher-educators from 20 different American universities. Results showed that use of email and World Wide Web technology was resisted by approximately one-third of the teacher-educators surveyed (Ndahi, 1999). In their review of the status and future of technology in teacher education, Willis et al. concluded with a call for more case studies in innovation diffusion in education to guide research and development toward effective technology use (Willis, Thompson, and Sadera, 1999).

The gap between technology adoption and technology use in teaching has been noted worldwide. The International Association for the Evaluation of Educational Achievements (IEA) conducted a survey on the use of computers in schools from 1987 to 1990 in 18 countries with more than 69,000 participants (Pelgrum, Janssen, and Plomp, 1993). In most countries, computer integration into school subjects was initiated by small groups of teachers, focused within higher-grade levels, and resisted by a majority of teachers. In an application of innovation diffusion concepts to publicly available data, Hester Fuller of the Harvard Graduate School of Education used data from the IEA study 
to investigate the effects of computer coordinators working with teachers on the incidence of student computer coursework in grades five and eleven. Fuller's results showed that teacher training is more effective than student training in increasing student computer usage for coursework. Interestingly, Fuller noted that the effectiveness of teacher training for technology integration might be contingent on the degree to which the teacher-educator's job resembles that of the client teacher (Fuller, 2000).

Education that is "wired" is now believed to be required to produce well-educated students. Course materials via the World Wide Web, supplemented with tools for discussion and conversation, have taken higher education by storm. A spectrum of government, private, professional, and market forces aim to bring online services to college classrooms, with or without an implicit understanding that such technology liberates instruction from the classroom setting.

Online courses challenge cherished assumptions about the value and necessity of corporeal presence in education in ways that have never been experienced in higher education. The American Association of University Professors (AAUP) noted this in their Statement on Distance Education: 
More important, the development of distance-education technologies has created conditions seldom, if ever, seen in academic life... for example, in distance education the teacher does not have the usual face-to-face contact with the student that exists in traditional classroom settings... In order to communicate with the student, the teacher frequently utilizes... technological devices which are not under the teacher's exclusive control and which often require special technical knowledge that the teacher may not fully possess. (AAUP, 1998, p. 1).

New elements of challenge and competition that surround online courses may not result in more integration with classroom activities, but it probably can't result in less. According to Tom Loveless:

No setting has appeared more impervious to external reform than the classroom, especially when it comes to changing methods of instruction... Initiatives designed to alter ways of conducting instruction have met with continual disappointment. Large-scale federal efforts to create new math and science programs in the 1960s succeeded in capturing the attention of academics, the policy community, and the media, but just a few years after an initial burst of enthusiasm, researchers found most of the new instructional materials hidden away in storage closets and not in classroom use (Loveless, 1996, p. 452).

Added to the documented challenges of computer integration is added a new challenge of relevance: If online services cannot be integrated into the classroom, then 
elements of the classroom may be integrated into the online service, bypassing the classroom entirely. In essence, classrooms as a cultural practice now compete with the online technology being installed in them. In an article for The Behavior Analyst about new considerations for higher education classes, David Schmitt notes:

The need to understand the immediate and enduring effects of a course's components is more critical now, as distance learning emerges as a powerful competitor to in-class instruction. Although many opponents of distance learning claim beneficial effects of face-to-face contact, there is little supporting evidence beyond the anecdotal. If research finds face-toface activities to be valuable, it may be possible to capture essential features in computer mediated exchanges among students" (Schmitt, 1998, p. 288).

Online courses continue to challenge higher education because of the cultural adoption of such technology outside of academics, but also because of persistent claims that education "at a distance" is no less effective than face-to-face education. The substantial reduction or complete elimination of the costs of travel to-and-from an "onground" classroom holds compelling benefits to the entire enterprise of higher education in the short term, but it remains a compelling benefit if, and only if, there is no significant difference in student learning. An extensive body of literature has repeatedly shown that, regardless of technology, there is no significant difference in student learning when faceto-face meetings are faded or removed (Wegner, Holloway, and Garton, 1999). Thomas Russell's annotated bibliography entitled The No Significant Difference Phenomenon 
lists 355 research studies over the last 70 years that consistently found no significant difference between face-to-face learning and distance learning, regardless of technology (Russell, 1999; Russell, 2000). As collated by Russell, a lack of significant difference in learning outcome measures was noted in coursework by mail (Crump, 1928), by audio loudspeaker (Loder, 1937), by radio (Woelfel and Tyler, 1945), film (VanderMeer, 1950), television (Stromberg, 1952), computer program (Lang, 1973), videotape (Thorman and Amb, 1974), videoconferencing (Weingand, 1984), videodisc (Smith and Shen, 1992), satellite (Hudson, Dietzel, Sandiford, and Morris, 1993), and finally online (Lin and Davidson, 1994; Goldberg, 1997; Jones, 1997; Vachris, 1999; Koch, 1998; Navarro and Shoemaker, 1999; Johnson, Aragon, Shaik, and Palma-Rivas, 2000; Gagne and Shepherd, 2001).

A 1999 review commissioned by the National Education Association entitled What's The Difference? (Phipps and Merisotis, 1999) urged a more cautious view, calling into question the quality of the research supporting the no significant difference (NSD) phenomenon, and policies based on it. Phipps and Merisotis were able to locate only 40 studies that involved actual research comparing any form of distance education with traditional classes, and most research they located was flawed, in their view. In particular, a lack of control of extraneous variables was noted, along with almost no use of randomization in experiments to link learning outcomes to specific distance education technologies. Most NSD studies did not include information about the reliability and validity of measurement instruments like exams, questionnaires, or attitude scores. Only a minority of those 40 studies dealt with online instruction since other distance education 
formats, such as videoconferencing, havebeen in use far longer.

Perhaps the most noticed exception to the NSD phenomenon was a study at California State University - Northridge in which students were randomly assigned to traditional and online sections of a sociology class (Schutte, 1996). One section of traditional face-to-face meetings and written assignments, and another section which included online methods for delivery of information (such as email, newsgroups, realtime chat conversations, and web-based assignments) but which required only 4 meetings (two introductory lectures about course technologies, a midterm, and a final). Given an identical pretest and posttest, Schutte reported no significant differences between the two sections in age, sex, ethnicity, familiarity with computers, years in school, or grade point average. The only significant difference found was between midterm and final exam scores: "virtual" students scored an average of 20 points higher on each exam. Schutte's newsworthy ${ }^{\text {ii }}$ exception to the NSD phenomena (McCollum, 1997) has been called "to date... the most methodologically sound investigation to evaluate the effectiveness of online instruction" (Schulman, 1999) because of the randomization of subjects, though issues of reliability and validity of testing instruments were not addressed. In addition, Schutte has been criticized for offering substantially different, small-group instruction to the online sections, confounding any attribution of increased learning to the online technology itself (Neal, 1998).

Most recently, a study by LaRose, Gregg, and Eastin recruited 49 subjects from a college course in communications, and randomly assigned each to either an experimental (online) group or a control (traditional) group. After testing the reliability and validity of 
measurement instruments (multiple-choice exams and attitude surveys) and controlling for class level, grade point average, andattendance, their analysis of covariance showed no significant differences between online and tradition groups on exam scores, student attitude scores, and teacher immediacy ratings (LaRose, Gregg, and Eastin, 2001).

Regardless of opposition from faculty associations (AAUP, 1998), the higher education press (Perley and Tanguay, 1999), and prominent web pioneers like Clifford Stoll (Cervini, 2001), online courses and so-called "virtual" programs, colleges, and institutions have swept through higher education. Overviews of three established educational enterprises (MIT, Cornell University, and Temple University) illustrate the spectrum of institutional integration of online courses into the mission of the modern university.

In April, 2001, Massachusetts Institute of Technology (MIT) announced a 10 year, 100 million dollar commitment to OpenCourseWare, its own course management system, with a goal to create public Web sites for almost all of its 2,000 courses. The OpenCourseWare system will provide free, public web access to MIT course materials like lecture notes, problem sets, syllabi, exams, simulations, even video lectures. Professors' participation will be voluntary, but the university is committing itself to post sites for all its courses. With a debut in 2002, initial funding for OpenCourseWare amounts to 12 million dollars of funding from the Mellon and Hewlett Foundations (Young, 2001; MIT OpenCourseWare Fact Sheet, 2001).

In September, 2000, Cornell University created eCornell as a separate organizational entity for the purpose of providing online coursework to professionals in 
fields where Cornell University has proven academic leadership. eCornell is a private sector corporation that is a wholly owned subsidiary of Cornell University. eCornell will produce, market, and deliver nondegree educational programs developed in conjunction with the university's schools and colleges. The first such school is Cornell's School of Industrial and Labor Relations, which will debut a full-length online professionalcertification program on November $1^{\text {st }}, 2001$. So far, eCornell has offered two courses from its Weill Medical College, with a six-course program from the School of Hotel Administration due for debut in Spring, 2002 (Arnone, 2001; eCornell Press Release, 2000).

As Michael Arnone notes: “eCornell's optimism contrasts with the drubbing some other universities for-profit distance learning projects have taken... Temple University pulled the plug on Virtual Temple last July... (Arnone, 2001). In November, 1999, Temple University announced the creation of Virtual Temple, a for-profit corporation marketing online courses regionally and internationally - among the first institutions to establish a separate, for-profit arm to do so. Virtual Temple, like the later eCornell, would not market accredited courses, instead planning to vend certificate programs aimed at job training for adult learners. Temple Chief Financial Officer Martin Dorph stated 'If we've not created some results by producing a business plan and identifying some joint ventures within the next 6-12 months, we'll have blown a big opportunity. Now is the time to move" (O’Neill, 1999).

20 months later, new Temple University President David Adamany quietly shut down Virtual Temple, stating "I didn’t see any profit potential here” (Blumenstyk, 
2001a). Virtual Temple had never developed a single online course, had no chief operating officer, or business plan when it was shut down officially in July, 2001, and its closing had few consequences among faculty or staff. John DeAngelo, associate dean for information technology in the Fox School of Business noted: "I don't think anyone is crying about the demise of Virtual Temple" (ibid, 2001b). In an interview with The Chronicle of Higher Education, Dr. Adamany expressed his doubts about other university ventures into online courses, programs, and degrees: "Good luck to them... when they make money, tell them to call me" (Blumenstyk, 2001b).

Distinct from computer hardware and software, the Internet and online services pose new challenges for (and to) teachers, including the reduction or elimination of faceto-face meetings, a foundational component of traditional education. Explosive growth of adoption of online services has swept over the larger culture in which education happens, surrounding schools, and making a virtue of a new necessity. William Bennett exemplifies the grudging resignation of the majority of educators to the seeming inevitability of Internet technology in education: "Technology is here. The question is not whether it will be used in education; the question is whether we use it right. Mostly, we have not" (Bennett, as quoted in Anonymous, 2001, p. 13).

In distinction to elementary, secondary, and home schools, "whether or not technology will be used" is exactly the question in college classrooms. In higher education, to adopt or not to adopt, that is still the question. That the Temple Blackboard course management system is both a digital educational innovation, and an apparatus for precision measurement of its own rate of adoption, is serendipity incarnate. 


\section{Measuring Rate: The Reciprocal Values of B. F. Skinner and Everett Rogers}

Innovation diffusion research investigates how new ideas, products, behaviors, or cultural practices become more (or less) frequent in a given social context. Diffusion research spans five decades, multiple disciplines, and many methodologies. Since the 1943 Ryan and Gross investigation of the rate of hybrid corn adoption by Iowa farmers, a diffusion of innovation research tradition has produced 3,890 studies across anthropology, rural sociology, public health, economics, marketing, education, and more (Rogers, 1995). Relevance to diverse disciplines, an accrued theoretical framework, easily understood methodology, and pragmatic emphases on facilitating wanted innovations has made innovation diffusion research a popular endeavor supported by governments and Fortune 500 companies alike (Downs and Mohr, 1976).

The common thread emerging from thousands of innovation diffusion studies across diverse settings and disciplines is the methodological tactic of measuring, charting, and analyzing "rate of adoption" of innovations across time (Karahanna, Straub, and Chervany, 1999). The paradigmatic definition of "rate of adoption" is given by Everett M. Rogers in his seminal text Diffusion of Innovations: "Rate of adoption is the relative speed with which an innovation is adopted by members of a social system. It is generally measured as the number of individuals who adopt a new idea in a specified period, such as each year" (Rogers, 1995, p. 206).

Innovation diffusion literature is built around rate of adoption, and the Rogerian concept of rate of adoption is built around the change in the number of adopter organisms, and the properties of those organisms. Rogers, in his chapter Innovativeness and Adopter Categories (Rogers, 1995, pp. 252-280) summarizes the general focus of 
innovation diffusion research methods:

- Number of adopters over time. Of 100 Peruvian villagers, how many adopted hand-washing? Of those adopters, when did each adopt in the time observed?

- Number of nonadopters vs. adopters. How many Peruvian villagers never adopted handwashing? What is the ratio of adopters to nonadopters?

- Adopter categories, based on standard deviations from average time of adoption: innovator, early adopter, early majority, late majority, laggards.

- Adopter characterizations, based on observations of "the dominant characteristics and values" of people in adopter categories: Venturesome, respectful, deliberate, skeptical, traditional.

Along with characteristics of adopters, education innovation researchers have used statistical analyses of surveys based on recall to analyze the characteristics of innovations. Analysis of innovation characteristics is prominent enough to warrant a meta-analysis (Tornatzky and Klein, 1982) of such research, highlighting important properties of innovations (such as relative advantage, complexity, and compatibility) in addition to properties of the adopter organisms.

Innovation diffusion researchers understand rate of adoption as change in the number of people adopting an innovation. While innovation diffusion is defined as a human behavioral process (Rogers, 1986; 1995), both foundational and recent concepts used in innovation diffusion are metaphorical extensions from physical science to behavior. Diffusion, for example, is a basic physical process of random motion of 
molecules from a higher concentration to a lower concentration, characteristic of liquids, gases, and solutions in water (Fick, 1855; Flynn, Yalkowsky, and Roseman, 1974). Classic examples of diffusion include the distribution of dye in water, or perfume in air. Understood non-metaphorically, diffusion is caused by Brownian motion inherent in all molecules and atoms ("Brownian Motion," Microsoft ${ }^{\circledR}$ Encarta ${ }^{\circledR}$ Online Encyclopedia 2001; Ford, B. J., 2000). However, the physical science concept of diffusion has only tenuous metaphorical applicability to the human, behavioral, verbal, and cultural process called innovation diffusion.

Another physical science metaphor used by innovation diffusion scholars is the concept of autocatalysis. Autocatalysis is a chemical process in which one of the products of a catalytic reaction is a catalyst for further reaction. During autocatalysis, the probability of occurrence of some property, event or object increases as a function of the number of such properties, events or objects already present. (Heylighen, 2001). The autocatalytic principle states that it suffices for a chemical configuration to be stable, and in some respect autocatalytic, in order to undergo potentially explosive growth. Emphasizing "feedback", "non-linearity" and "self-causation" (auto = self, catalysis = cause), the non-metaphorical process of autocatalysis describes organic biological processes, as well as inorganic processes such as the growth of crystals in substrate. Like diffusion, autocatalysis is a physico-chemical concept, albeit with a history of metaphorical extension to human behavior in the fields of cybernetics (Heylighen, 1992) and evolutionary theory (McKee, 2000). In evolutionary theory, autocatalysis is said to endow Darwinian natural selection with a "feedback loop" from the physical 
environment. In The Riddled Chain: Chance, Coincidence, and Chaos in Human Evolution, Jeffrey McKee offers autocatalytic evolution as "a superior model for explaining the complexities of life because, as biologists have discovered in recent decades... simple linear models fail to account for complex biological systems" (Shermer, 2001). As relates to innovation diffusion, Stephen B. Lawton and William Lawton proposed an autocatalytic model for analyzing rate of adoption of an educational innovation based on the Bass marketing model of innovation diffusion (Bass, 1969; Lawton and Lawton, 1976).

By measuring rate of adoption, an investigator is exposed to the human behaviors called innovation, and the characteristics of those behaviors called diffusion. Such scholars intuitively note the evolutionary nature of innovation diffusion in human, verbal, social networks, but have used the metaphors of physics and chemistry to describe it. A natural science of behavior offers new ways to describe, define, and measure rate of adoption of innovation.

The Rogerian research tactic of rate of adoption, binding together diverse disciplines, settings, innovations, and literature into a shared innovation diffusion tradition, shares the common thread of analysis of rate as a datum with classical Skinnerian research. The Skinnerian, behavioral, or natural science research tradition, evolving concurrently with innovation diffusion literature, offers new ways to define, chart, and interpret the Rogerian concept of rate of adoption that are not metaphorical extensions from physics or chemistry. "Behavior-centric" strategies and research tactics can supplement the exclusive reliance on metaphors based on physics and chemistry with 
empirical research emphasizing the practical impact of behavioral consequences. Skinnerian contributions such as selection by consequences (Catania \& Harnad,1988; Skinner, 1981) offers non-metaphorical ways to talk about adoption of innovation which, like autocatalysis, emphasizes evolution, feedback, and the control of consequences over subsequent events.

The natural science of behavior research tradition not only emphasizes rate measurement and natural selection, but it does so with a consistent, coherent conceptual framework (Liegland, 1999) based on experimental analysis and empirical investigation in basic and applied settings (Lattal and Perone, 1998; Schroeder, 1990). While natural science of behavior practices under various guises (behavioral psychology, behavior analysis, behaviorology) have not become mainstream in academia (Leahey, 1997), or education generally (Watkins, 1997), such practices have repeatedly proven both effective (Crandall, Jacobson, and Sloane, 1997; Kazdin, 1994) and applicable to diverse, science-driven professions like psychopharmacology (Higgins and Katz, 1998) and organizational behavior management (Bohrer, 1998; Mawhinney, 1999).

A thorough reinterpretation of innovation diffusion concepts is beyond the scope of this document. However, the innovation diffusion concepts summarized in Roger's seminal text Diffusion of Innovations may be reinterpreted using the ANTECEDENTSBEHAVIOR-CONSEQUENCES rubric derived from Skinnerian analysis of behavioral contingencies:

- ANTECEDENTS: Mass and Interpersonal Communication Networks, Announcements of Incentives and Mandates, Change Agents. Such 
concepts address the parts of the environment that can precede or occasion the behavior of adoption.

- BEHAVIOR: Rate of adoption as rate of adoption behavior. Current innovation diffusion analyses measure adoption by measuring numbers of adopters, but measurement of adopter behaviors is also possible and profitable.

- CONSEQUENCES: Incremental Innovation (Immediate, positive consequences) vs. Preventative Innovation (Avoiding or deferring negative consequences); Incentive systems; Discontinuance. While the consequences of adoption of innovations are important, little innovation diffusion research has focused on consequences (Rogers, 1995, pp. 405412).

Placing innovation diffusion concepts in the $\mathrm{ABC}$ rubric of Skinnerian contingency analysis makes clear that innovation diffusion scholars not only investigate behavior, but also relationships between behavior and the social, organizational, and cultural practices which surround it. Until recently, natural science of behavior analyses of organizations and cultures focused on individuals (Redmon and Agnew, 1991), prompting calls for natural science of behavior analyses of organizations and cultures with a "macro focus" (Redmon and Wilk, 1991; Thompson and Luthans, 1990). The recent conceptual analysis of metacontingencies (Glenn, 1986; 1988; 1991) have led to relevant applied research involving natural science of behavior practices at the macro levels of organizations. 


\section{Metacontingencies: The Behavior of Organizations}

Metacontingencies are contingent relationships among practices in an organization or culture and the consequences of those practices to the organization or culture (Glenn, 1986). While behavioral contingencies are functional relationships between individuals and environmental events, metacontingencies describe the aggregate outcomes related to the survival or extinction of "interlocking behavioral contingencies" of cultural practices (Bohrer, 1998; Glenn, 1991). Glenn (1986) defined the concept of the metacontingency in a conceptual analysis of Skinner's Walden Two, distinguishing between the antecedent-behavior-consequences of Skinner's ABC rubric of behavioral contingencies (where local consequences select the behaviors of individuals), and the metacontingency. In a metacontingency, aggregate outcomes that "work" in the prevailing organization or culture contribute to the success of that organization or culture, but not necessarily the success of individuals (Glenn, 1988). When individuals repeatedly engage in these interlocking contingencies, the resultant organizations or cultures are termed "permaclones". Permaclones, according to Glenn, may remain stable while their constituent individuals come and go. Clusters of organizations, called a permaclonic system, work together to adjust to incoming and outgoing members, contribute to the success or failure of each member permaclone, and survive or extinguish through selection by consequences.

Practices endure because of their past success, but past successful practices may become static under changing metacontingencies, leading to reduced success or threatened survival. Glenn refers to the adherence to prior practices regardless of prevailing conditions as ceremonial control. In ceremonial control, current practices are 
retained (or past practices reinstated) in the face of changing metacontingencies. Ceremonial control is a way to restrain constructive change, often precluding "change of any kind, even when current contingencies produce serious problems" (Glenn, 1986, p. $3)$.

As Rogers (1995) notes: “An exciting potential contribution could be made by the education research tradition, stemming from the fact that organizations are involved, one way or another, in the adoption of educational innovations." (p. 63). While most metacontingency literature is conceptual (Mawhinney, 1992; Lowery and Mattaini, 1999), research tactics based on metacontingency analysis have recently appeared, mostly in organizational behavior management. The rise of such research is timely: measuring and monitoring the performance of education organizations with online course management systems is a practical matter which may be both the basis for, and improved by, "applied metacontingency" research.

While not the only natural science of behavior approach to analyzing organizations (Hantula and Crowell, 1994) or cultural practices (Lamal, 1997; Morris and Zarcone, 1999; Ulman, 1998), recent metacontingency analyses have used direct measurement and charting of aggregate data to analyze whole organizations. Kathleen Bohrer offers a metacontingency analysis of a retail dress shop in which an aggregate outcome (total retail sales) is measured over a 19-month period (Bohrer, 1998). Of particular interest is a "Improving the management of overtime costs through decentralized controls: Managing an organizational metacontingency", which prefaces the methods and issues of the RATES OF ADOPTION project (Clayton, Mawhinney, 
Luke, and Cook, 1997). In Clayton et al, two experiments in two different organizations collected data over long periods (two and five years). Both experiments analyzed computerbased records of monthly payroll summaries, which were available at the two different organizations studied. Importantly, multiyear data from both experiments were graphed as cumulative records. Viewing aggregate outcome data, the authors comment: "the data, as it appears in a traditional graph, is difficult to interpret in a straightforward way"(Ibid, p.88). The investigators chose instead to portray organizational data in cumulative records "much as Skinner used cumulative records to track the behavior of single organisms over 60 years ago... Compared to the traditional approach to data graphing, the cumulative record provides a more orderly picture of the entire system." (Ibid, p. 88-89). These recent field experiments illustrate shared features of emerging applied metacontingency research: Focus on organizations, measurement of aggregate outcomes, analysis of data collected over months or years. Clayton, Mawhinney, Luke, and Cook sets a prescient precedent for the RATES OF ADOPTION study.

The concept of metacontingencies arose from an attempt at synthesis of natural science of behavior practices with the research community of cultural materialism in anthropology lead by the late Marvin Harris (Harris, 1964; 1979) - one of many attempts to connect with other professions and endeavors which hold in common a naturalized philosophy of science (Batts and Crawford, 1991). For a natural science of behavior admittedly outside of the mainstream, such professional connections decrease ghettoization while increasing the representation of natural science of behavior concepts in new professional settings. But a natural science of behavior must not only connect 
with other research communities, it must connect with research communities with a higher probability of reciprocal valuation. Far-flung matches with Zen Buddhist (Sato, 1995) and Native American (Lowery and Mattaini, 1999) worldviews, while inclusive to a natural science of behavior, may not be reciprocally valued.

Innovation diffusion scholars may find more to value in a natural science of behavior. For innovation diffusion scholars, a pantheon of natural science of behavior research strategies are available now to enhance traditional methods for measuring rate of adoption. For a natural science of behavior, innovation diffusion literature offers an established research tradition with its own independent history of focusing on behavior, organizations, and cultures through the shared tactics of charting rate measurements.

Perhaps the fastest, most focused contribution of a natural science of behavior research tradition to innovation diffusion lies in the strategies and tactics of measuring rates of adoption. The digital cumulative recording apparatus embedded in the Temple Blackboard course management system increases the quantity and quality of data about adoption. Specifically, it measures number of adoptions per person, a novel change from the classic innovation diffusion tactic of measuring number of adopters.

Diverse methods have been brought to bear to study rate of adoption of innovations, but their common thread is counting people, not behaviors. Anthropologist Paul Wellin studied the rate of adoption of water-boiling by villagers in Los Molinas, Peru via immersion in the village context for over two years (Wellin, 1955). In contrast, a 1957 Columbia University study collected drugstore prescription records to analyze adoption of tetracycline by doctors in Illinois (Burt, 1987; Coleman, Katz, and Menzel, 
1957). In both studies, what was measured were a number of people, in a village or national medical community, who adopted an innovation - not the number of adoptions per person. For example, Paul Wellin did not measure the number of water-boilings by people of Los Molinas; he measured the number of people who adopted water-boiling. Use of objective measurement in innovation diffusion is rare. The aforementioned 1957 Columbia University drug study is singularly important because "it used an objective measure of time of adoption, obtained from the record of drugstore prescriptions that were written by the doctors of study" (Rogers, 1995). In researching educational innovation, use of objective measures is rarer still. Nine percent of innovation of diffusion literature comes from education - the fourth most active discipline in the history of innovation diffusion (Rogers, 1995). Researchers in education innovation typically use mailed questionnaires, one-shot survey interviews, and statistical analysis of recalled answers to study adoption of novel educational practices in schools, such as driver training, modern math, or computer technology (Carlson, 1965; Lawton and Lawton, 1979; Moore, 2001; Rogers, 1986). Education is representative of diffusion of innovation studies in general, almost all of which are "forced to depend on recall-type data about innovativeness" (Rogers, 1995).

When objective measures are available, analysis of every record of adoption, especially by communities, organizations, or entire cultures, may not be feasible. Faced with thousands of paper prescription records, researchers in the aforementioned 1957 Columbia University drug study did not analyze every record of adoption, relying instead on a 10-percent sample of available records (Valente, 1994). 


\section{From Rate of Adopter to Rate of Adoption}

Missing from innovation diffusion literature is mechanical tracking of every adoption of an innovation. The Temple Blackboard course management system serves as a digital analogue of the cumulative recorder pioneered by B. F. Skinner (Skinner, 1938; Skinner, 1959), itself an innovation subsequently adopted by natural science of behavior research communities (Ledoux, 1997; Johnston and Pennypacker, 1993; Sidman, 1962).

Importantly, the digitization of each course adoption record makes sorting and analysis of the entire population of records for a large organization feasible for a single investigator, making statistical sampling unnecessary, and statistical analysis optional. As Everett Rogers notes: "Because the organizational innovativeness investigations typically gathered data only from the top executive of each organization in a sample of organizations, there is no way to determine how adequately these data truly represented the entire organization's behavior with regard to a technological innovation" (Rogers, 1995, p. 378). With the advance of course management systems in higher education, a new mechanism vastly increases and speeds organizational measurement, providing a more accurate, representative "learning picture" of the innovation behavior of an entire organization.

Digital cumulative recording of adoption also addresses the foremost criticism of innovation diffusion research: Pro-innovation bias. "Pro-innovation bias is the implication in diffusion research that an innovation should be diffused and adopted...that it should be diffused more rapidly, and that the innovation should be neither re-invented nor rejected. (Rogers, 1995, pp. 100-101). Rogers lists "pro-innovation bias" as the first in a summary of criticisms of the field of innovation diffusion research since it's 
inception. Pro-innovation bias was the first major criticism of innovation diffusion research (Rogers and Shoemaker, 1971, pp. 46-47, 78-79), and its most serious and persistent shortcoming. Pro-innovation bias may lead researchers to:

1. Study innovations selected and funded by a sponsor or change agency (public or private) with vested interest in the adoption of the innovation;

2. Assign only positive valuation to innovations. Researchers equate innovation with improvement, neglecting analyses of fads, negative consequences of innovation, or discontinuance (Downs and Mohr, 1976);

3. Study only fast-paced, "successful" diffusion. Innovations being rapidly adopted are seen as "noteworthy and dynamic...more likely to have policy implications" (Rogers, 1995, p. 105).

Rogers declares: ““"The conventional methodologies used by diffusion researchers lead to a focus on investigating successful diffusion. Thus a pro-innovation bias came into diffusion research... For balance, we need a number of diffusion researches with an anti-innovation bias in order to correct past tendencies" (Rogers, 1995, p. 105-106). How can digital cumulative recording as used in the RATES OF ADOPTION project provide an anti-innovation bias?

- Digital cumulative recording provides an unconventional methodology, unprecedented in the literature of innovation diffusion.

- Digital cumulative recording reduces costs, while increasing access. Digitization of course records vastly simplifies data collection and handling, reducing the costs of analysis of rate of adoption even for large 
organizations. Little or no funding would be necessary to replicate similar analyses of Blackboard course adoptions, or adoptions of course management systems of differing brands. The Blackboard course management system itself is deployed at more than 4000 colleges, schools and other organizations, in all 50 states of the US and more than 70 countries worldwide. ${ }^{\text {iii }}$

Digital cumulative recording is not simply unconventional: it embodies Rogers' two key methodological practices to overcome pro-innovation bias: Repeated measures of adoption in real-time, and automatic measurement.

Digital cumulative recording is what Rogers calls an "in-process research design", measuring rate of adoption repeatedly, during the adoption process. Typical innovation diffusion research designs measure adoption once (by survey), and long after the adoption process is over. Rogers states: 
"Alternative research approaches to after-the-fact data gathering about how an innovation has diffused should be explored. Diffusion research does not necessarily have to be conducted after an innovation has diffused completely to the members of a system. Such a rearward orientation to most diffusion studies helps lead them to concentration on successful innovations... It is possible to investigate the diffusion of an innovation while the diffusion process is still underway. Data can be gathered at two or more points during the diffusion process, rather than just after the diffusion process is completed... an in-process diffusion research design allows a scholar to investigate less successful, as well as more successful, cases of innovation diffusion, and therefore to avoid the pro-innovation bias" (Rogers, 1995, p. 106-107).

Digital cumulative recording of course records not only measures rate of adoption repeatedly, but also in real time, day in and day out - a methodological leap in terms of frequency of measurement.

For Rogers, a second key to overcoming pro-innovation bias involves the selection of which innovations to study. Rogers states: 
"Diffusion researchers should become much more questioning of, and careful about, how they select their innovations of study. Even if a successful innovation is selected for investigation, a diffusion scholar might also investigate an unsuccessful innovation that failed to diffuse widely among members of the same system. Such a comparative analysis would help illuminate the seriousness of the pro-innovation bias." (Rogers, 1995, p. 107).

The digital cumulative recording process is inherent in, not selected for, the Temple Blackboard course management system. Temple Blackboard produces digital cumulative records of course adoptions regardless of researcher intention, resources, or biases. In that respect, the author did not select Temple Blackboard for measurement, but merely fit its automated data to the practical pursuit of adding knowledge to the field of innovation diffusion in education.

Digital cumulative recording of rate of adoption of Temple Blackboard digital courses is a practical intersection of innovation diffusion with the strategies and tactics of a natural science of behavior. Cumulative recording of every adoption of an innovation is unprecedented in the literature of innovation diffusion, but its value lies beyond mere novelty. If frequent, automatic measurement is a remedy for pro-innovation bias, then digital cumulative recording may be its long-awaited vaccine. This unwitting remedy has happened at the right time to add new methods, precision, and objectivity to the valuation and evaluation of the newest new paradigm sweeping education: online courses. 


\section{Research Questions}

1. How many "online courses" were offered before the March 25, 1999 installation of the Temple University Blackboard course management system (CMS)?

2. What was the rate of adoption (ROA) of the Temple University Blackboard $\mathrm{CMS}$ ? Is there a cumulative $\mathrm{S}$ curve when adoptions are measured per response, as opposed to per organism? If so, in which phase of the S curve is Temple University?

3. For Temple University as a whole, what was the rate of adoption per full-time faculty person?

4. What was the rate of adoption for each Temple University college?

5. What Temple University college had the highest rate of adoption? For this college, what was the rate of adoption per full-time faculty person? For this college, is there a cumulative $S$ curve when adoptions are measured per response, as opposed to per organism? If so, in which phase of the $\mathrm{S}$ curve is this college?

6. What is the performance ratio between the full-time faculty of the highest ROA college and all full-time faculty of Temple University?

7. What changes, if any, in rates of adoption occurred after CMS upgrades on Tuesday, Aug 17, 2000 and Thursday, May 17, $2001 ?$ 


\section{Method}

\section{Participants}

This research involves the collection and analysis of course records in publicly available course schedules and catalogs. Published both in booklet form and online, these catalogs track the number of digital courses adopted by Temple University faculty and staff. Only faculty and staff with a Temple Blackboard username and password account are enabled to adopt Temple Blackboard courses; students and the public cannot adopt. As of Wednesday, November 21, 2001 there were 48,801 user accounts in the Temple Blackboard course management system. Temple University enrolled 29,946 students and employed 2,309 faculty (1,227 full-time and 1,082 part-time) as of Fall, 2000. iv

The author is a Temple University employee in the Fox School of Business, and Temple Blackboard system support staff. The author's tenure at Temple University as Digital Education Project Director in the On-Line Learning Program began on July 15, 1998, predating the March 25, 1999 activation of Temple Blackboard by 253 days. On August 15, 2000, the author began a full-time position as Director of Digital Education for the Fox School of Business at Temple University, his current position at end of study.

\section{Setting}

Temple University, of the Commonwealth System of Higher Education, is a comprehensive public research university and the 39th largest university in the United States. Based in Philadelphia, Pennsylvania, USA, Temple has five regional campuses and international campuses in Tokyo, Japan, and Rome, Italy. Temple also offers educational programs in the People's Republic of China, Israel, Greece, Great Britain, 
France and other countries. Dr. Russell H. Conwell founded the institution in $1884 .^{\mathrm{v}}$

\section{Measurement}

On-Line Learning Program (OLL) courses were measured by analysis of the Temple University Course Schedule booklets from the inception of the On-Line Learning Program in Spring 1997 (January 16, 1997) through Summer 2001 and up to the end of the study on September 7, 2001. On-Line Learning Program courses for that duration (14 semesters) are published in fourteen Temple University Course Schedule booklets. OnLine Learning Program course listings from all fourteen course schedules were Xerox copied (contact the author for complete data). Collated OLL course records were then typed by the author into an Excel spreadsheet template of the author's design, enabling charting and analysis of rate of adoption of Online Learning Program courses both before and during the operation of Temple Blackboard.

Temple Blackboard courses were measured in real time by the web-enabled server database of the Temple Blackboard course management system. Since the first recorded adoption of a Temple Blackboard course on March 25, 1999, each course adoption was tracked as a digital database record. A Temple Blackboard digital course record consists of:

1. A DATESTAMP which lists the DATE OF ADOPTION provided by the clock of the Temple Blackboard web server,

2. A COURSE ID, assembled from text typed by the adopter during the completion of an online Course Creation Request Form,

3. A COURSE NAME, also assembled from text typed by the adopter during the completion of an online Course Creation Request Form. 
Units of Measurement: On-Line Learning Program Course Records. The unit of measurement of On-Line Learning Program courses consists of On-Line Learning Program courses listed course records in the Temple University Course Schedule booklets. . On-Line Learning Program course records listed slightly different information for each course from semester to semester.

\section{\begin{tabular}{l|l|l}
\hline SEMESTER & COURSE_ID & COURSE_NAME
\end{tabular}}

\begin{tabular}{|l|l|l|}
\hline SPRING1997 & ARCH015 & Digital Design Modeling \& Rendering \\
\hline
\end{tabular}

Table 1: A basic On-Line Learning Program course record, constructed by the author.

Courses in the On-Line Learning Program are not standardized course units, tracked daily by machine transduction. Instead, OLL courses differ greatly in terms of format (web vs. videoconferencing) and features. OLL courses can be broadly characterized as:

- Instructor-made websites. Since each website is idiosyncratic in terms of its authorship, features, pages, and navigation, each OLL website course can differ markedly in basic features from course to course. One OLL course may include a website with ten pages, an online forum, and a chat room, vs. another OLL course with a single web page listing a syllabus and 3 hyperlinks.

- Videoconference courses. While listed as "on-line learning", videoconference courses do not involve computerbased instruction. Instead, two-way videoconferencing rooms, located at two or more physical sites, allow classes to meet in their respective classrooms while interacting with classrooms at other, connected sites. Videoconference 
courses require students to travel to the videoconference classroom near them to meet with an instructor specially trained to use built-in videoconferencing units. No aspect of the videoconferencing process works through a web browser, instead requiring dedicated videoconferencing rooms, large screen videoconferencing units, motion sensing tracking cameras, and a dedicated videoconference technician in the classroom during each class meeting at each meeting site. The Temple University Course Schedule indicates which courses are videoconferencing courses, and has done so from inception to end of study.

Units of Measurement: Temple Blackboard Course Records. Unique to this study is the central web-enabled server database which logs and datestamps each Temple Blackboard course adoption. "When... responses are detected by a mechanical, electrical, or electronic device, we may say that a machine transducer is being used." (Johnston and -Pennypacker,1993). While not designed for measurement of participant responses or tracking rate of adoption per se, the Temple Blackboard course management system collects and archives a record of each course adoption, a record which includes verbatim verbal responses from the adopter in the COURSE ID and COURSE NAME fields, and from which rates of adoption per day may be derived from the DATESTAMP of each record. 


\begin{tabular}{|l|l|l|}
\hline COURSE_ID & COURSE_NAME & DTCREATED \\
\hline STAT402 & Statistical Analysis / Quantitative Business Methods 3/25/1999 \\
\hline
\end{tabular}

Table 2: A basic Temple Blackboard course record, tracked mechanically.

These records of course adoption are standard and absolute as tracked by the Blackboard course management system's web-enabled database. Measurement of each Temple Blackboard course adoption by a web-enabled central server database is direct, continuous, unobtrusive, nonreactive, and highly complete: a close approximation of Skinner's cumulative recorder apparatus ${ }^{\mathrm{vi}}$ (Skinner, 1938, 1959). All Blackboard phases feature a count of this standard unit, the definition of which does not change from Blackboard phase to phase, from Blackboard grade to grade (Blackboard 4 to Blackboard 5 to Blackboard 5.5), or from Blackboard setting to setting (Temple University or Arizona State University). Use of standard, absolute units of measurement is termed idemnotic, while units of measurement whose meaning can vary is termed vaganotic (Johnston and Pennypacker, 1993, p. 93). Measurement by a machine transducer is easier, more reliable, and more strategically advantageous than observations by humans or subjects themselves (Johnston and Pennypacker, 1993, p. 118-123).

Unlike OLL courses, each Blackboard course shares a common web-based format and most common features (left and right frames, navigation buttons, content areas, instructor controls, and interactive tools such as DISCUSSION BOARD forums, VIRTUAL CLASSROOM chat tools, and DIGITAL DROPBOX file sharing). This "template" approach gives each Temple Blackboard course the same basic function, navigation, and terminology. Instructors and students can customize, but not basically 
alter, the shared look and function of each Blackboard course. Instructors may customize the tools available in a course, hiding the VIRTUAL CLASSROOM tool while enabling the DISCUSSION BOARD tool for example. Instructor customization occurs within the standard, default, "factory" course environment, guaranteeing a standard navigation, function, and toolset missing from On-Line Learning Program courses. Blackboard courses focus instructors on providing instructional content and processes which are idiosyncratic to the instructor, while eliminating the website design, HTML, and other site construction tasks characteristic of OLL courses.

Approximately 24 hours after adoption, Blackboard generates a standard Course with standard features customizable through a standard set of controls. Ensuing Blackboard courses have idiosyncratic instructional content and instructional processes delivered through a standard "course template". Regardless, the Temple Blackboard course records generated at time of adoption are the same for each Temple Blackboard course. Such records cannot be amended, though they can be deleted if the Temple Blackboard course is later deleted. ${ }^{\text {vii }}$

Combining standard, idemnotic measurement units with digital, mechanical apparatus brings two powerful measurement strategies of a natural science of behavior (Skinner, 1938; Johnston and Pennypacker, 1993) to bear upon rates of adoption of a digital education innovation on the part of a large educational organization. 


\section{Procedures}

On-Line Learning Program courses. The pages listing each On-Line Learning Program course were Xerox copied and collated from inception, listing the OLL courses from Spring semester, 1997 up to Summer, 2001, the end of which corresponded to the end of data collection for this study. OLL course information was entered into an Excel spreadsheet template of the author's design, approximating the layout of data of Temple Blackboard course adoptions to facilitate comparisons of the respective rates of adoption of OLL courses with Temple Blackboard courses.

In the Temple University Course Schedule, each On-Line Learning course was listed by date, by course ID (in this case, the Temple University course number), and by course name (the name listed in the schedule).

SEMESTER COURSE_ID COURSE_NAME

\begin{tabular}{|l|l|l|}
\hline SPRING1997 & ARCH015 & Digital Design Modeling \& Rendering \\
\hline
\end{tabular}

Table 3: Basic On-Line Learning Program course record, as created by author.

The archival course schedules of OLL courses listed different information for each OLL course from semester to semester. During semesters where additional information of interest was listed, such information was added as new columns to the Excel template of OLL course records. For example, while OLL Program courses began in Spring 1997, the course schedule for Summer 1998 was the first to list a FACULTY NAME and EMAIL for each course:

\begin{tabular}{|l|l|l|l|l|}
\hline SEMESTER & COURSE_ID & COURSE_NAME & FACNAME & EMAIL \\
\hline SUMMER1998 & FMAX155 & Introduction to Video and Film Analysis & Swann, Paul & pswann@ @m.temple.edu \\
\hline SUMMER1998 & HRA330 & Communication in Organizations & Geddes, Deanna geddes@ surfer.sbm.temple.edu \\
\hline SUMMER1998JPRA320 & Race and Racism in the News & Turner, Karen & kturner@ astro.temple.edu \\
\hline
\end{tabular}

Table 4: On-Line Learning Program course records, listing FACULTY NAME and EMAIL. 
Based on techniques developed by the author in the analysis and charting of Temple Blackboard course data, On-Line Learning Program course records were assembled in a single Excel worksheet template listing 330 courses from 1/16/1997 up to 9/7/2001, a span of 1,695 days (contact the author for complete data), allowing the calculation of the overall rate of adoption per day -for On-Line Learning Program courses. Customizations were added to the Excel spreadsheet to allow for visual comparison with Temple Blackboard course records, and the charting styles possible with those records. A column of COLLEGE CODE (COL) hyperlinks was added, marking each OLL course by its respective Temple college or school, and allowing the viewer of the data to click the code and view the Temple website for that college.

Once coded, OLL courses may then be sorted by college, allowing the overall ROA for the On-Line Learning Program to be analyzed into respective rates of adoption for each constituent college, and the ranking of each college from first to last in terms its college rate of adoption (CROA). Once ranked, the college with the highest college rate of adoption (Fox School of Business) was selected for further coding of each of its OLL courses by DEPARTMENT in a new column (DEP). Once each Fox School OLL course was coded by department, the CROA for the Fox School could be analyzed into the respective rates of adoption for each constituent department, allowing the ranking of each Fox School department from first to last in terms of its departmental rate of adoption per day (FOXROA).

Each OLL course record was given a CUMULATIVE NUMBER (OLL) in a new column, serially numbering each of the 330 course records. Lastly, where the Temple 
Course Schedule listed an OLL course as a videoconferencing course, the VC column noted this format distinction.

At the most, the Excel template worksheet listing each On-Line Learning Program course record shows a SEMESTER column, a DATES column, and CUMULATIVE NUMBER, COLLEGE CODE, VC CODE, COURSE ID, COURSE NAME, FACULTY NAME, and EMAIL columns:

\begin{tabular}{|c|c|c|c|c|c|c|c|c|}
\hline SEMESTER & DATES & $\mathrm{OL}$ & $\mathrm{LCOL}$ & $\mathrm{DEP}$ & VCCOURSE_ID & COURSE_NAME & FACNAME & EMAIL \\
\hline SUMMER1998 & $5 / 21 / 1998$ & 67 & SCT & & FMAX155 & $\begin{array}{l}\text { Introduction to Video and } \\
\text { Film Analysis }\end{array}$ & Swann, Paul & pswann@vm.temple.edu \\
\hline SUMMER1998 & $5 / 21 / 1998$ & 68 & FOX & HRA & HRA330 & $\begin{array}{l}\text { Communication in } \\
\text { Organizations }\end{array}$ & $\begin{array}{l}\text { Geddes, } \\
\text { Deanna }\end{array}$ & geddes@ surfer.sbm.temple.edu \\
\hline SUMMER1998 & $5 / 21 / 1998$ & 69 & SCT & & JPRA320 & $\begin{array}{l}\text { Race and Racism in the } \\
\text { News }\end{array}$ & Turner, Karen & kturner@astro.temple.edu \\
\hline SUMMER 1998 & $5 / 21 / 1998$ & 70 & AHP & & PHTHER630 & Falls in Older Adults & $\begin{array}{l}\text { Newton, } \\
\text { Roberta }\end{array}$ & newtonra@vm.temple.edu \\
\hline SUMMER1998 & $5 / 21 / 1998$ & 71 & SCT & & BTMM375/77: & 5 Cybermedia Workshop & $\begin{array}{l}\text { Ingersoll, } \\
\text { David }\end{array}$ & dave@bubba.temple.edu \\
\hline
\end{tabular}

Table 5: On-Line Learning Program course records, with extra columns.

As we shall see, the lack of a Temple Blackboard machine-transduced daily datestamp for each OLL course limits a researcher's ability to precisely track and visualize the time-series of actual faculty adoption. However, the lack of real-time recording of course adoptions does not hamper basic visualization and comparison of the rate of adoption of On-Line Learning courses with those of the later but contemporaneous Temple Blackboard course management system.

Temple Blackboard courses. The Temple Blackboard CMS logs each course at time of adoption, approximating the sensitivity of behavioral measurement of Skinner's cumulative recorders. Aggregated data are extracted from the web enabled database management system of Temple Blackboard by a server administrator. viii "Raw" system table data are emailed to the author on demand, generally at or before the 6th of each month. Repeated snapshots of all Temple Blackboard course adoption records were 
cumulatively appended by the author, resulting in a highly complete, daily log of every

Temple Blackboard course adopted from March 25, 1999 to September 7, 2001.

Unlike OLL course records, Temple Blackboard course records originated as digital database records that were saved as Excel spreadsheet documents. In their basic format, Temple Blackboard course records include a CREATION datestamp, a COURSE ID typed by (or for) the adopter, and a COURSE NAME typed by (or for) the adopter. Table 6 shows Temple Blackboard course records, reformatted and sorted to show Temple Blackboard courses by date of creation.

\begin{tabular}{|l|l|l|}
\hline CREATION & COURSE_ID & COURSE_NAME \\
\hline $3 / 25 / 99$ & STAT402 & Statistical Analysis / Quantitative Business Methods \\
\hline $6 / 17 / 99$ & cis55 & Computers and Applications \\
\hline $6 / 17 / 99$ & Ill-002 & Hanley on Film \\
\hline $6 / 17 / 99$ & letour & The Tour De France \\
\hline $6 / 17 / 99$ & SW101 & Star Wars 101 \\
\hline $6 / 24 / 99$ & GRClR112 & Race in Greece and Rome \\
\hline $6 / 28 / 99$ & BA90 & Introduction to Business (Honors) 001 \\
\hline $6 / 28 / 99$ & EC201 & Intermediate Microeconomics: Fall 2000 \\
\hline $6 / 28 / 99$ & EC265 & Economics of Sports: Fall 2000 \\
\hline $6 / 29 / 99$ & Nursing0130 & Teaching Strategies RN-BSN Section \\
\hline $6 / 29 / 99$ & BA90-S & Introduction to Business (Honors) \\
\hline $7 / 7 / 99$ & CIS578 & User Interface Design \\
\hline $7 / 7 / 99$ & OLL101 & Online Learning \\
\hline $7 / 12 / 99$ & MLA114-001 & Writing Technologies \\
\hline $7 / 12 / 99$ & Psych000 & PhychTest \\
\hline $7 / 12 / 99$ & Math000 & Calculus (TEST) \\
\hline $7 / 12 / 99$ & ECON500 & Decision Making in the Firm \\
\hline $7 / 12 / 99$ & MKT401 & Introduction to Marketing \\
\hline $7 / 12 / 99$ & MSOM105 & Operations Management - MSOM 105 \\
\hline $7 / 12 / 99$ & MSOM525 & Games of Strategy in Business \\
\hline TABLE & Temple B & Tackboard course records artanged and \\
\hline
\end{tabular}

TABLE 6: Temple Blackboard course records arranged and sorted by date.

By collection of repeated "snapshots" of the totality of Temple Blackboard course record data in successive Excel spreadsheets, the author assembled a single Excel worksheet template listing 2,839 Temple Blackboard course records from 3/25/1999 up to $9 / 7 / 2001$, a span of 898 days (contact the author for complete data), allowing the 
calculation of the overall rate of adoption (BBROA) for Temple Blackboard courses.

Customizations were added to the Excel spreadsheet to allow for determination of rates of adoption by Temple Colleges. Each Temple Blackboard course record was given a CUMULATIVE NUMBER (TU) in a new column, serially numbering each Temple Blackboard course record from 1 to 2839 , matching the sequence of its point of adoption datestamp (CREATION). A COLLEGE CODE (COL) column of hyperlinked codes was added, marking each Temple Blackboard course by its respective Temple college or school, and allowing the viewer of the data to click the COL code and view the Temple website for that college. Table 7 shows Temple Blackboard course records with TU column and the COL column:

\begin{tabular}{|l|l|l|l|l|l|}
\hline CREATION & TU & COL & COURSE_ID & COURSE_NAME \\
\hline $3 / 25 / 1999$ & 1 & FOX & STAT402 & Statistical Analysis / Quantitative Business Methods \\
\hline $6 / 17 / 1999$ & 2 & CST & cis55 & Computers and Applications \\
\hline $6 / 17 / 1999$ & 3 & ISC & Ill-002 & Hanley on Film \\
\hline $6 / 17 / 1999$ & 4 & ISC & letour & \multicolumn{1}{|c|}{ THE TouR DE FR ANCE } \\
\hline $6 / 17 / 1999$ & 5 & ISC & SW101 & Star Wars 101 \\
\hline $6 / 24 / 1999$ & 6 & CLA & GRCIR112 & Race in Greece and Rome \\
\hline $6 / 28 / 1999$ & 7 & FOXX & BA90 & Introduction to Business (Honors) 001 \\
\hline $6 / 28 / 1999$ & 8 & FOX & EC201 & Intermediate Microeconomics: Fall 2000 \\
\hline $6 / 28 / 1999$ & 9 & FOX & EC265 & Economics of Sports: Fall 2000 \\
\hline $6 / 29 / 1999$ & 10 & AHP & Nursing0130 & Teaching Strategies RN-BSN Section \\
\hline $6 / 29 / 1999$ & 11 & FOX & BA90-S & Introduction to Business (Honors) \\
\hline $7 / 7 / 1999$ & 12 & CST & CIS578 & User Interface Design \\
\hline $7 / 7 / 1999$ & 13 & OLL & OLL101 & Online Learning \\
\hline $7 / 12 / 1999$ & 14 & CLA & MLA114-001 & Writing Technologies \\
\hline $7 / 12 / 1999$ & 15 & CLA & Psych000 & PhychTest \\
\hline $7 / 12 / 1999$ & 16 & CST & Math000 & Calculus (TEST) \\
\hline $7 / 12 / 1999$ & 17 & FOX & ECON500 & Decision Making in the Firm \\
\hline $7 / 12 / 1999$ & 18 & FOX & MKT401 & Introduction to Marketing \\
\hline $7 / 12 / 1999$ & 19 & FOX & MSOM105 & Operations Management - MSOM 105 \\
\hline $7 / 12 / 1999$ & 20 & FOX & MSOM525 & Games of Strategy in Business \\
\hline
\end{tabular}

TABLE 7: Temple Blackboard course records with TU and COL columns.

Once coded, Temple Blackboard courses may be sorted by college, allowing the overall ROA for Temple Blackboard to be analyzed into each constituent college's rate of 
adoption (BBCROA), and the ranking of each college from first to last. Table 8 shows

Temple Blackboard course records, sorted by COLLEGE.

\begin{tabular}{|l|l|l|l|l|}
\hline CREATION & TU & COL & COURSE_ID & COURSE_NAME \\
\hline $6 / 29 / 1999$ & 10 & AHP & Nursing0130 & Teaching Strategies RN-BSN Section \\
\hline $6 / 24 / 1999$ & 6 & CLA & GRCIR112 & Race in Greece and Rome \\
\hline $7 / 12 / 1999$ & 14 & CLA & MLA114-001 & Writing Technologies \\
\hline $7 / 12 / 1999$ & 15 & CLA & Psych000 & PhychTest \\
\hline $6 / 17 / 1999$ & 2 & CST & cis55 & Computers and Applications \\
\hline $7 / 7 / 1999$ & 12 & CST & CIS578 & User Interface Design \\
\hline $7 / 12 / 1999$ & 16 & CST & Math000 & Calculus (TEST) \\
\hline $3 / 25 / 1999$ & 1 & FOX & STAT402 & Statistical Analysis / Quantitative Business Methods \\
\hline $6 / 28 / 1999$ & 7 & FOX & BA90 & Introduction to Business (Honors) 001 \\
\hline $6 / 28 / 1999$ & 8 & FOX & EC201 & Intermediate Microeconomics: Fall 2000 \\
\hline $6 / 28 / 1999$ & 9 & FOX & EC265 & Economics of Sports: Fall 2000 \\
\hline $6 / 29 / 1999$ & 11 & FOX & BA90-S & Introduction to Business (Honors) \\
\hline $7 / 12 / 1999$ & 17 & FOX & ECON500 & Decision Making in the Firm \\
\hline $7 / 12 / 1999$ & 18 & FOX & MKT401 & Introduction to Marketing \\
\hline $7 / 12 / 1999$ & 19 & FOX & MSOM105 & Operations Management - MSOM 105 \\
\hline $7 / 12 / 1999$ & 20 & FOX & MSOM525 & Games of Strategy in Business \\
\hline $6 / 17 / 1999$ & 3 & ISC & Ill-002 & Hanley on Film \\
\hline $6 / 17 / 1999$ & 4 & ISC & letour & The Tour De France \\
\hline $6 / 17 / 1999$ & 5 & ISC & SW101 & Star Wars 101 \\
\hline $7 / 7 / 1999$ & 13 & OLL & OLL101 & Online Learning \\
\hline TABLE & Temple Blackb0ard & \\
\hline
\end{tabular}

TABLE 8: Temple Blackboard course records sorted by COLLEGE CODE.

Note that the CUMULATIVE NUMBER column (TU) is out of ascending order in Table 8 . The TU column allows fast, visual re-sorting of all 2,839 courses back into their default, datestamped sequence.

The non-automatic coding of each Temple Blackboard course by the author is one area of weakness of this study, in that the process of decisionmaking for each of 2,839 course adoption records increases the probability of incomplete codes and errors. While referred to as a COLLEGE CODE, the coding system for Temple Blackboard course records includes both Temple colleges and other organizational entities whose members adopted a Temple Blackboard course. Table 8 gives several examples of Blackboard 
courses adopted not by colleges, but by administrative units such as Temple's Instructional Support Centers (ISC) ${ }^{\mathrm{ix}}$ and On-Line Learning Progam (OLL) ${ }^{\mathrm{x}}$. Coding of all 2,839 Temple Blackboard course records resulted in a total of, as shown in Table 9.

\begin{tabular}{|l|l|l|}
\hline COLLEGE & BBTOTAL & ORGANIZATION \\
\hline TU & 2839 & Temple University \\
\hline \hline FOX & 872 & Fox School of Business \\
\hline \hline CLA & 548 & College of Liberal Arts \\
\hline SOL & 394 & School of Law \\
\hline \hline SC & 180 & Instructional Support Centers \\
\hline \hline CST & 174 & College of Science and Technology \\
\hline SCT & 146 & School of Communications and Theater \\
\hline \hline EDU & 120 & School of Education \\
\hline \hline AHP & 60 & College of Allied Health Professions \\
\hline SPM & 46 & School of Podiatric Medicine \\
\hline \hline TST & 43 & Test courses \\
\hline COM & 40 & College of Music \\
\hline \hline SOP & 40 & School of Pharmacy \\
\hline SSA & 36 & School of Social Administration \\
\hline \hline SOM & 34 & School of Medicine \\
\hline \hline TSA & 32 & Tyler School of Art \\
\hline$! ! !$ & 16 & Example Cases \\
\hline FSM & 12 & Freshman Seminars \\
\hline \hline$? ? ?$ & 11 & Undetermined \\
\hline RCC & 10 & Russell Conwell Center \\
\hline SOD & 9 & School of Dentistry \\
\hline \hline OLL & 7 & On-Line Learning Program \\
\hline VPR & 4 & Vice Provost for Research \\
\hline \hline HLP & 2 & Temple HelpDesk \\
\hline \hline CDS & 1 & Career Development Services \\
\hline \hline ECC & 1 & Educational Computing Center \\
\hline LIB & 1 & Temple Library \\
\hline Courses & 2839 & \\
\hline Days & 898 & \\
\hline TABLE & The & code groups by which all \\
\hline
\end{tabular}

TABLE 9: The 26 code groups by which all 2,839 Temple Blackboard course records were sorted.

While rates of adoption of Temple Blackboard courses for administrative or parainstructional uses may also be precisely rendered, the major focus in Results and Discussion sections will be on analysis of rates of adoption by Temple colleges and faculties. 
For each of the 2,839 Temple Blackboard courses, a code determination was made through a process of matching the Temple Blackboard course record information to its faculty person, then matching the faculty person to a Temple college. This procedure required the use of web-based course catalogs, staff directories, and, in some cases, verification requests to faculty and dean's offices. For example, Table 7 shows that the first recorded adoption in the Temple Blackboard system was on 3/25/1999, with a COURSE ID of "STAT402" and a COURSE NAME of "Statistical Analysis / Quantitative Business Methods". Given this information, any user of the World Wide Web may search the Temple Blackboard course management system for the COURSE ID desired using the public Course Catalog. Figures 1 and 2 show screenshots of the Temple Blackboard Course Catalog, before and after searching for the COURSE ID of STAT402: 


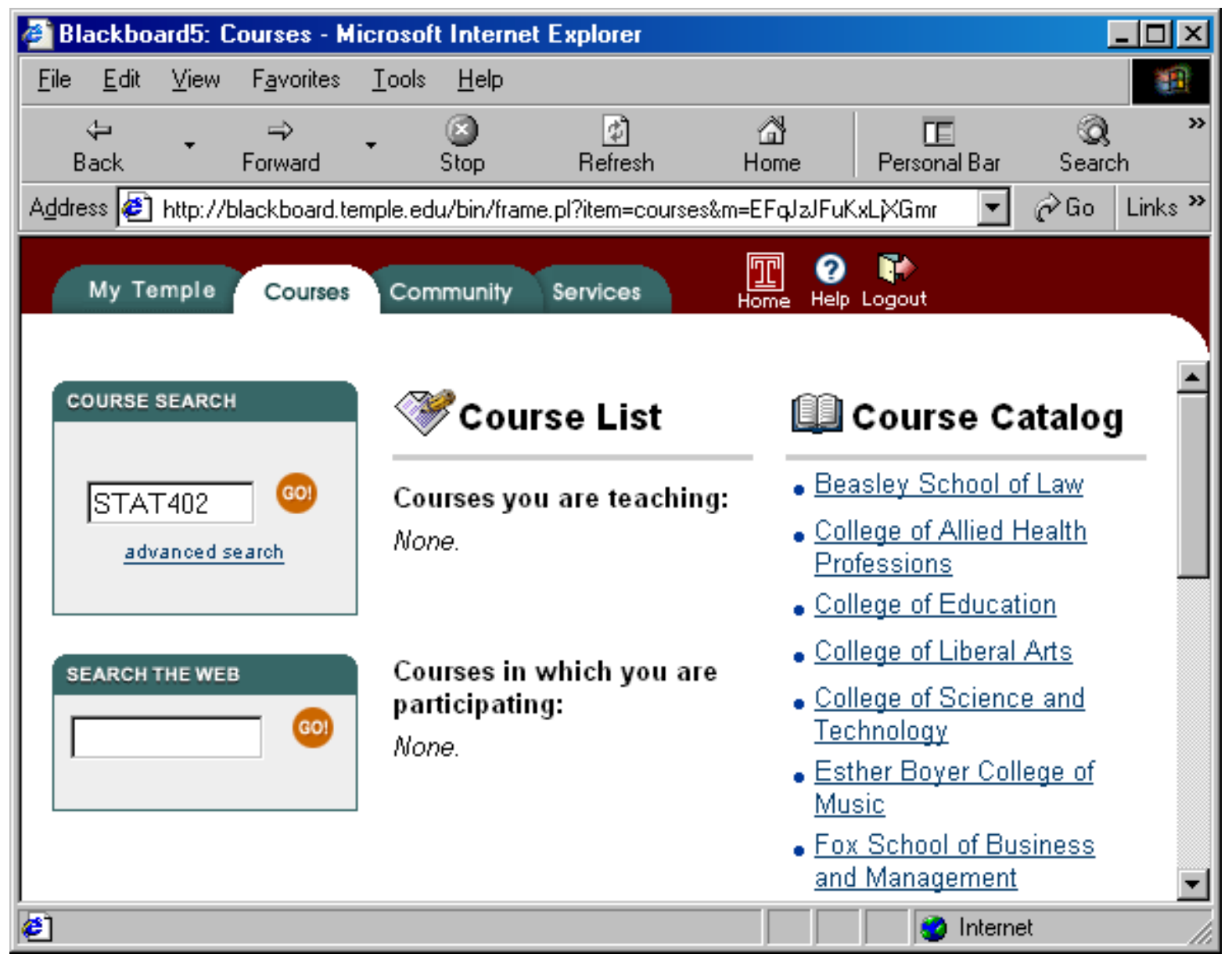

FIGURE 1: Temple Blackboard Course Catalog, preparing to search for STAT402. 


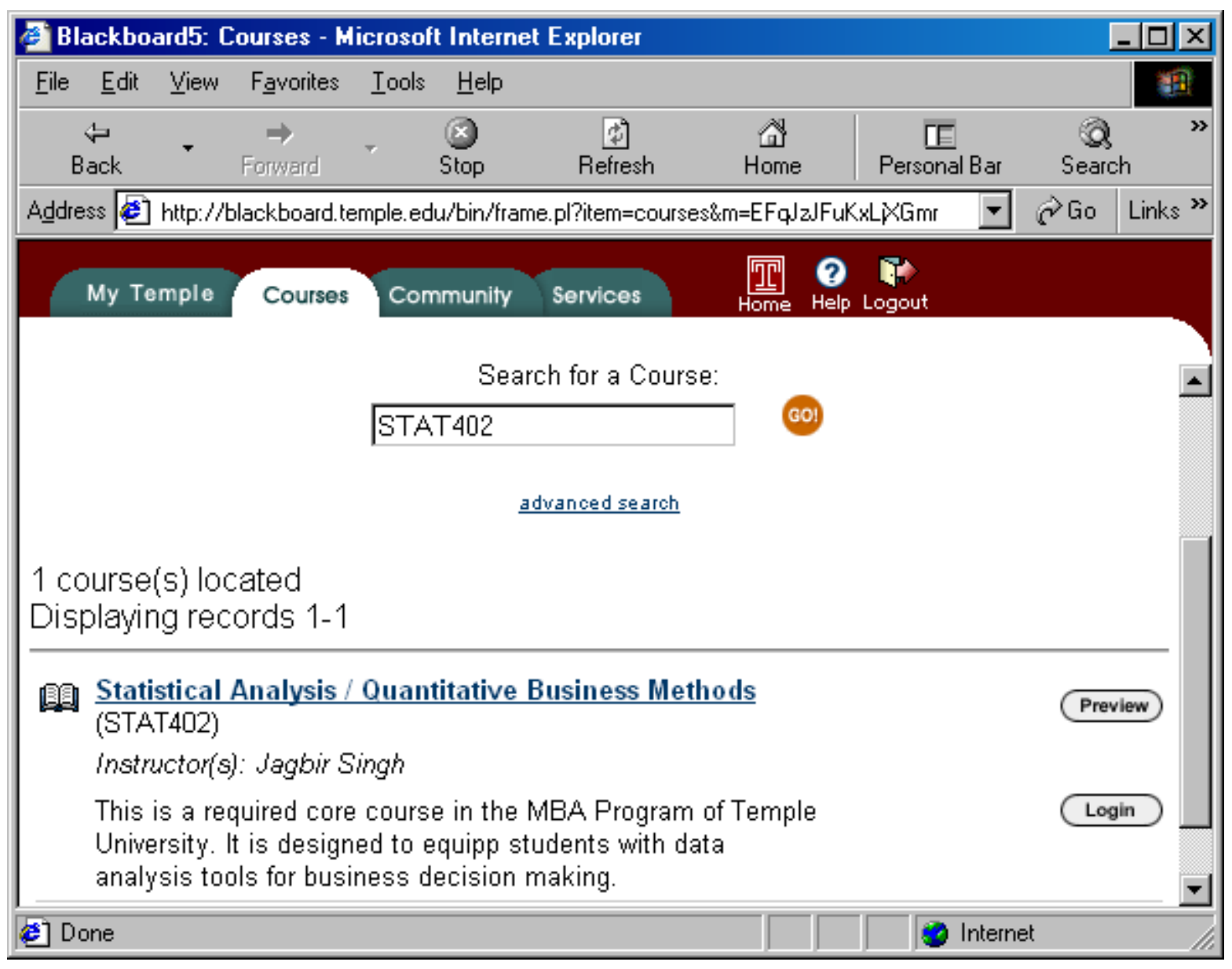

FIGURE 2: Temple Blackboard Course Catalog search results for STAT402. 
The Temple Blackboard Course Catalog allows the determination of the faculty name, or team of faculty, managing the Blackboard course of interest. In cases where the Temple Blackboard course record, or Temple Blackboard Course Catalog information allowed an unambiguous determination, that Temple Blackboard course record was coded accordingly. In most cases, coding of FOX courses was less ambiguous for the author, who is currently employed in the Fox School of Business with duties as a faculty teacher-trainer.

However, it was routine for neither the course record nor the faculty name information to unambiguously determine a CODE for a Temple Blackboard course record. For many course records, additional investigation was required to determine the college or organization to which the course manager belonged. In addition, verification strategies changed based on available means during the timespan of this research. Such strategies included:

1. Search of public Temple Blackboard Course Catalog areas. As shown in Figure 1, the Course Catalog shows clickable areas such as Beasley School of Law, College of Allied Health Professions, etc. If a Temple Blackboard course was categorized in such an area, the CODE for that course was considered verified. However, course categorization in Temple Blackboard is not automatic; the course manager must categorize the course as a setup task. Most Temple Blackboard course managers skip this task, leaving courses routinely uncategorized.

2. Search of Temple Blackboard course catalog using ADMIN access. The 
author has a low level of administrative access to Blackboard course records. In cases where a course record could not be coded by public means, the author used his Temple Blackboard admin access to find more information, such as the BLACKBOARD USERNAME (BBUSERNAME) of the course manager, or "hidden" but existing courses. While searching the Temple Blackboard course catalog with ADMIN access was less labor-intensive than searching the public course catalog, such ADMIN access did not yield information such as course categorization if the course manager had not first indicated it. Instead, searching with ADMIN access allowed the determination of the BBUSERNAME, which in the Temple Blackboard system is identical to the TEMPLE EMAIL username. In many coding cases, this allowed the use of a TEMPLE DIRECTORY to match the TEMPLE EMAIL username to a publicly available, web-based staff directory listing.

3. Search of Temple Directory. Temple University implemented a web-based personnel directory, CHERRY \& WHITE PAGES, listing a web page of information for current students, faculty, and staff. ${ }^{x i}$ This public resource added a new level of verification with its ability to match Temple Blackboard course manager names, usernames, or email addresses to a definitive Temple web page listing the person's college affiliation. In preparation of this manuscript, all 2,839 Temple Blackboard course records were re-verified using this new public resource, allowing many 
prior UNDETERMINED courses to be definitively coded and errors in prior coding to be corrected. Figure 3 shows before and after screenshots of a Temple Directory search: 


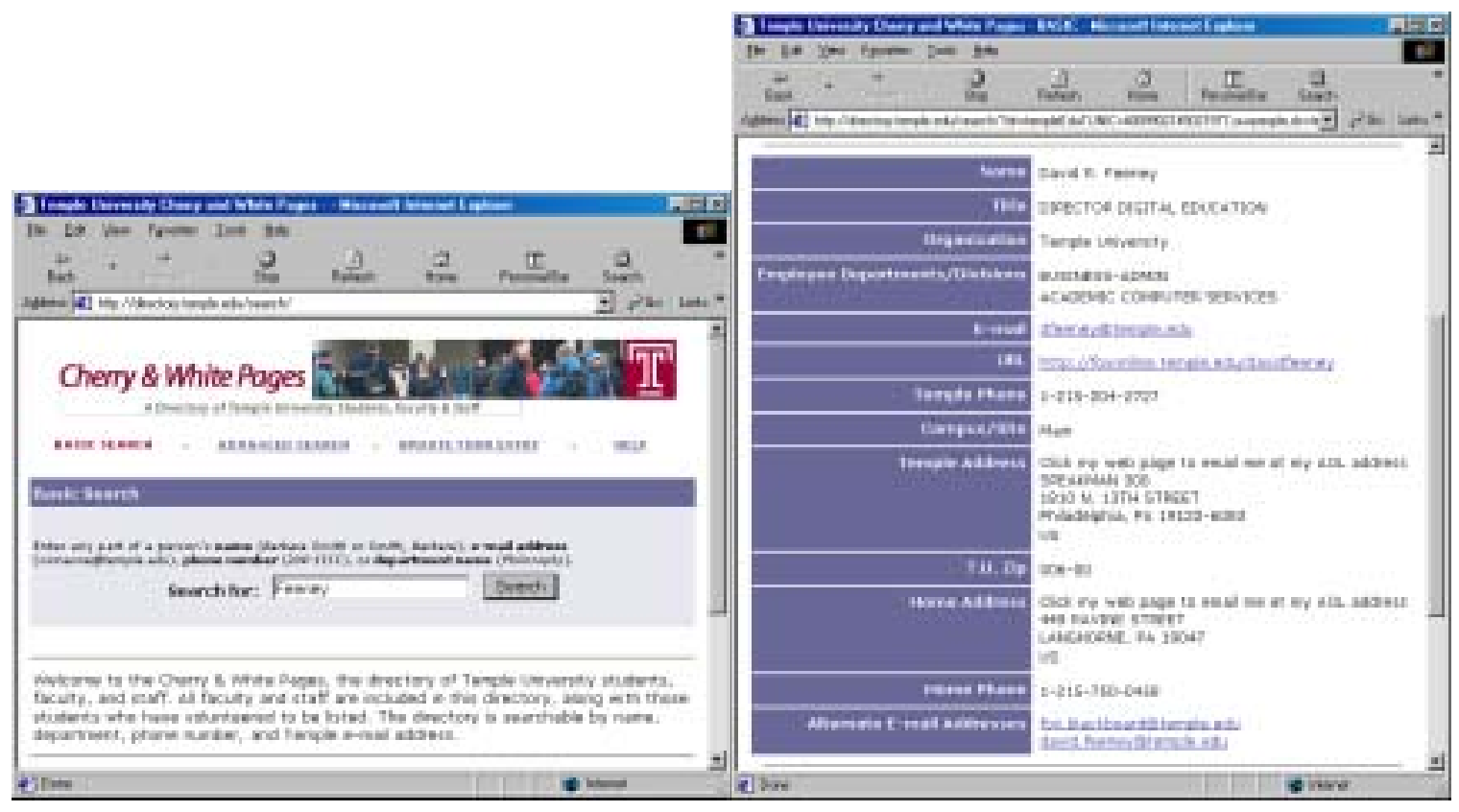

FIGURE 3: Temple Directory before and after searching for FEENEY. 
Not all Temple Blackboard courses could be definitively coded by college. As shown in Table 9, of the 2,839 course records, 27 (0.9\%) were coded as either ??? or !!!, indicating the course record as UNDETERMINED, or as an EXAMPLE CASE. To be UNDETERMINED, a course record could be reliably matched to either a course manager, or a course manager to a Temple college. All EXAMPLE CASES were UNDETERMINED, but marked to allow use of those records to illustrate Temple Blackboard course adoption phenomena of interest.

Once definitively coded, all 2,839 Temple Blackboard course records were sorted by college (see Table 8). Once sorted, the college with the highest number of Blackboard course adoptions was be determined, and its Blackboard rate of adoption calculated by dividing the total number of course adoptions per college by the number of days of Blackboard operation (898). The rate of adoption for that college may then be compared to the rate of adoption for Temple University as a whole.

Sorted by CODE, the total numbers of course adoptions for every other Temple college may also be divided by 898 days, giving the Blackboard rate of adoption for each college (as well as administrative and organizational units). Every constituent college's rate of adoption may then be ranked from first to last, compared with each other, and with adoption rates for Temple administration and organizations.

As the college with the highest number of Blackboard course adoptions, the Fox School of Business was selected for further coding of each of its 872 Temple Blackboard courses. The sorted list of 872 Fox Blackboard course records were copypasted from the 
Temple Blackboard Excel worksheet into a duplicate of the Temple Blackboard worksheet, to inherit all the conventions of the original Temple Blackboard analysis. In this duplicate Excel worksheet, the 2,839 Temple course records were deleted, and replaced with the 872 Fox Blackboard course records as sorted from the original worksheet. Each Fox Blackboard course record was given a new CUMULATIVE NUMBER (FOX) from 1 to 872, matching the sequence of each point-of-adoption datestamp (CREATION). To the prior CREATION, COL, COURSE_ID, and COURSE_NAME columns was added a DEPARTMENT column (DEP), allowing coding of all 872 Fox Blackboard course records by FOX DEPARTMENT, and a SUBCODE (SUB) which allowed a second code to be added for any course record (see TABLE 10):

\begin{tabular}{|c|c|c|c|c|}
\hline CREATIO & $\mathrm{FO}$ & COLDEP & \begin{tabular}{l|l|l|} 
SUB FOX COURSE I \\
\end{tabular} & FOX COURSE TITLE \\
\hline $3 / 25 / 1999$ & 1 & FOXSTAT & STAT402 & Statistical Analysis / Quantitative Business Methods \\
\hline $6 / 28 / 1999$ & 2 & FOXBUSA & BA90 & Introduction to Business (Honors) 001 \\
\hline $6 / 28 / 1999$ & 3 & FOXECON & EC201 & Intermediate Microeconomics: Fall 2000 \\
\hline 6/28/1999 & 4 & FOXECON & EC265 & Economics of Sports: Fall 2000 \\
\hline 6/29/1999 & 5 & FOXBUSA & BA90-S & Introduction to Business (Honors) \\
\hline $7 / 12 / 1999$ & 6 & FOXECON & ECON500 & Decision Making in the Firm \\
\hline $7 / 12 / 1999$ & 7 & FOXMKTG & MKT401 & Introduction to Marketing \\
\hline $7 / 12 / 1999$ & 8 & FOXMSOM & MSOM105 & Operations Management - MSOM 105 \\
\hline $7 / 12 / 1999$ & 9 & FOXMSOM & MSOM525 & Games of Strategy in Business \\
\hline $7 / 22 / 1999$ & 10 & FOXBUSA & BA050 & BA 50: Freshman Seminar - Introduction to Business \\
\hline $7 / 29 / 1999$ & 11 & FOX $\mathrm{ACCT}$ & ACCT91 & Accounting 91 - Honors \\
\hline $8 / 25 / 1999$ & 12 & FOXBUSL & LAW_C001 & Law and Society \\
\hline $8 / 30 / 1999$ & 13 & FOXMIS & staffordr_cis & CIS H095 - Computers and Applications Honors \\
\hline $8 / 30 / 1999$ & 14 & FOX MIS & CIS410_001 & Management Information Systems \\
\hline $8 / 30 / 1999$ & 15 & FOX ACCT & krishk_acct & Auditing and Assurance Services \\
\hline $8 / 31 / 1999$ & 16 & FOX|ACCT & epress & Accounting 401 Fall 1999 \\
\hline $8 / 31 / 1999$ & 17 & FOXMIS & patnayak_cis & Concepts in Data Processing and Information Systems \\
\hline $9 / 2 / 1999$ & 18 & FOX ADM & dfeeney_facdev & FOX eCoaching LIVE! \\
\hline 9/2/1999 & 19 & FOX STAT & fernholzl_stat1 & Stat H092: Basic Quantitative Foundations II (Honors) \\
\hline 9/4/1999 & 20 & FOXECON & buck_econ1 & Principles of Microeconomics \\
\hline
\end{tabular}

TABLE 10: 872 Fox Blackboard course records were coded by Fox department.

Once each Fox School Blackboard course was coded by department, all 872 Fox 
Blackboard course records could be sorted by department, allowing the calculation of the respective rates of adoption for each constituent Fox School department, along with the ranking of each Fox School department, comparisons between departments, and comparisons with department rates with college rates. Table 11 shows the 16 FOX Departmental codes and their totals for all 872 Fox Blackboard course records:

\begin{tabular}{|l|l|l|}
\hline FOXDEP & TOTAL & ORGANIZATION \\
\hline FOX & 872 & Fox School of Business \\
\hline \hline BUSA & 123 & Business Administration Dept. \\
\hline \hline ECON & 93 & Economics Dept. \\
\hline \hline FINA & 92 & Finance Dept. \\
\hline MKTG & 82 & Marketing Dept. \\
\hline \hline ACCT & 81 & Accounting Dept. \\
\hline \hline HRA & 76 & Human Resources Administration Dept. \\
\hline \hline THM & 76 & School of Tourism and Hospitality ${ }^{\text {ii }}$ \\
\hline STAT & 60 & Statistics Dept. \\
\hline MIS & 54 & Management Information Sciences Dept. \\
\hline \hline RIHM & 54 & Risk, Insurance, \& Healthcare Management Dept \\
\hline \hline ADM & 32 & Administration and Communities \\
\hline BUSL & 20 & Business Law Dept. \\
\hline MSOM & 19 & Management Science/Operations Management Dept. \\
\hline SBDC & 6 & Small Business Development Center \\
\hline \hline EBZ & 3 & E-Business Dept. \\
\hline \hline LAP & 1 & Honors Laptop \\
\hline \hline & & \\
\hline Courses & 872 & \\
\hline Days & 898 & \\
\hline
\end{tabular}

TABLE 11: 872 Fox Blackboard course records were placed in 17 code groups.

Coding of all Fox School of Business courses by department required the verification strategies used in the coding of Temple Blackboard course records by college, plus additional information from the Dean's Office of the Fox School of Business. Staff of the Fox Dean's Office provided official lists of Fox departments, in addition to official lists of Fox full-time faculty per department, as well as numbers of 
part-time faculty per department. The smaller number of Fox Blackboard course records, the proximity and familiarity of the author with Fox faculty and Blackboard courses, and cooperation on the part of Dean's Office staff resulted in the definitive coding of all 872 Fox Blackboard course records by department and, in an early profitable mistake, by departmental program in parts. While rates of adoption of Temple Blackboard courses for Fox School programs may also be precisely rendered, the focus in Results and Discussion sections will be on analysis of rates of adoption by Fox departments and faculties.

Once the rate of adoption for each Fox School of Business department is determined, that rate may be divided by the number of full-time faculty in that department, allowing the full-time faculty rate of adoption to be calculated. However, Temple Blackboard course records, including Fox Blackboard course records, includes courses adopted by part-time faculty The number of part-time faculty for each Fox School department may be added to the number of full-time faculty, yielding a total number of faculty per Fox department. ${ }^{\text {xii }}$ By dividing the prior departmental rates of adoption by the number of full-time faculty, or all faculty, a rate of adoption per department, per faculty may be calculated. Whether divided by all faculty or full-time faculty alone, each department may be ranked anew in terms of the rates of adoption per faculty. 


\section{Research Design}

Natural science of behavior researchers, as well as Skinner himself, identified cumulative recording as the source of his most enduring contributions to science (Bjork, 1987; Lindsley, 1999; Skinner, 1987). Machine transduction of data with long-term participant observation in the adopter organization results in a novel action research design. Lately termed "treatment-only" (Moxley, 1997) or "Level 1" (Moore, 1999) research, this kind of databased case study involves recording, monitoring, and analyzing changes in a standard unit of adoption without attempting to prove what is causing those changes. Level 1 research is characterized as a means to track and improve practices in clinical and educational settings, in distinction to program evaluation in Level 2 and randomized, control-group research in Level 3 (Moxley, 1998; Hawkins \& Hursh, 1992; Hawkins \& Mathews, 1999).

Regardless of its place in a hierarchy, this research design incorporates features of noted importance to innovation diffusion research. First, the real-time automation of data at the point of adoption has been discussed as ameliorating the important pro-innovation bias problem persistent in innovation diffusion research. This apparatus-based, web based measurement strategy also addresses what Rogers calls the respondent recall problem: that traditional innovation diffusion methods depend on the memory of adopters to derive rate of adoption. The recall problem may be remedied, suggest Rogers, by 
“(1) Field experiments, (2) longitudinal panel studies, (3) use of archival records, and (4) case studies of the innovation process with data from multiple respondents (each of whom provides a validity check on the others' data)... Unfortunately, alternatives to the one-shot survey not been widely used in past diffusion research... research designs prominently used in diffusion research do not tell us much about the process of diffusion over time, other than what can be reconstituted from respondent's recall data" (Rogers, 1995, pp. 122-123).

The digital cumulative recording used in this research design allows repeated measurement, another factor identified by Rogers as a remedy to the recall problem (Rogers, 1995, p. 124), as well as measurement at "point-of-adoption" in real-time. Measuring adoption at the time it occurs "solves the recall problem by gathering data at the time of adoption. Very few point-of-adoption studies have been conducted to date" (Rogers, 1995, pp. 124-125). Lastly, this "natural history" research design is a natural precursor to the field experiment, the value of which was explicitly recognized by E. M. Rogers:

"We recommend that much greater use should be made of field experiments in diffusion research to help avoid the respondent recall problem and to evaluate diffusion policy alternatives" (Rogers, 1995, pp. 123-124). 


\section{Data Analysis}

Prior education innovation studies have analyzed the number and characteristics of organisms adopting an innovation (adopter vs. nonadopter, early vs. late adopter, etc.). Rate of adoption as conventionally measured in innovation diffusion can more accurately be termed "rate of adopter". Digital cumulative recording and charting allows for visualization and analysis of rate of adoption over time, not simply rate of adopters.

Course records from On-Line Learning Program and Temple Blackboard may be divided into two distinct phases:

- A or OLL PHASE: From January 16, 1997 to September 7, 2001, a total of 1696 days.

- B or BLACKBOARD PHASE: From March 25, 1999 to September 7, , a total of 898 days.

B or BLACKBOARD PHASE may then be divided into phases based on the version of the Blackboard product. Such phases mark the duration of product versions and "feature environments" during the 898 days from date of first adoption to the end of this study:

- B1: BLACKBOARD 4.0: From March 25, 1999 to August 16, $2000=510$ days. B1 is color-coded as RED on all cumulative records charts

- B2: BLACKBOARD 5.0: From August 17, 2000 to May 16, $2001=272$ days. B2 is color-coded as GREEN on all cumulative records charts

- B3: BLACKBOARD 5.5: From May 17, 2001 to September 9, $2001=114$ days. B3 is color-coded as BLACK on all cumulative records charts

The A (OLL) phase continued contemporaneously after the onset of B 
phases. During all B phases, On-Line Learning Program courses and Temple Blackboard courses occurred simultaneously and, for the most part, independently of each other. However, it should be noted that several On-Line Learning Program course records during the Summer 2001 semester were being delivered by Fox School of Business faculty using Temple Blackboard courses.

\section{Charting Rate of Adoption as Cumulative Records}

Importantly, Excel will chart On-Line Learning Program and Temple Blackboard course records cumulatively. When considering Temple Blackboard course records, digital cumulative recording of rates of adoption are portrayed in a classic charting convention pioneered by B. F. Skinner for portraying rates of responding of organisms (Skinner, 1938; Skinner, 1959).

For Temple Blackboard course records, Excel will chart the rate of adoption using the automatic point-of-adoption datestamp (CREATION) along the $\mathrm{X}$ axis and the CUMULATIVE NUMBER of each course record along the Y axis. By careful formatting of Excel chart options, the rate of adoption of Blackboard courses per day for Temple University as a whole may be charted as a cumulative record, as shown in Figure 4. 


\begin{tabular}{|l|l|l|l|l}
\hline CREATION & TU & COL & COURSE_ID & COURSE_NAME \\
\hline $3 / 25 / 1999$ & 1 & FOX & STAT402 & Statistical Analysis / Quantitative Business Methods \\
\hline $6 / 17 / 1999$ & 2 & CST & Cis55 & Computers and Applications \\
\hline $6 / 17 / 1999$ & 3 & ISC & Ill-002 & Hanley on Film \\
\hline $6 / 17 / 1999$ & 4 & ISC & letour & he Tour De France \\
\hline $6 / 17 / 1999$ & 5 & ISC & SW101 & Star Wars 101 \\
\hline $6 / 24 / 1999$ & 6 & CLA & GRCIR112 & Race in Greece and Rome \\
\hline $6 / 28 / 1999$ & 7 & FOX & BA90 & Introduction to Business (Honors) 001 \\
\hline $6 / 28 / 1999$ & 8 & FOX & EC201 & Intermediate Microeconomics: Fall 2000 \\
\hline $6 / 28 / 1999$ & 9 & FOX & EC265 & Economics of Sports: Fall 2000 \\
\hline $6 / 29 / 1999$ & 10 & AHP & Nursing0130 & Teaching Strategies RN-BSN Section \\
\hline $6 / 29 / 1999$ & 11 & FOX & BA90-S & Introduction to Business (Honors) \\
\hline $7 / 7 / 1999$ & 12 & CST & CIS578 & User Interface Design \\
\hline $7 / 7 / 1999$ & 13 & OLL & OLL101 & Online Learning \\
\hline $7 / 12 / 1999$ & 14 & CLA & MLA114-001 & Writing Technologies \\
\hline $7 / 12 / 1999$ & 15 & CLA & Psych000 & PhychTest \\
\hline $7 / 12 / 1999$ & 16 & CST & Math000 & Calculus (TEST) \\
\hline $7 / 12 / 1999$ & 17 & FOX ECON500 & Decision Making in the Firm \\
\hline $7 / 12 / 1999$ & 18 & FOX & MKT401 & Introduction to Marketing \\
\hline $7 / 12 / 1999$ & 19 & FOX & MSOM105 & Operations Management - MSOM 105 \\
\hline $7 / 12 / 1999$ & 20 & FOX & MSOM525 & Games of Strategy in Business \\
\hline
\end{tabular}

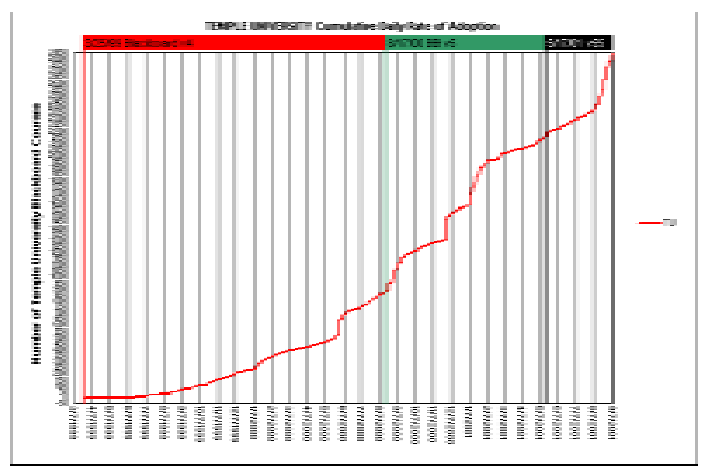

FIGURE 4: Using CREATION datestamps and CUMULATIVE NUMBERS, Excel will chart all 2,839 Temple Blackboard courses per day as a cumulative record. 
Since On-Line Learning Program courses were not given a time-of-adoption datestamp, the author inserted a DATES column, changing with the official Temple semester starting dates, which allowed cumulative charting of rates of adoption for OnLine Learning Progam using a common $\mathrm{Y}$ axis of 2,839 courses (though the $\mathrm{X}$ axis, 1696 days, is $89 \%$ longer than the 898 day axis common to Temple Blackboard cumulative records).

Once discovered, such Excel charting procedures allow rates of adoption to be charted for every Temple college, making rate of adoption visible for each of the 898 days of Temple Blackboard operation studied. The Fox School of Business may be seen as not only the highest rate of adoption college, but as the earliest and consistently highest ROA college, part of the rationale for further analysis of Fox Blackboard course records by department. The cumulative records of each Fox department were displayed on one chart, showing each Fox department's rate of adoption across the same $\mathrm{X}$ axis (898 days) as Temple colleges and Temple University charts. The Fox departmental rates of adoption per faculty were also portrayed on single charts, sharing a common $\mathrm{X}$ axis of 898 days. Respective rates of adoption are visualized as cumulative record lines throughout the duration of Temple Blackboard adoption, and changes in variability, level, trend, and slope for the each chart compared and analyzed, then compared to the overall (and in part, contemporaneous) rate of adoption of On-Line Learning courses. Common phases, based on dates of course management system upgrades, are noted on each Temple Blackboard chart, and the variability, level, trend, and slope of Temple Blackboard phases are analyzed. The goal is both to detect any visual or significant 
increases in rate of adoption due to phase changes, and to allow the accumulation of Temple Blackboard data to point out adoption patterns and events that may be correlated with organizational patterns, events, or adoption strategies. Figure 5 shows thumbnail charts, illustrating how cumulative records of rates of adoption progress from On-Line Learning Program to Temple Blackboard as a whole, Temple Blackboard colleges, Fox School Blackboard, Fox Blackboard departments, and Fox Blackboard departments per full-time and all faculty (contact the author for complete data). 


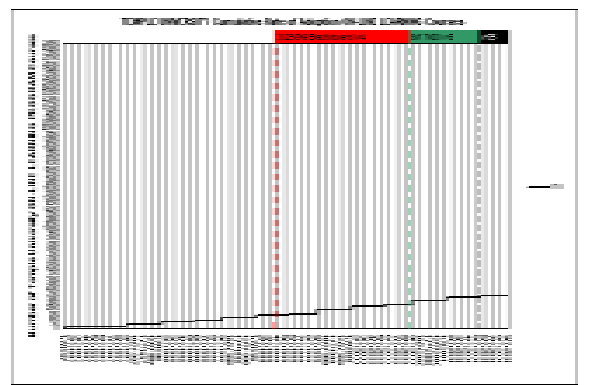

Temple On-Line Learning Program
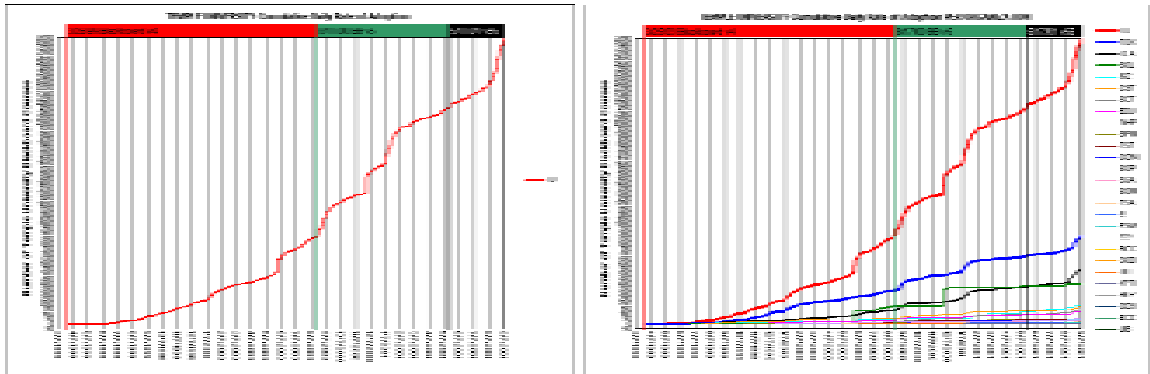

Temple Blackboard

Blackboard Colleges

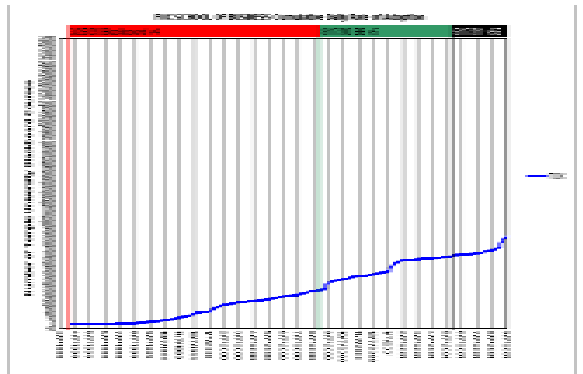

Fox School of Business

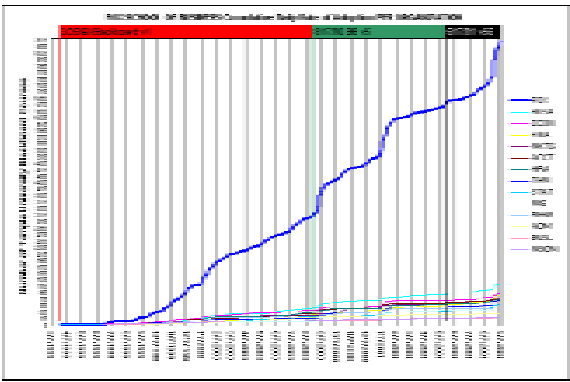

Fox School Departments

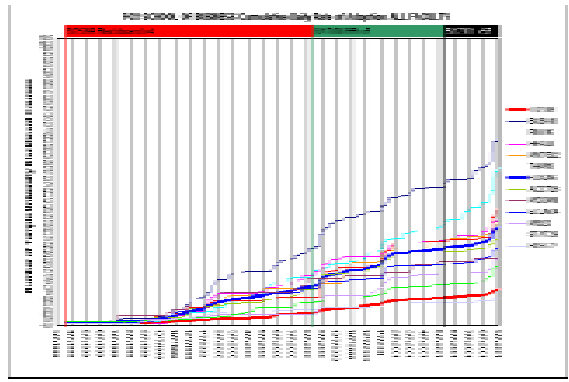

All Fox Faculty

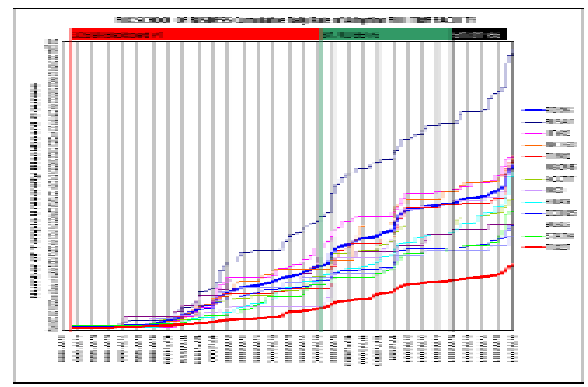

Fox Full-Time Faculty

FIGURE 5: Cumulative records of rates of adoption by Temple On-Line Learning Program, Temple Blackboard, Blackboard colleges, the Fox School, Fox School departments, and Fox School faculties. 
As noted above, On-Line Learning courses and records were not the result of course management system software. Not every OLL course was web based, and not every web based OLL course had similar numbers of pages, or similar navigation, features, or interactive tools. Importantly, no web database existed to collect point-ofadoption data or archive datestamped records of OLL courses. Finally, Temple's OnLine Learning Program was not resourced for enterprise-wide adoption; instead, On-Line Learning Program awards three year grants to individual faculty who request such a grant. OLL courses were not, and are not, equipped with "do it yourself" web based course requests forms.

In contrast, the Temple Blackboard course management system was equipped throughout each B phase with a web based course request form, a Temple web page collecting point-of-adoption information for use in the default properties of the subsequent Temple Blackboard course. Note that these course request forms collect typed verbalizations from the adopter directly into COURSE ID and COURSE NAME fields of the Blackboard course records. Interestingly, the web-based course request form for Temple Blackboard changed substantially during the $30+$ months of this study. Figure 6, shows thumbnail screenshots of Temple Blackboard point-of-adoption web forms during respective $\mathrm{B}$ phases. 


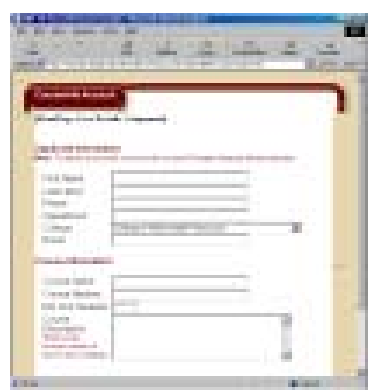

B1 Course Request: A single, public Temple web page.
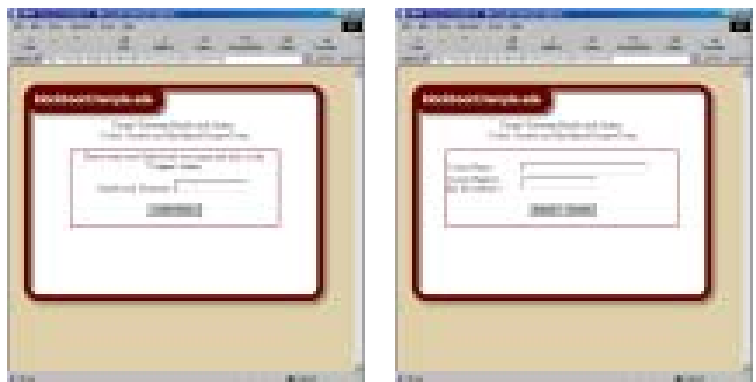

B2 \& B3 Course Request: A Blackboard username page, then a single Temple web page.

FIGURE 6: Temple Blackboard course request web forms from phases B1 and B2-B3. 
Other events occurred during the 898 days of Blackboard operation that may have changed rates of adoption. During the B1 (BLACKBOARD 4.0) phase, the Temple Blackboard course management system, at that time called CourseInfo, was the focus of a front page article in Temple Computer Services local magazine, BITS N PCs. The BITS N PCs article, focusing on the increasing number of course adoptions at Temple, was published and distributed on Temple campuses via paper and website starting Monday, April 3, 2000. ${ }^{\text {xiv }}$

Lastly, it is reasonable to suspect that the onset of each new semester may be precursor to increases in course adoptions, as faculty and staff elect to request creation of Temple Blackboard courses in preparation for the first week of classes. In this respect, the On-Line Learning Program cumulative record is helpful because its regular increases occur uniformly at the onset of each Temple semester, since OLL course records are compiled from the Temple Course Schedules published each semester (see Figure 7). Official Temple semester start dates, compiled during the creation of the On-Line Learning cumulative chart, may also be noted during the B phases of Temple Blackboard, to see how the onset of semesters relates to changes in rate of adoption for Temple as a whole, but more importantly, to the changes in the constituent colleges, the Fox School, its departments, and its faculty rates of adoption. By discriminating cumulative lines for each of these constituent organizations, we may see what, if any, patterns of rate of adoption are shared across multiple colleges, departments, and faculties. 


\section{Results and Discussion}

$\underline{\text { How many "online courses" were offered before the March 25, } 1999 \text { installation }}$ of the Temple University Blackboard course management system (CMS)? The Temple University On-Line Learning Program listed 130 online courses during the 799 days between its inception on January 16, 1997 and March 25, 1999. 130 courses adopted over 799 days results in a rate of adoption of 0.162 for the period before March 25, 1999. After March 25, 1999, the On-Line Learning Program listed 200 more courses over the 897 days up to the end of the measurement period for this study (September 7, 2001), resulting in a "post-Blackboard" daily rate of adoption of .222. All totaled, Temple's On-Line Learning Program accounted for 330 courses over the 1,696 days since its inception to the end of this study, an overall daily rate of adoption of .194. OnLine Learning course data were charted using the same $\mathrm{Y}$ axis values as Temple Blackboard (0 to 2,839) and the same $\mathrm{X}$ axis values (days) to aid in visual comparison of their respective rates of adoption. To aid in answering research questions, Blackboard B1, B2 and B3 phases were added to the On-Line Learning chart at their respective dates of onset (see Figure 7). 


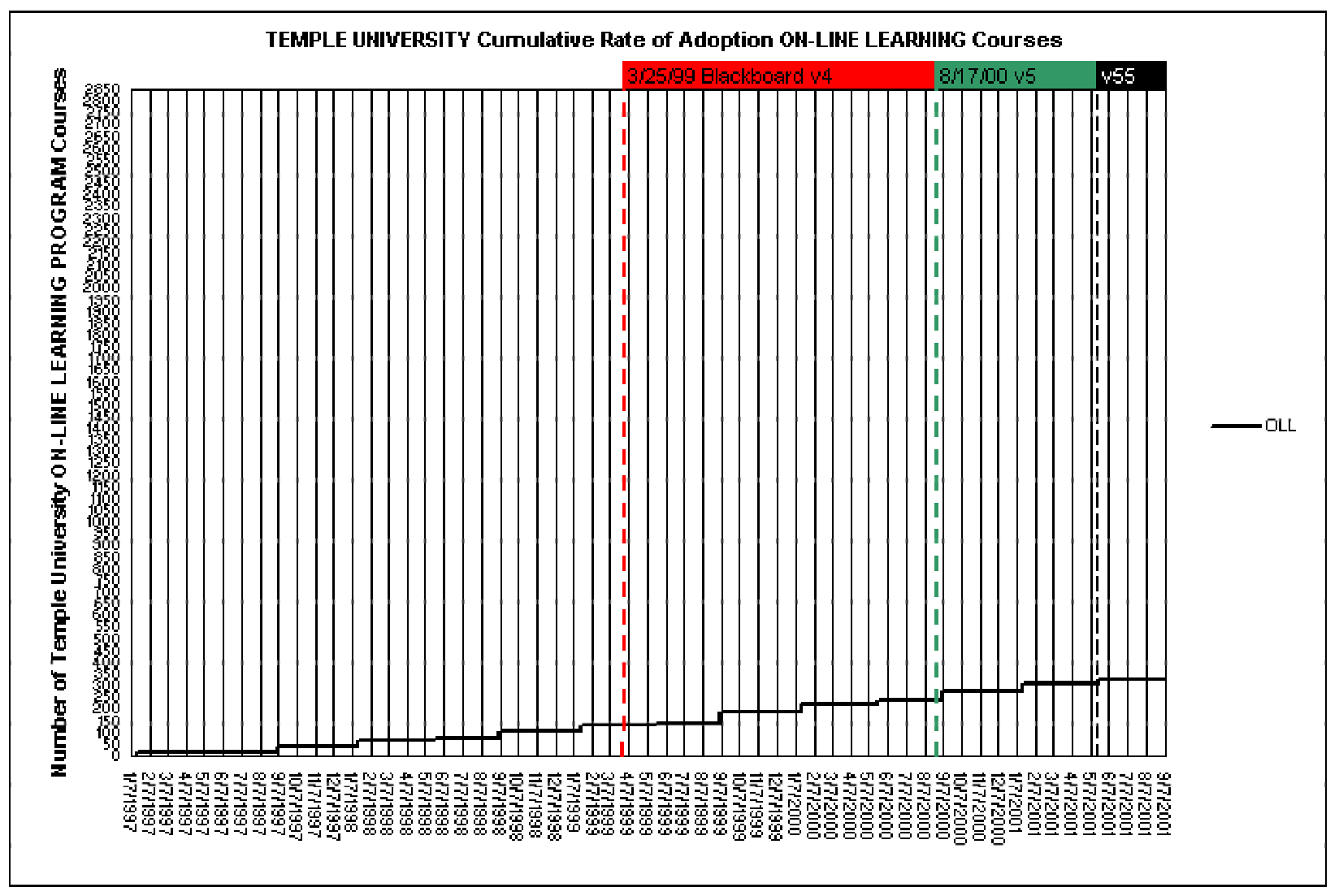

FIGURE 7: Rate of adoption for On-Line Learning Program with Blackboard phases. 
What was the rate of adoption (ROA) of the Temple University Blackboard

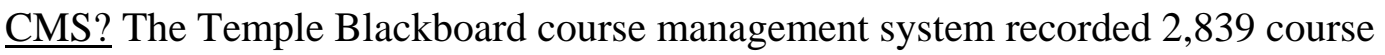
adoptions during the 898 days between its inception on March 25, 1999 and the end of the measurement period for this study (September 7, 2001). This results in an rate of 3.16 Blackboard course adoptions per day. All Temple Blackboard course data were charted using the same $\mathrm{X}$ axis values (898 days) to aid in visual comparison of their respective rates of adoption. To aid in answering research questions, Blackboard B1, B2 and B3 phases were added to each Temple Blackboard chart at their respective dates of onset (see Figure 8). 


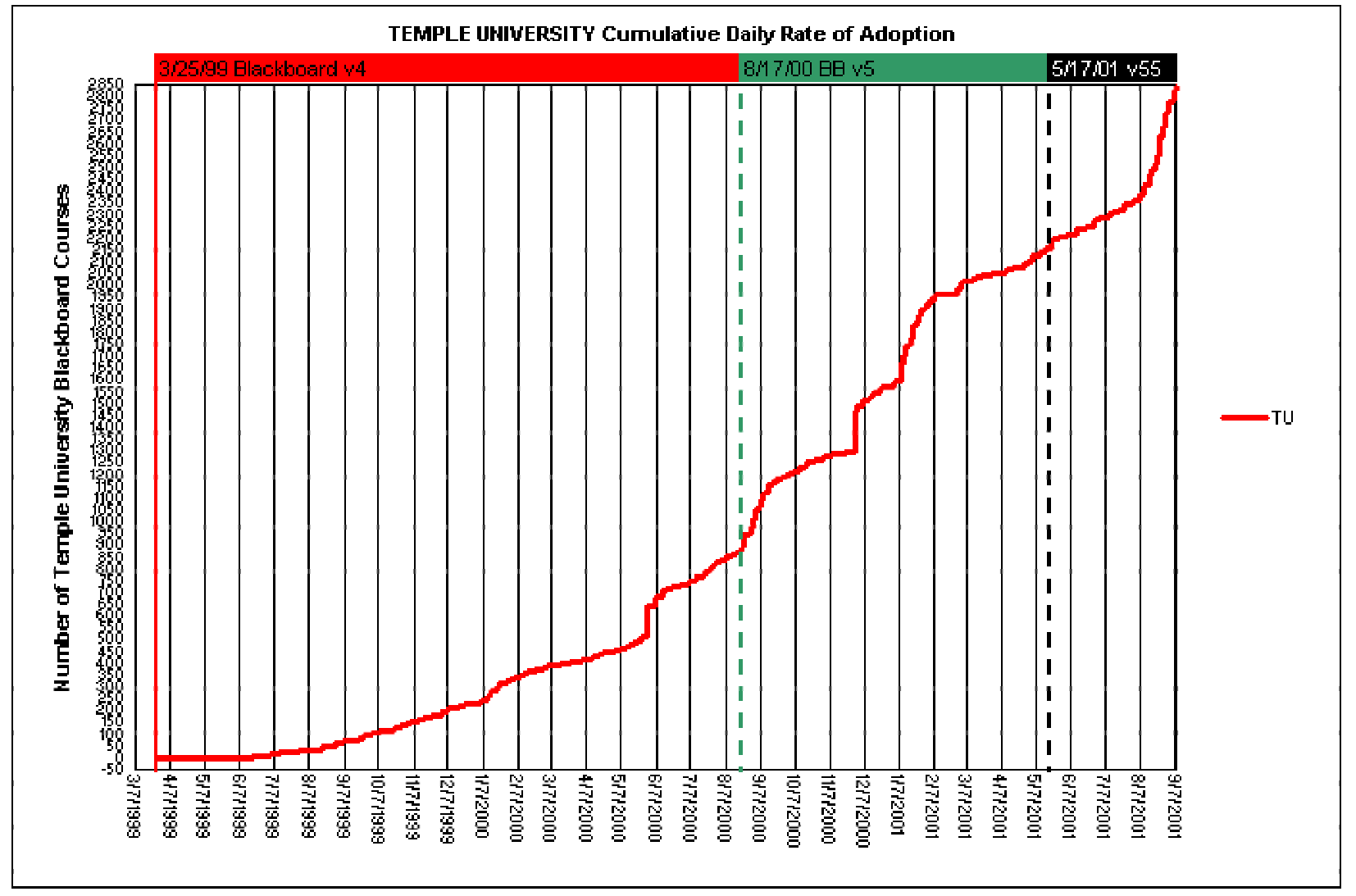

FIGURE 8: Rate of adoption for Temple Blackboard, showing B1, B2, and B3 phases. 
$\underline{\text { Is there a cumulative } S \text { curve when adoptions are measured per response, as }}$ opposed to per organism? If so, in which phase of the S curve is Temple University? The traditional S curve of innovation diffusion derives from the research of Frank Bass, analyzing rate of adopters of new products in marketing (Bass, 1969; Mahajan, Muller, and Bass, 1990). The Bass model measures and forecasts the number of people adopting an innovation, not the number of adoptions per person. This fundamental but subtle change from measuring adopters to measuring adoptions was the rationale for asking this research question.

Looking at Figure 8, it is not immediately intuitive that the cumulative record of Blackboard course adoptions for Temple University is an S curve. This might be expected, since the "classic" S curve of the Bass model relies on traditional innovation diffusion methodologies, the weaknesses of which (low frequencies of recall-based measures counting numbers of people, as opposed to the number of adoptions per person) have been discussed. The formulaic curves of the Bass model, while mathematically sophisticated, are models of rate of adoption, not actual rate of adoption curves. Perhaps for the first time, real-time performance measurement of "true" rate of adoption is available to provide empirical check and balance to the traditional S curve of the Bass model.

The software used to chart Temple Blackboard data was able to superimpose an exponential trendline over the Temple Blackboard cumulative record data. This illustrates the upwardly sloping trend across the fine-grained, daily cumulative curve (see Figure 9). 


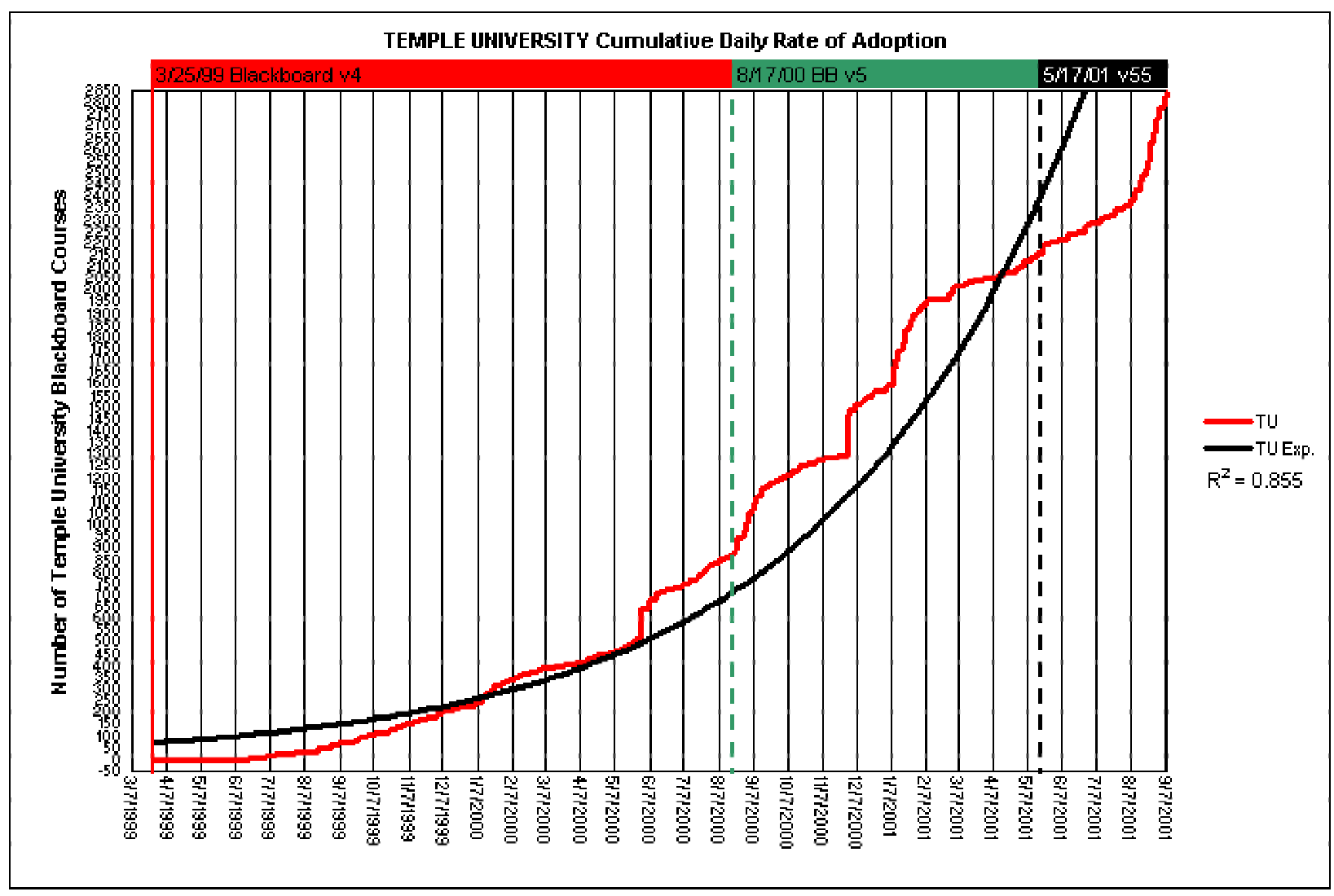

FIGURE 9: Exponential trendline applied to Temple Blackboard cumulative curve. 
The exponential trendline indicates that the overall Temple Blackboard rate of adoption is an S curve, but only the lower half. The upper half of the S curve extends beyond the end of the measurement period for this study, in the realm of forecasting. As noted in the Bass forecasting model, a cumulative $S$ curve includes one point of inflection - the point at which the cumulative $\mathrm{S}$ curve changes its direction of curvature. The Bass model used to forecast rate of adopter assumes that each half of the cumulative $\mathrm{S}$ curve is symmetrical. Figure 10 shows the same chart from Figure 9, along with a duplicate that has been inverted, simulating how Temple Blackboard rate of adoption would look if the top half of the S curve were symmetrical. 


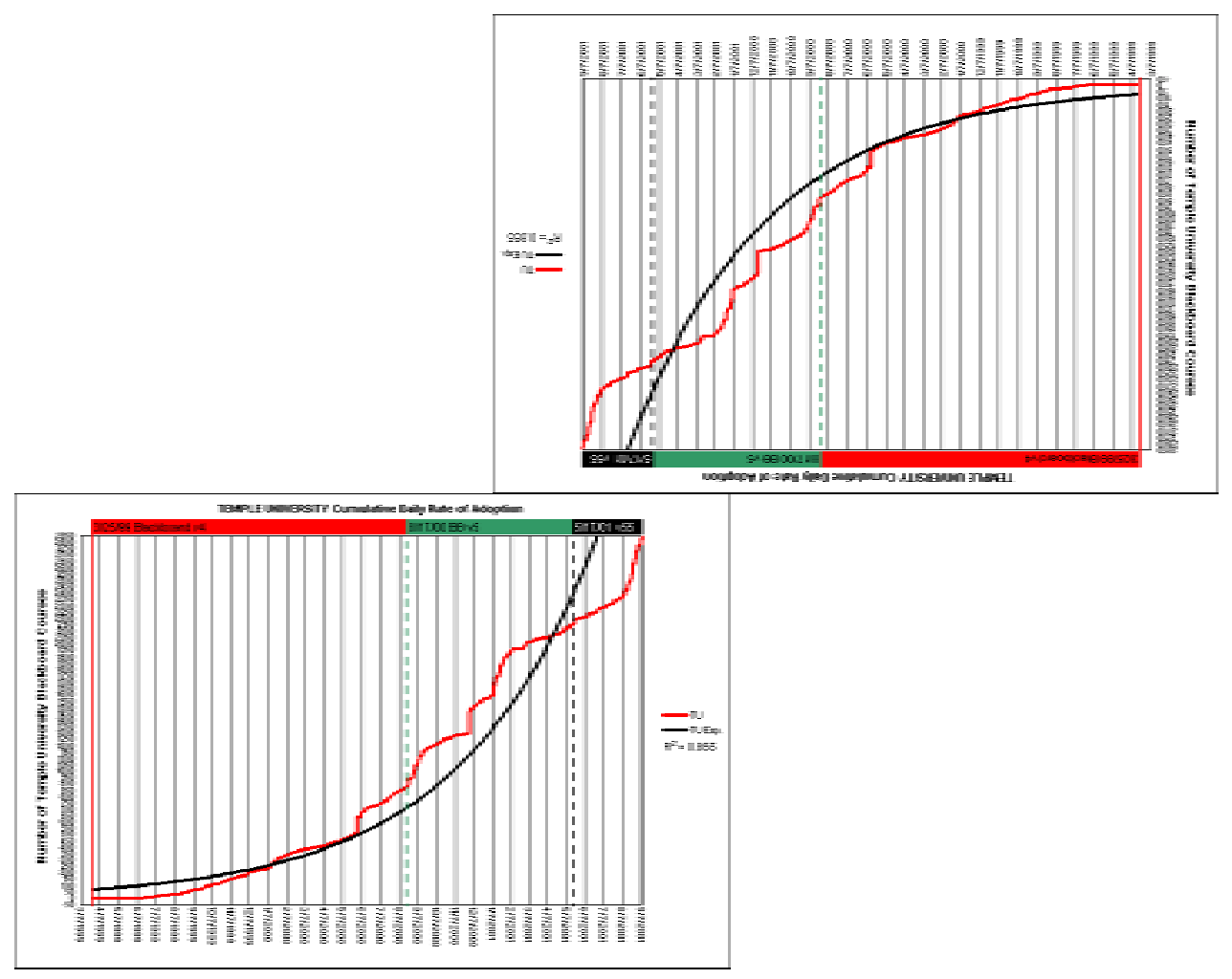

FIGURE 10: The Temple Blackboard chart, and its inverse. 
It is beyond the scope of this document to forecast the rate of adoption of Temple Blackboard, or to determine if the lower half of the cumulative $\mathrm{S}$ curve of Temple Blackboard data is before, at, or after its point of inflection. It does seem clear, however, that the overall shape of the cumulative record of Temple Blackboard course adoptions is the lower half of an $\mathrm{S}$ curve as routinely observed in innovation diffusion research.

For Temple University as a whole, what was the rate of adoption per full-time faculty person? According to the Common Data Set of Temple Factbook ${ }^{\mathrm{xv}}$, as of Fall 2000 Temple University employed 1,227 full-time faculty and 1,082 part-time faculty, for a total of 2,309 total faculty employed at Temple University.

To calculate a rate of adoption per full-time faculty person, 2,839 Temple Blackboard courses adoptions may be divided by 1,227 Temple full-time faculty, resulting in an average rate of adoption of 2.31 Blackboard courses per Temple full-time faculty. 2,839 Temple Blackboard courses divided by the number of all Temple full-time and part-time faculty $(2,309)$ results in an average rate of adoption of 1.22 courses per Temple faculty.

However, Temple Blackboard courses could be adopted by staff as well as faculty. Of 2,839 Temple Blackboard courses, 276 (9.7\%) were coded in parainstructional areas such as On-Line Learning, Instructional Support Centers, etc. (see Table 9, above). In addition, of the 872 Temple Blackboard courses coded as FOX, 39 (4.47\%) were coded in para-instructional areas like ADM, SBDC, and LAP (see Table 11, above), for a total of 315 para-instructional courses to be removed from the 
calculation of faculty average rates of adoption.

Removing these 315 para-instructional Blackboard courses from the 2,839 total Blackboard courses results a revised total number of Temple Blackboard courses: 2,524. This lower total number of Temple Blackboard courses results in slightly lowered average rates of adoption for full-time and all Temple faculty:

- 2,524 Blackboard courses adopted by 1,227 Temple full-time faculty = 2.057 Blackboard courses per Temple full-time faculty.

- 2,524 Blackboard courses adopted by all 2,309 Temple faculty $=1.093$ Blackboard courses per Temple faculty.

What was the rate of adoption for each Temple University college? Temple University lists 20 colleges in its Factbook ${ }^{\mathrm{xvi}}$. However, Temple Blackboard courses were adopted by Temple organizations as well as Temple colleges. Table 12 lists the total number of Blackboard courses adopted by all 20 Temple colleges and six organizations ranked from highest ROA to lowest. 


\begin{tabular}{|c|c|c|}
\hline COLLEGE CODE AND NAME & \multicolumn{2}{|c|}{ BBCOURSES/COLROA (BBCOURSES / 898 days) } \\
\hline TU Temple University & 2839 & 3.1615 \\
\hline FOX School of Business & 872 & 0.9710 \\
\hline CLA College of Liberal Arts & 548 & 0.6102 \\
\hline SOL Beasley School of Law & 394 & 0.4388 \\
\hline ISC Instructional Support Centers & 180 & 0.2004 \\
\hline CST College of Science \& Technology & 174 & 0.1938 \\
\hline SCT School of Communications \& Theater & 146 & 0.1626 \\
\hline EDU College of Education & 120 & 0.1336 \\
\hline AHP College of Allied Health Professions & 60 & 0.0668 \\
\hline SPM School of Podiatric Medicine & 46 & 0.0512 \\
\hline TST Test Courses & 43 & 0.0479 \\
\hline COM Esther Boyer College of Music & 40 & 0.0445 \\
\hline SOP School of Pharmacy & 40 & 0.0445 \\
\hline SSA School of Social Administration & 36 & 0.0401 \\
\hline SOM School of Medicine & 34 & 0.0379 \\
\hline TSA Tyler School of Art & 32 & 0.0356 \\
\hline !!! Example Cases & 16 & 0.0178 \\
\hline FSM Freshman Seminars & 12 & 0.0134 \\
\hline ??? Undetermined & 11 & 0.0122 \\
\hline RCC Russell Conwell Center & 10 & 0.0111 \\
\hline SOD School of Dentistry & 9 & 0.0100 \\
\hline OLL On-Line Learning Program & 7 & 0.0078 \\
\hline VPR Vice Provost for Research & 4 & 0.0045 \\
\hline HLP Temple HelpDesk & 2 & 0.0022 \\
\hline CDS Career Development Services & 1 & 0.0011 \\
\hline ECC Education Computing Center & 1 & 0.0011 \\
\hline LIB Temple Library & 1 & 0.0011 \\
\hline
\end{tabular}

TABLE 12: Blackboard courses and rates of adoption per Temple college and organization, ranked from highest to lowest.

Because each coded Temple Blackboard course record has its own daily point-ofadoption datestamp, a cumulative record for each college and organization may be graphed on the same chart. Figure 11 shows the cumulative record of Blackboard course adoptions for each Temple college and organization shown in Table 12, above. 


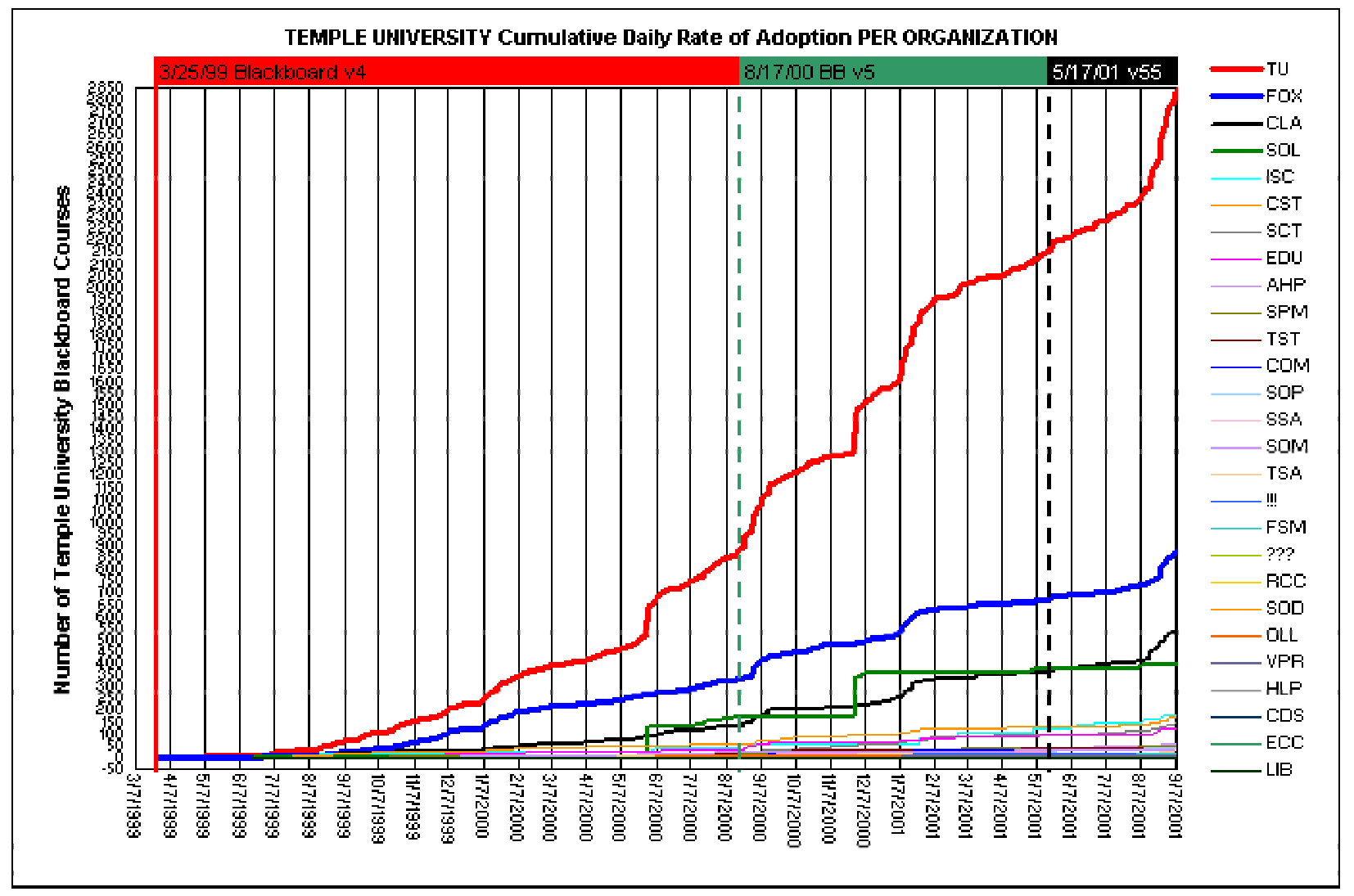

FIGURE 11: Cumulative records of rates of adoption for Temple colleges and organizations. 
In addition to the cumulative record for Temple University as a whole (in red) are the constituent cumulative records of each Temple college and organization, including “!!!” (Example Cases) and "???” (Undetermined) course records. Rates of adoption of each college and organization across the timespan and phases of Temple Blackboard illustrate how changes in level, variability, and trend of the overall Temple Blackboard rate of adoption is comprised of various changes in its constituent colleges and organizations. Graphing multiple organizations records on one chart allows visualization of:

Distinct patterns in rates of adoption by colleges. For example, note the vertical increases in ROA by the Beasley School of Law before 6/7/2000 and again before 12/7/2001 (SOL, dark green). Two vertical increases in level (indicating single-day increases) are each followed by weeks or months of horizontal flatline (indicating zero ROA). This "stairstep" pattern contrasts sharply with every other Temple Blackboard college. While corresponding near-vertical increases are apparent in the cumulative record for Temple University as a whole (red), charting the cumulative records of each organization reveals such changes to be solely the result of two single-day increases unique to the Beasley School of Law (5/30/00, 122 courses and 11/28/00, 172 courses). The Beasley School of Law single-day increases are $58.4 \%$ and $123.37 \%$ higher than the largest single-day cumulative increase of 77 courses on 8/24/01 (an aggregate of all the ROA for that day). The Beasley stairstep ROA curve shares common features, however, with ROA curves of para-instructional organizations, most notably Instructional Support 
Center (see Figures 11 and 12).

Multiple organization records on one chart show first adoption, and the long timespan between first and second adoption. In the 84 days between 3/25/99 and 6/17/99, the Fox School of Business had the first and only Blackboard course in operation (3/25/99, FOX, STAT402, Statistical Analysis / Quantitative Business Methods), followed by the second course adoption by College of Science \& Technology (6/17/99, CST, cis55, Computers and Applications).

Early acceleration and "breakaway" is revealed. The highest ROA college (FOX, blue) began an early differentiation in its ROA from the mass of nearly identical rates of adoption of other colleges. The FOX ROA began its breakaway acceleration just before 10/7/99, at which point other organizations had either no ROA, or an ROA not discriminably higher than others. Visually, the FOX breakaway period lasts until 1/6/00, at which point the College of Liberal Arts (CLA, black) and College of Science and Technology (CST, gold) begin their own differential accelerations from the rest of Temple University organizations. At the start of the Fox breakaway period (10/6/99), the Fox School accounted for 35.19\% of all Temple Blackboard courses, while by the end of this period (1/6/00) Fox accounted for 52.9\% of all Temple Blackboard courses. The highest proportion of Temple Blackboard courses coded as FOX (55.65\%) happened on 2/4/00, as CLA and CST continued their respective breakaway accelerations. The top seven organizations in Figure 11 (FOX, CLA, SOL, ISC, CST, SCT, and EDU) managed to breakaway from the remaining 19 college and organizational records, and become discriminable by the end of the study. 
Crossover patterns, where college or organization cumulative records intersect, are also shown. In Figure 11, the most conspicuous crossovers happen between Beasley School of Law (SOL, dark green) and College of Liberal Arts (CLA, black). The stairstep pattern of SOL crosses over CLA on the aforementioned two single-day increases unique to the Beasley School of Law (5/30/00 and 11/28/00). Owing to subsequent days of flatline, SOL crosses CLA on a horizontal trajectory twice more (before 9/7/00 and after 3/7/01). CLA and SOL share nearly identical levels, variability, and trend for the next four months, at which time CLA begins its subsequent breakaway from SOL's near horizontal level of ROA. Crossover resulting from nearly identical ROA over time characterizes the performance of all Temple colleges and organizations in Figure 11 except the top seven: FOX, CLA, SOL, ISC, CST, SCT, and EDU.

Common ROA changes across multiple organizations are shown. Perhaps the most helpful attribute of charting the cumulative rates of adoption of all Temple organizations on one chart is the ability to discriminate shared accelerations across multiple organizations at the same points in time. While it is easy to see idiosyncratic changes on the part of a single college (Beasley School of Law mentioned above), such charting also makes clear when changes in level, variability, and trend happen in tandem across more than one Temple organization. For example, one obvious shared acceleration started on 8/20/00 (immediately after the onset of B2: Blackboard v5 phase of 8/17/00) in the ROAs of FOX, CLA, ISC, and EDU, while CST and SCT start accelerating in tandem on $8 / 23 / 00$. Together, six of the top seven organizations began significant accelerations on or near $8 / 20 / 00$, with only SOL showing no acceleration. Another shared acceleration 
by FOX, CLA, CST, and EDU occurred starting 1/8/01 involving FOX, CLA, CST, and EDU). The third shared acceleration (8/14/01) shows common trends in six of the top seven organizations (FOX, CLA, ISC, CST, SCT, EDU) plus AHP, TST, COM, SOP, SSA, and SOM: a total of 12 organizational accelerations at once. Figure 12 shows the same chart, but on a logarithmic scale allowing the level at which most colleges perform to be viewed more easily. Accelerations or decelerations in ROA happening across multiple Temple organizations at once is a more reliable indicator of the presence of factors that influence Temple Blackboard rate of adoption. Such correlated performances are both clues about possible metacontingencies influencing Temple Blackboard ROA, as well as signals for further investigation derived inductively from actual performance data. 


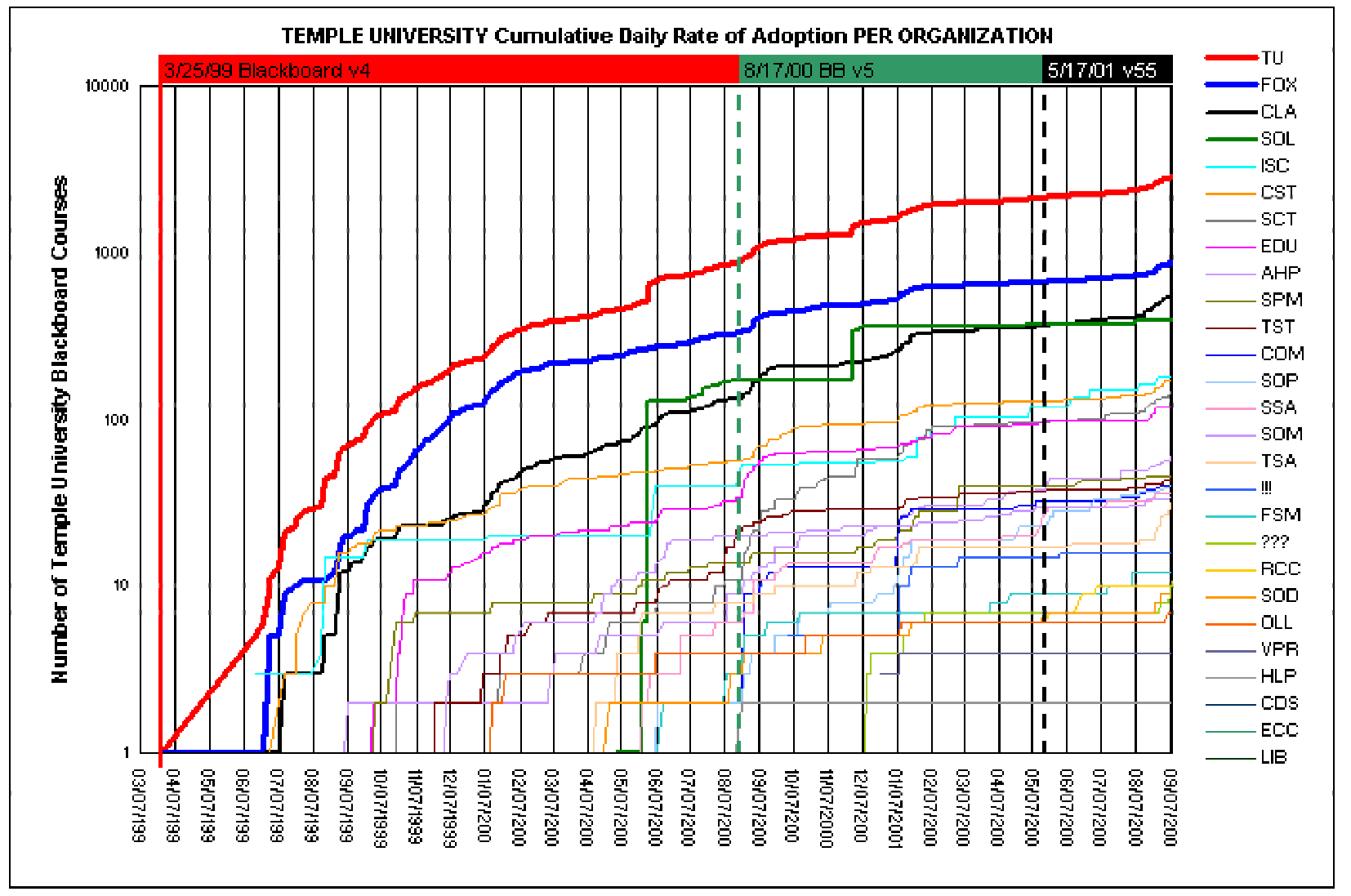

FIGURE 12: Cumulative records of rates of adoption for Temple colleges and organizations on a logarithmic scale. 
What Temple University college had the highest rate of adoption? For this

college, what was the rate of adoption per full-time faculty person? For this college, is

$\underline{\text { there a cumulative } S \text { curve when adoptions are measured per response, as opposed to per }}$ organism? If so, in which phase of the S curve is this college? What is the performance ratio between the full-time faculty of the highest ROA college and all full-time faculty of Temple University? As discussed above, the Fox School of Business is the highest rate of adoption organization at Temple University. After removing Fox para-instructional courses from its 872 total courses results in

- 833 Fox Blackboard courses adopted by 154 Fox full-time faculty $=5.41$ Blackboard courses per Fox full-time faculty.

- As noted above, both part and full-time Fox faculty contributed to Fox Blackboard. Adding the number of part-time faculty (100), 833 Blackboard courses adopted by 254 Fox faculty $=3.28$ Blackboard courses per Fox faculty.

Figure 13 shows the percentage of Temple Blackboard courses made up by Fox Blackboard courses over the duration of this study: 


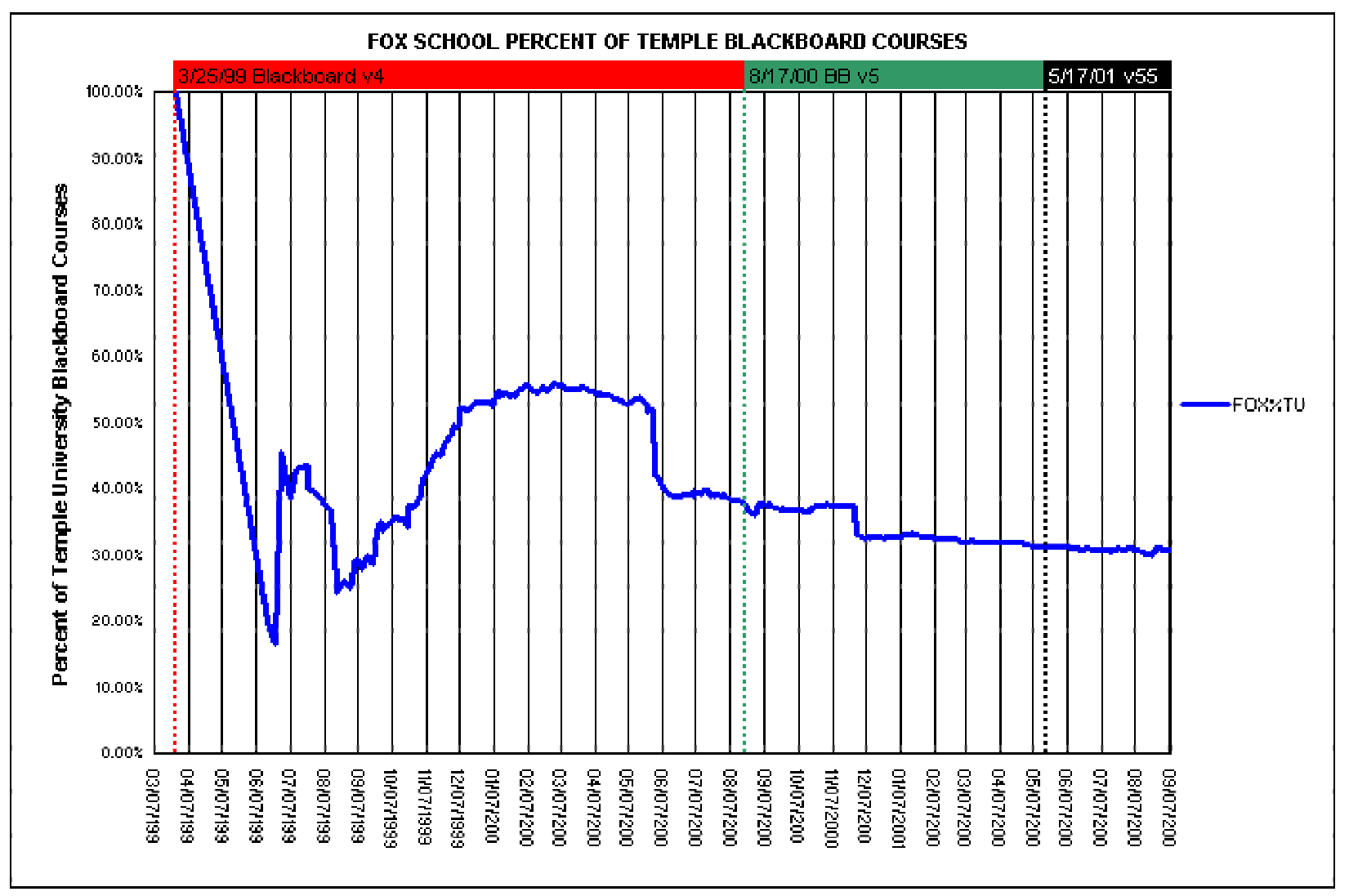

FIGURE 13: Fox School percentage of Temple Blackboard courses. 
As noted above, the Fox School of Business was the first and only college to adopt a Temple Blackboard course in the 84 days between 3/25/99 and 6/17/99, during which the Fox School comprised $100 \%$ of all Temple Blackboard courses. As other colleges and organizations began to adopt Temple Blackboard courses after 6/17/99, the Fox School percentage fell significantly, only to steadily increase to its highest point on 2/4/00 with 55.65\% of all Temple Blackboard courses being Fox School of Business courses. On the final day of the measurement period for this study, the Fox School held $30.72 \%$ of all Temple Blackboard courses.

As of 7/20/01, the Fox School of Business employed 154 full-time faculty (contact the author for complete data). 872 Fox Blackboard courses adopted by 154 fulltime faculty results in an average adoption of 5.66 Temple Blackboard courses per Fox full-time faculty. As shown in Table 11, however, of the 872 Fox Blackboard courses, 39 (4.47\%) were para-instructional courses coded ADM, SBDC, or LAP. Such Blackboard course units were not used to deliver course credits by full-time faculty, and as such should be dropped from consideration of full-time faculty performance in Fox Blackboard. Subtracting the 39 para-instructional course records results in an average of 5.41 Temple Blackboard courses per Fox full-time faculty. This average does not reflect the actual performance of any individual Fox full-time faculty person. By graphing the cumulative records of Fox Blackboard courses coded by department, we begin to view the performance of Fox faculty as characterized per department, and per faculty.

As shown in Table 11, each of the 872 Fox Blackboard course records was coded by Fox department, allowing portrayal of multiple Fox departmental cumulative records 
on the same chart (see Figure 14).

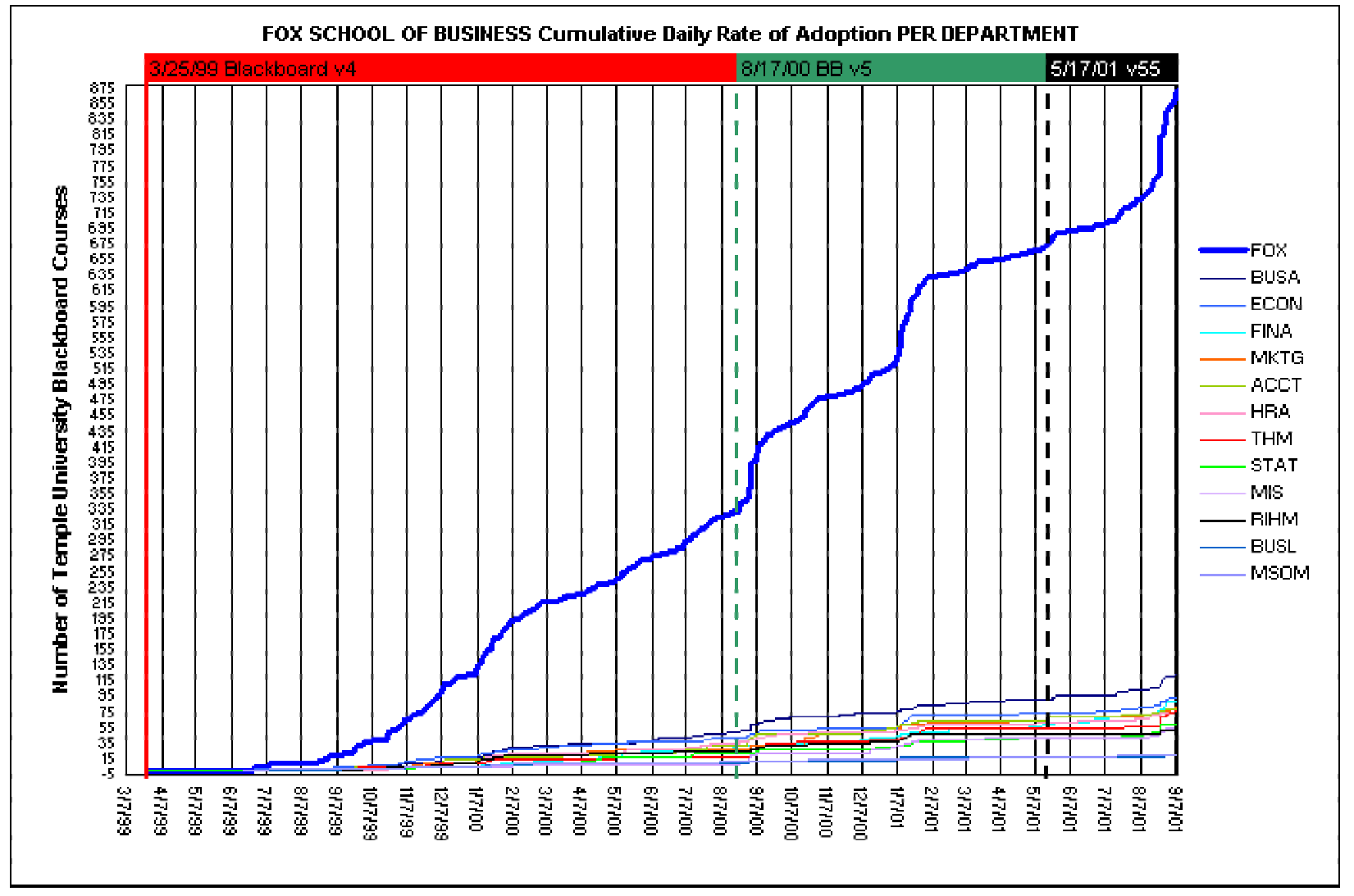

FIGURE 14: 872 Fox School Blackboard courses and constituent departmental ROAs. 
Like Figure 11, Figure 14 shows the total rate of adoption for an organization along with the constituent organizations comprising that total rate. Whereas the Temple Colleges chart has a scale from -50 to 2,850, the Fox Departments chart above uses a scale from -5 to 875 , allowing the cumulative records of 872 Fox Blackboard courses (blue) to fill the chart frame. Both Figures 11 and 14 share a common date range of 898 days, as well as common Blackboard phase markers. By showing the 12 cumulative records for each Fox department, Figure 14 allows the same visualization features as Figure 11, illustrating the levels, variability, and trends of the constituent departments that aggregate to the total Fox School rate of adoption. In addition, shared accelerations may be compared not only across Fox departments, but also between Temple Colleges and Fox Departments, adding 12 departmental cumulative records to the 19 distinct Temple college cumulative records as shown in Figure 11. Each new organizational cumulative record adds another "meter" which, changing in sync, adds more clues about factors that affect Temple Blackboard ROA in and across organizations. In the Fox Departments chart, each department is ranked from highest to lowest rate of adoption, with each department's overall ROA listed in Table 13. 


\begin{tabular}{|l|l|l|}
\hline FOXDEP & BBCOURSES & FOXDEPROA (BBCOURSES / 898 days) \\
\hline FOX & 872 & 0.9710 \\
\hline BUSA Business Administration & 123 & 0.1370 \\
\hline \hline ECON Economics & 93 & 0.1036 \\
\hline FINA Finance & 92 & 0.1024 \\
\hline MKTG Marketing & 82 & 0.0913 \\
\hline ACCT Accounting & 81 & 0.0902 \\
\hline \hline HRA Human Resource Administration & 76 & 0.0846 \\
\hline THM Tourism \& Hospitality & 76 & 0.0846 \\
\hline STAT Statistics & 60 & 0.0668 \\
\hline MIS Management Information Science & 54 & 0.0601 \\
\hline RIHM Risk, Insurance, \& Healthcare Management & 54 & 0.0601 \\
\hline \hline ADM Administration & 32 & 0.0356 (Removed from faculty counts) \\
\hline BUSL Business Law & 20 & 0.0223 \\
\hline \hline MSOM Management Science/Operations Management & 19 & 0.0212 \\
\hline SBDC Small Business Development Center & 6 & 0.0067 (Removed from faculty counts) \\
\hline EBZ eBusiness & 3 & 0.0033 \\
\hline LAP Laptop Honors & 1 & 0.0011 (Removed from faculty counts) \\
\hline TABLE 13: Fox Blackboard courses
\end{tabular}

TABLE 13: Fox Blackboard courses and rates of adoption per Fox department and organization, ranked from highest to lowest.

In Figure 14, each Fox departmental cumulative record is the total number of Blackboard courses adopted by that department over time. However, each Fox department is comprised of different numbers of faculty, both full and part time. By dividing each departmental cumulative record line by the number of full-time faculty assigned to that department, we begin to view departmental performance data indexed per faculty (see Figure 15). 


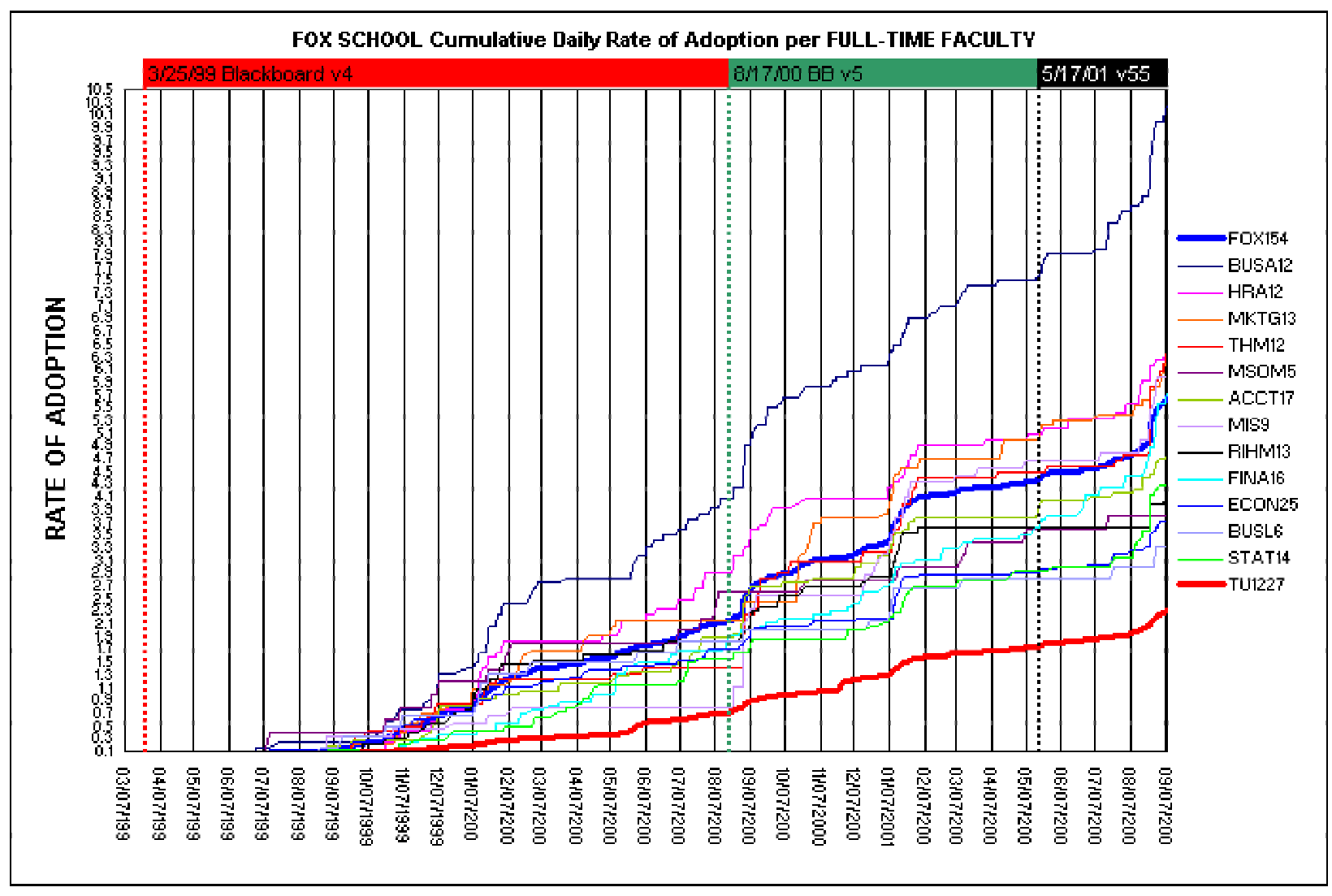

FIGURE 15: Fox Departmental rates of adoption per full-time faculty. 
In Figure 14, each department is ranked from first to last in terms of its rate of adoption. In Figure 15, however, each department is ranked by the average number of courses adopted by full-time faculty members. As shown, the level of each departmental cumulative record drops proportionately, which may be scaled from 0.1 to 10.5 while keeping an identical date range. Included in Figure 15 are both Fox School and Temple University cumulative record lines as divided by their respective full-time faculty totals. Above and beyond an average number of courses adopted per faculty, Figure 15 shows both an adjusted Fox School of Business cumulative record line as well as how each Fox department's cumulative record relates to the overall Fox record and the overall Temple record. Immediately apparent are the changed rankings of each Fox department compared to Figure 14. Departments that rank higher in Figure 14 (such as ECON) are reduced in rank proportionately by the number of full-time faculty who could be adopting, while departments with fewer full-time faculty (such as HRA) rise in rank. Perhaps the most useful features of Figure 15 are the decompression of lower-performing departmental course records so that ROA per full-time faculty at levels either above or below the adjusted Fox cumulative record. In addition, the inclusion of the Temple fulltime faculty rate of adoption record allows the comparison to each Fox full-time faculty rate of adoption.

Dividing the Temple, Fox, and Fox department rates by their respective full-time faculty numbers accurately portrays the performance ratio between Fox School of Business and Temple University full-time faculty. Table 14 lists the Temple University and Fox School full-time faculty overall rates of adoption. 


\begin{tabular}{|l|l|}
\hline Organization/faculty & ROA \\
\hline Full-time Temple faculty $(1,227)$ & 2.057 \\
\hline All Temple faculty $(2,309)$ & 1.093 \\
\hline Full-time Fox faculty (154) & 5.41 \\
\hline All Fox faculty (254) & 3.28 \\
\hline
\end{tabular}

TABLE 14: Temple University vs. Fox School rates of adoption.

In terms of full-time faculty, the Fox School of Business average rate of adoption is much higher than Temple University, both numerically and graphically. Fox ROA is 2.6 times higher, on average, than Temple University, an obvious gap in performance as manifest in Figures 11, 12, and 15.

We may expect the Fox School of Business cumulative curve, being a constituent of the overall Temple University curve, to be the lower half of an S curve. Figure 16 shows Figure 14 with a similar exponential trendline, along with its inverse duplicate, simulating how Fox rate of adoption would look if the projected top half of its $\mathrm{S}$ curve ran symmetrically. 

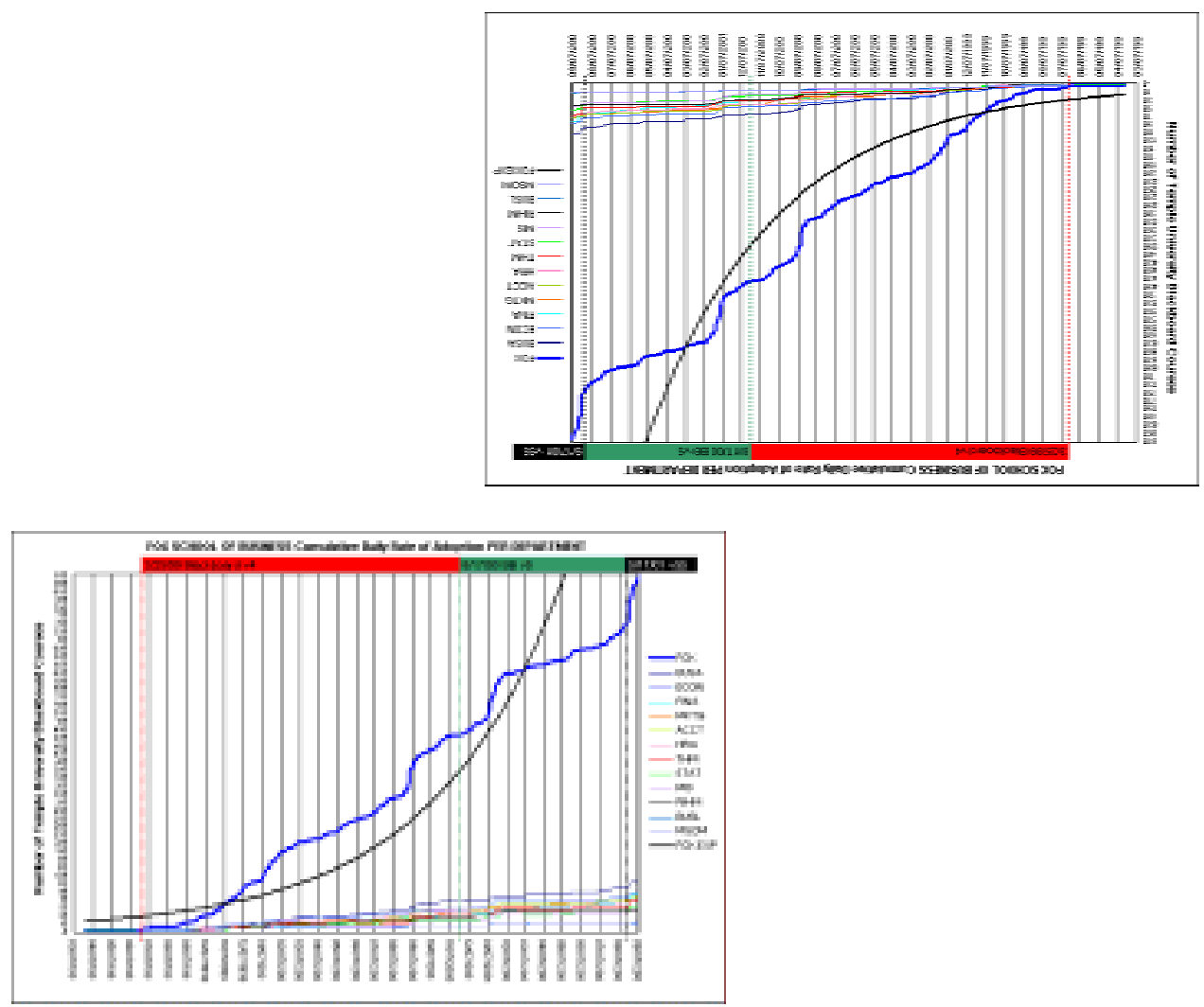

FIGURE 16: The Fox Departments chart, and its inverse. 
As noted throughout, Temple Blackboard course adoption was open to part-time, as well as full-time faculty. No comparison of performance ratio between Fox School and Temple University would be complete without factoring in the contributions of parttime faculty. Figure 17 shows the same Fox rates of adoption as in Figure 16, but divided by total faculty per department, with subsequent changes in level and rank based on the total personnel per department. 


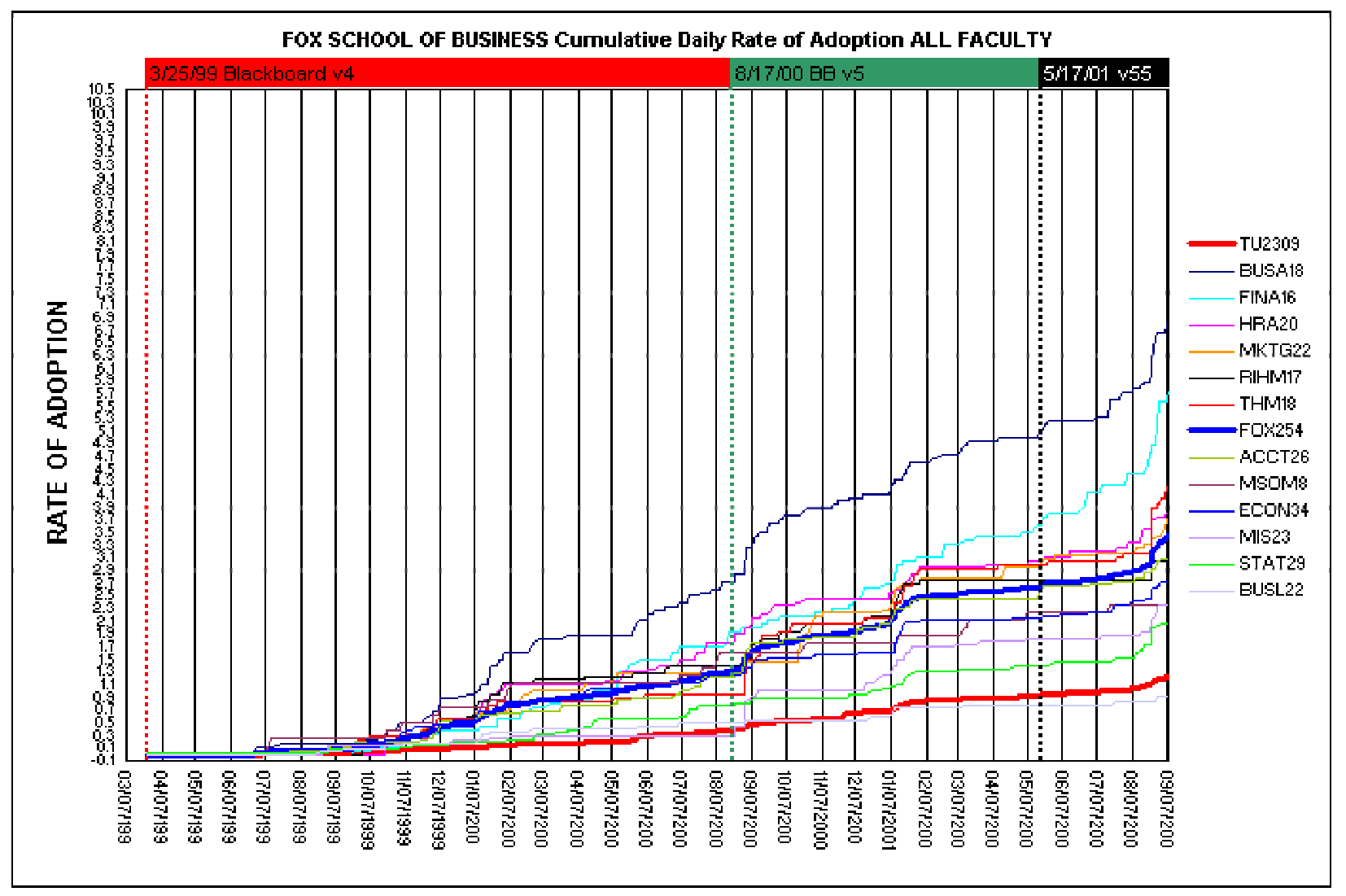

FIGURE 17: Fox Departmental rates of adoption per all faculty. 
While each record line is proportionately reduced in level, departments with higher numbers of total faculty are re-leveled. For example, MIS with 23 total faculty falls four ranks while FINA with no part-time faculty rises in rank. As in Figure 15, which departments are above or below the Fox School cumulative record are apparent. Only three departments rank higher than the Fox average when only full-time faculty data is used vs. six departments ranking higher than the Fox average when all faculty data is used. Perhaps the most striking change in departmental rate of adoption divided by all faculty are the number of departments whose performance ratio lowers with respect to Temple University. MIS, STAT, and BUSL descend toward the Temple cumulative record, with BUSL crossing over and ending below Temple.

What changes, if any, in rates of adoption occurred after CMS upgrades on Tuesday, Aug 17, 2000 and Thursday, May 17, 2001? A course management system upgrade is defined in the context of this project as a replacement of CMS software and/or hardware, occurring at a certain point in time and over a certain duration (i.e. number of days). In this respect, a CMS upgrade is the closest analogue to an "intervention" as understood in a natural science of behavior. A CMS upgrade uniquely changes its own look, features, and contingencies of operation. Such upgrades do so for every user of the CMS. No other Temple Blackboard factor is as encompassing, or as consistently trackable, as a CMS upgrade. In addition, such upgrades are linked to issues of cost and usability, important considerations in the maintenance of online courses in any organization.

Perhaps most important, course management system upgrades are variables which 
can be manipulated, as opposed to natural or cultural variables intractable to change. Should a CMS upgrade be correlated with decreased or flattened rate of adoption, such knowledge would be valuable in the decision to purchase or maintain subsequent upgrades, regardless of institution.

Distinct from the hardware and software aspects of a CMS upgrade are the formal and informal institutional announcements that accompany it. From email broadcasts, to website announcements, to listserv discussion, to "word of mouth", verbal behavior through official mass communication channels (contact the author for complete data) and informal conversations must be acknowledged when considering what changes if any occurred in rates of adoption after Temple CMS upgrades.

The Excel software used to chart each Temple Blackboard dataset allowed the calculation of the slope of the Temple University overall cumulative record (see Figures 8 and 9), as well as the slope of its curve during the B1, B2, and B3 phases. The software uses a regression formula to calculate the slope of a regression trendline for each phase. Table 15 shows the slope calculations for Temple University rate of adoption as a whole, and its three phases:

\begin{tabular}{|l|l|}
\hline Cumulative Record & Slope \\
\hline Temple University & 3.2149761 \\
\hline B1: Blackboard 4.0 Phase (511 days) & 1.6881100 \\
\hline B2: Blackboard 5.0 Phase (273 days) & 4.8692064 \\
\hline B3: Blackboard 5.5 Phase (114 days) & 4.7470241 \\
\hline
\end{tabular}

TABLE 15: Slope calculations for Temple Blackboard and its three phases. 
Slope calculations, as well as visual inspection of the Temple University cumulative record line show that the most substantial increases in rates of adoption occurred during B1 and B2 phases. But how much of that increase may be attributed to the CMS upgrades (and the suite of verbal events surrounding them)?

Figure 18 shows a composite of all-faculty rates of adoption for Temple University and Fox departments that include only the 20 points before and after the first Temple Blackboard upgrade phase (B2). The multiple cumulative records of the highest ROA college at Temple may better illustrate localized changes in level, variability, and trend occurring around the onset of CMS upgrades. 


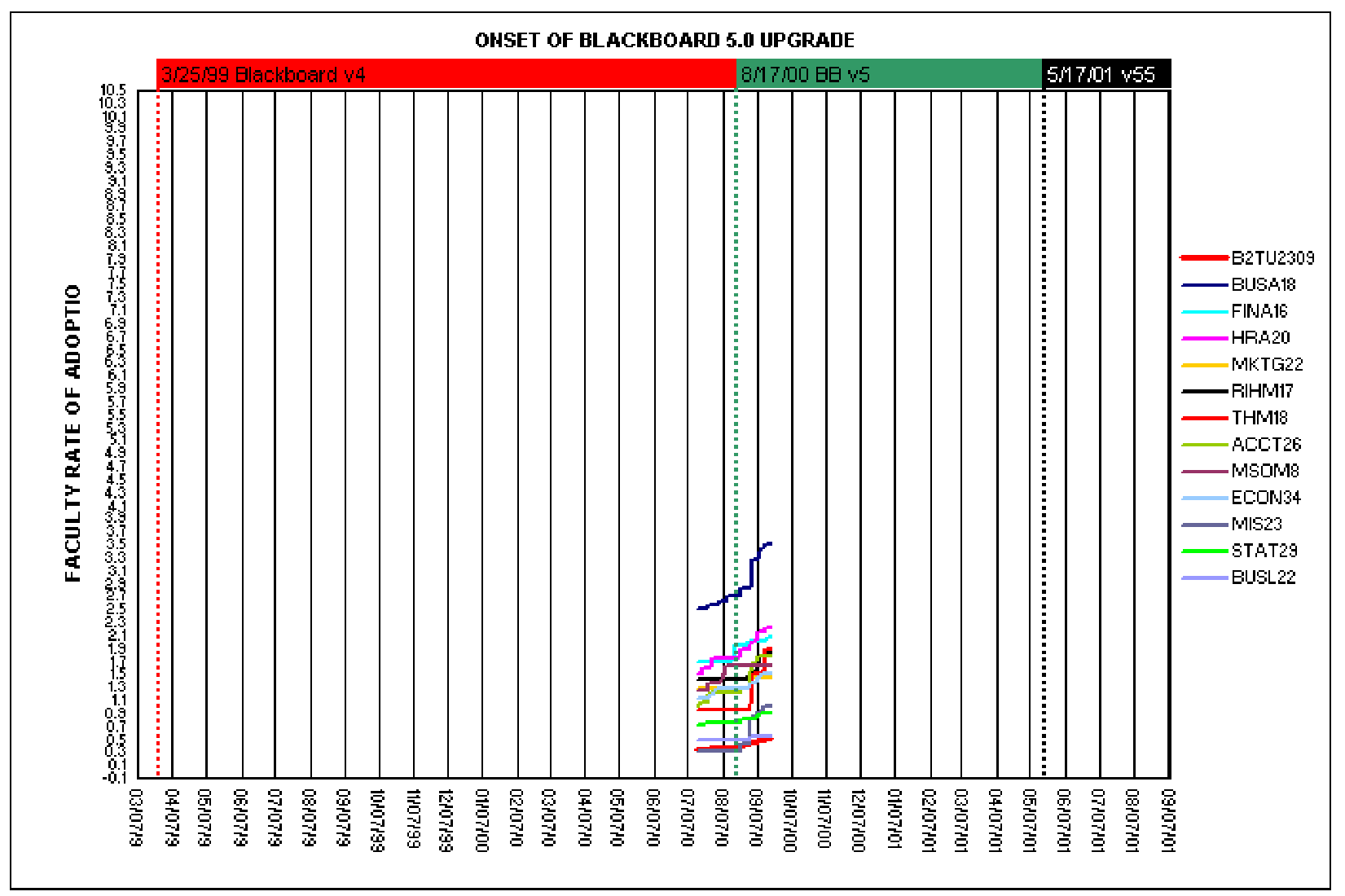

FIGURE 18: All-faculty rates of adoption 20 points before and after onset of B2 phase. 
This "narrowed view" isolates the before and after performance of Fox departments along with the Temple University cumulative record, placing with the onset of B2 phase at center. All 12 Fox departments increase subsequent to the B2 phase: however, eight Fox departments were already increasing prior to B2. Of particular interest are those departments who were not increasing, AKA flatline (indicating zero rate of adoption) in the 20 points before the onset of B2 phase. RIHM17, THM18, MIS23, and BUSL22 all showed horizontal ROA in the 20 points before B2; within two weeks each "flatline" department had experienced substantial accelerations. The sensitivity inherent in flatline departments is uniquely useful in teasing out effects of CMS upgrades as compared to departments with existing trajectories of acceleration.

The verbal components of CMS upgrades may help explain observed changes in cumulative rates of adoption in the week before the onset of the B2 phase on the parts of FINA16, MSOM8, and ECON34. Official verbal announcements now contact more people, faster, with longer shelf-life through email, listservs, and web pages. Inasmuch as such announcements are broadcast in the days before a CMS upgrade, ROA may summarily be increased antecedent to the dates of the CMS upgrade event.

Figure 19 repeats these charting conventions for the onset of the second Temple Blackboard CMS upgrade (B3) phase. Due to its later implementation, and continued acceleration of each Fox School department as well as Temple as a whole, cumulative record segments appear more widely dispersed across different levels, allowing easier visual discrimination. Three of the four flatline departments during B3 are the same as in B2: RIHM17, THM18, and BUSL22, with ACCT26 also flatline before the onset of B3. 
Perhaps most significant is the fact that RIHM17, THM18, and BUSL22 remained flatline throughout the B3 phase; a pattern which did not occur in any department during B2. In B3, only two departments (BUSA18, and ACCT26) accelerated on the day of the CMS upgrade; every other department was accelerating before and after. It is reasonable to suggest that CMS upgrades (along with their verbal behavioral components) do not retard rates of adoption, and may be a factor in visible increases both after and immediately before their implementation, as shown in Figures 18 and 19. Also, the comparison of $\mathrm{B} 2$ and $\mathrm{B} 3$ onsets seems to demonstrate that whatever power CMS upgrades may have over rate of adoption deteriorates over successive upgrades. However, more research is warranted to determine causal relationships between CMS upgrades and rate of adoption. 


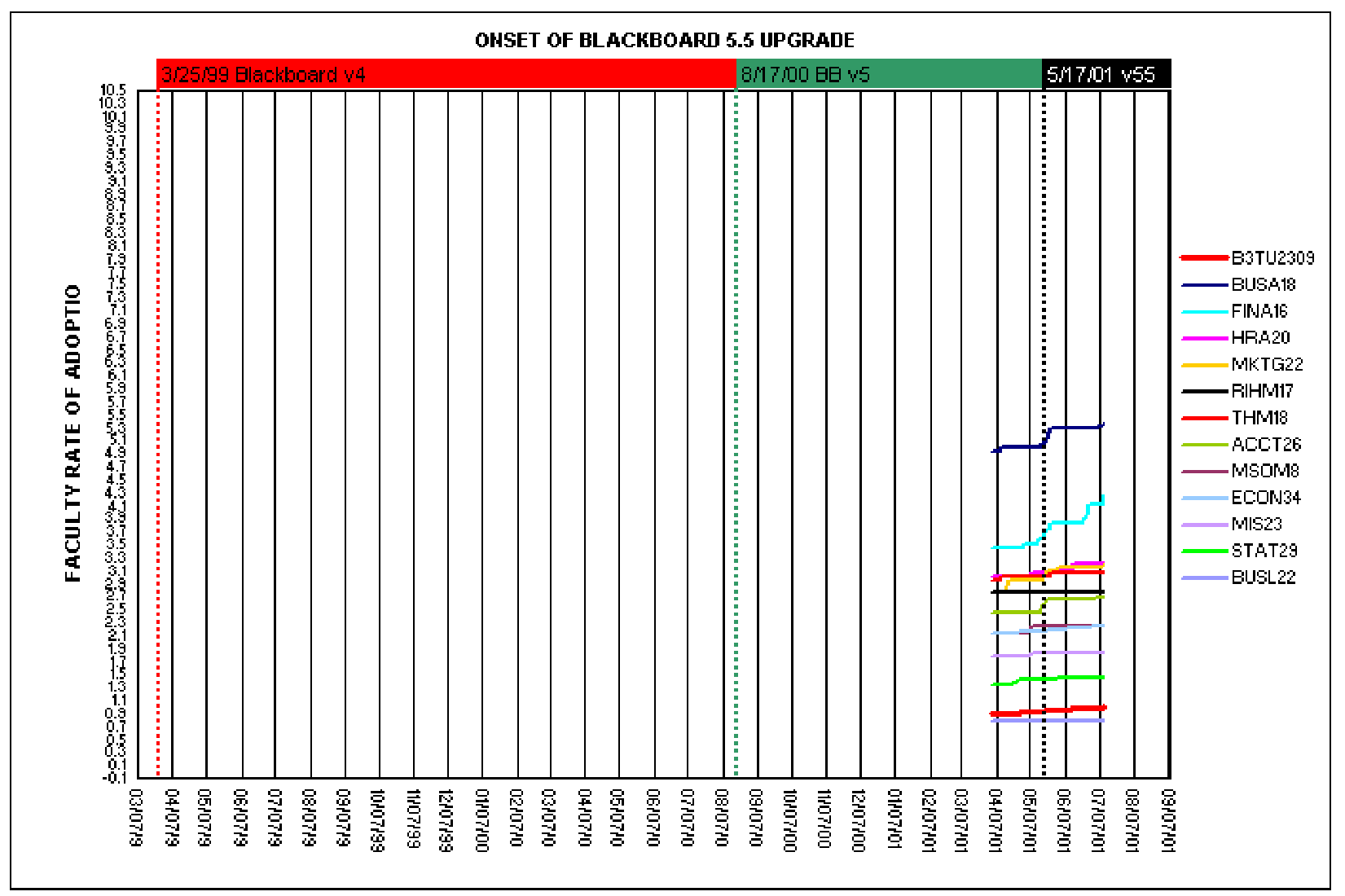

FIGURE 19: All-faculty rates of adoption 20 points before and after onset of B3 phase. 


\section{Conclusions}

\section{The New New Frontier}

In his June 2001 Institutional Self-Study, new Temple University president Dr.

David Adamany states:

“...many universities have strong programs to assist faculty to introduce technology into their classes... the Teaching Learning Technology Roundtable... reports that about $20 \%$ of courses are making some use of Blackboard, the Temple choice of comprehensive information system for classes... that $20 \%$ estimate is impressive, but it also reflects a long distance to go... We have no way of knowing the extent to which faculty have incorporated various information technology techniques into classes."

This research provides that "way of knowing" about the adoption of education technology by a whole University. This basic process provides the context for development of online courses, certificates, and degrees. Fundamental to developing a quality online course is the online course itself; without quantity, there is no quality. In this study, a remarkable amount of new data are generated about rate of adoption of online courses by a large organization. But digital cumulative recording of rate of adoption is itself a precursor to new issues about the instructional effectiveness and overall utility of a course management system; first quantity, then quality. As more emphasis is placed on online courses in higher education, both pro and con, Temple University Blackboard rate of adoption may be seen as the first map of a new New Frontier. 
Temple's "innovation explosion" is prelude to new questions, some of which may be answered within the current dataset; others which will require new data from new sources. From the vista of current data, for example, perhaps the most actionable question would involve the comparison of Temple Blackboard course adoption rates with the known number of all courses offered at Temple per semester. The known total number of Temple courses (as listed in various public Course Schedules) could be placed as "retroactive criterion" lines, illustrating points at which Temple Blackboard courses represented X percentage of all Temple courses offered. Preliminary investigation reveals that determining the total number of Temple course offerings to require substantial by-hand tallying as exemplified in the On-Line Learning course records detailed above.

The data and methodology derived from analyzing Temple Blackboard rates of adoption may serve a symbiotic role with prior innovation diffusion literature. The most salient mission may be to use Temple Blackboard style machine-monitoring as a precise platform from which to segue into further analysis of the "why and why not" of adoption of online courses in higher education. Rogers (1995) delineates questions of "why and why not" as strategically important for new innovation research. Since the "who, what, when, and how" of Temple Blackboard rates of adoption are known with precision, cumulative records of Fox School departmental adoption provide a powerful new context in which to research the why and why not of such adoption. For example, first, early, late, and last adopters from high-ROA faculty (BUSA, for example) may be approached with conventional surveys asking about the particulars of each individual's history relating to adoption of Blackboard courses. Such "targeted surveys" can document and compare the 
responses of adopters at different ROA levels (comparing BUSA with STAT, for example) and phases (first adopters in B1 phases vs. later adopters in B3 phases). Would high-ROA faculty have substantially different reasons for adoption or non-adoption than low-ROA faculty? The precision tracking of each adopter, even in anonymous format, sets the stage for more focused and productive generation of questions and answers regarding adopter and nonadopter motivations over time.

These and other questions may be answered out of research curiosity, but Temple Blackboard data spur practical questions whose answers support intervention and performance management. While basic distinctions between adopter and nonadopter are certainly possible, precision rankings based on cumulative records provide both answers to questions and directions for change. Answering a basic question such as "Who hasn't adopted a single Blackboard course?" suggests further inquiry into the control of nonpersonnel factors that block adoption (such as non-working course creation forms, or redundant and confusing required tasks). Of more importance is the ability to both answer questions about departmental performance (Which departments are below average adopters?) and to use such answers to lead to constructive, positive remediation (such as targeting lower ROA departments with seminars featuring those faculty who have adopted as professional models and peer supports).

Temple Blackboard data answer questions, generate new questions, and suggest appropriate venues for change, not only about Temple's adopter audience, but also about the innovation itself. In addition to questions, analysis of Temple Blackboard rate of adoption generates feedback about the Temple Blackboard tool, its apparatus, and its 
implementation. An implicit but unstated byproduct of this research is the demonstration of the lack of functional, real-time, aggregate performance indicators in the Temple Blackboard system. "What are the effects of real-time, public display of rate of adoption data on subsequent adoption?" is both a research question and a consumer demand, since such capabilities do not exist in current iterations of the Blackboard course management system. In short, important data are stockpiled but not exploited, leaving various analyses of importance to educators and administrators to whomever may discover them. It is incumbent upon the Blackboard company to exploit its own natural resource to add value for its customers, before the competition does.

The exploitation of course management system data for performance management transcends the arena of adoption into the inevitable forum of course quality. As quantity segues into quality, continuous real-time charting of adoption would set a clear precedent for the same presentation of data about student and faculty performances that comprise learning. As large institutions encounter the downsides of investment, maintenance, and support of course management systems, the "where's the beef" attitude of automatic skepticism, right or wrong, can be substantially assuaged not just with anecdotal reports and exemplary models, but with the routinization of real-time, continuous display of performance data, whether related to course quantity, course quality, or both in a seamless continuum. At the very least, institutions should demand that course management systems exploit the nature of their own digital cumulative recording devices to feature continuous, real-time charting of data relevant to course quantity and quality. 


\section{After The Gold Rush}

Temple Blackboard rates of adoption serve as an important benchmark of the innovativeness of a higher education institution. As such, this research exploits new technologies and methods that significantly increase data while reducing attendant costs. Of paramount importance, however, is that this research is eminently replicable: The Blackboard course management system has been installed at more universities and organizations worldwide than any other course management system. Owing to its digitization of point of adoption course records, thousands of rate of adoption data sets, similar to Temple Blackboard, lie in wait for research and application. Never have so many data been so available, to so many, for so little.

There's a catch. Blackboard course management systems, like those of other vendors, are implemented at lower or higher levels of institutional integration with prior student information systems. At so-called Levels 1 and 2, Blackboard systems run independently of priorly-installed University computer systems that comprise registration, course scheduling, library materials, or student records. Only at "Blackboard Level 3" is the Blackboard course management system integrated into legacy student information systems, and only after extensive planning and redesign of older computer systems.

As course management systems progress toward institutional integration, the nature of course creation changes from adoption to assignment. In the unintegrated environment, Blackboard courses are created in two general ways: by the adopter who completes a single course request webform to create a single course (see Figure 6), or by an institutional authority that may create dozens or hundreds of courses in a single "batch 
processing" request. The single-adopter webform method requires "online paperwork" on the part of the adopter for each course, each semester. While the batch-processing strategy (visible in the aforementioned Beasley School of Law) removes online paperwork for a cohort course-creators, it requires a human operator to assemble a list of course information, to decide on course ID and naming conventions, to time the batch processing appropriately, and other execution issues. In the unintegrated paradigm in which Temple Blackboard operates (and in which most Blackboard course management systems operate), a cadre of "human integrators" attempts to manage the rush of course management chores each semester.

Regardless, the accelerating progress of online education, course management systems, and institutional enterprise software convene in an unintended conspiracy to kill off rate of adoption data through the substitution of assigned, not adopted, online courses. It is ironic that the source of rate of adoption data springs from Temple University's unintegrated, piecemeal implementation of the Blackboard course management system. Requiring adopters to complete web-based course request forms, with their attendant hassles, is the fountainhead of point-of-adoption data collection as featured in this study. Rate of adoption as detected by the current Temple Blackboard system produces smooth curves that are the hallmark of the natural selection of behavior. The stair-step curves characteristic of automated "rate of assignment" will be purged of any selection-based patterns useful as an index of organizational, departmental, or staff innovativeness. Charts of such automated assignments of online courses will not be worth the paper they are not printed on. 
Temple University, following the lead of other institutions, will supplant its current process of course adoption with automatic assignment of Temple Blackboard courses to faculty. This fait accompli will accomplish the extinction of digital cumulative recording of rate of adoption. Nationally, the trend towards "back office" technology integration of course management systems will make digital cumulative records of rate of adoption an endangered species of digital data, universally available today, universally perishable tomorrow.

The status of such course management system data is analogous to gasoline before the inception of the internal combustion engine: gasoline as a petroleum distillate was so abundant as to be considered valueless, or of negative value. Once its value was discovered in the changing technological context of the internal combustion engine, gasoline was rapidly transformed from a liability to a commodity. Within one hundred years, gasoline has gone from effluvium to scarcity. While rate of adoption data from course management systems are currently relatively valueless, impending scarcity may take only one year, not one hundred.

What is to be done? In the near term, a concerted effort to collect, archive, and analyze rate of adoption data sets from national and international institutions is imperative. With windows of opportunity crashing closed, a systematic clearinghouse of comparable data sets is a worthwhile academic objective, one that I intend to achieve in my professional career. To paraphrase Abraham Lincoln: It is for me, to be here dedicated to the great task remaining before us... that these honored data shall not perish from the earth. 
In this crucial interim between paradigms of course adoption and assignment, institutions like Temple may leverage their control over web based request forms (see Figure 6) to improve quality and quantity of point-of-adoption data. Since Temple University controls the composition and function of Temple Blackboard point-ofadoption request forms, it is possible to collect mission-critical data with the least possible increase in task level. Two potent additions to a Temple University course request form would be sliding menus or check boxes indicating the adopter's college and department of record. While adding negligible complexity, such point-of-adoption changes would automate course coding, a necessary weakness of this study. Such changes would set the stage for the use of Temple Blackboard data as a real-time performance management tool.

Perhaps the way to "gasolinize" these unique, endangered data is to argue for their strategic preservation as a performance management apparatus and an innovation metering system for higher education. Real-time, automated, selection-based, rate of adoption data may be used analogously to an electro-cardiogram, an objective, legible gauge of the pulse of education technology innovation in an institution, regardless of its size or geographical location. By researching and investigating the performance management potential of course management systems nationally and internationally, the pulse of innovation may be monitored across organizations and cultures. By demonstrating the value of such data to decision makers inside local organizations and across international settings, it may be possible to engender changes to the course management system apparatus on the part of the mostly private, for-profit companies that 
manufacture them. Rate of adoption data may be lucrative.

In 1997, education and therapy practitioners had just begun a national stampede onto the internet, which I characterized as a gold rush which may not, in fact, imply gold (Feeney, 1997). Digital cumulative recording of rate of adoption of online courses is a lucky strike in a major vein of valuable data. 


\section{Bibliography}

American Association of University Professors (1998). Statement on Distance

Education. [On-line]. Available: http://www.aaup.org/spcdistn.htm

Anonymous. (2001). Old school in cyberworld. The American Enterprise, 12,

(6), 13-14.

Arnone, M. (2001). Cornell's distance education arm readies a new program, and hopes for profits. The Chronicle of Higher Education [On-line]. Available:

http://chronicle.com/free/2001/10/2001101601u.htm

Bass, F. M. (1969), A new product growth model for consumer durables.

Management Science, $13(5), 215-227$.

Batts, B., \& Crawford, L. L. (1991). Problematic progress [Review of the books Progress and its problems and Science and values]. Journal of the Experimental Analysis of Behavior, 55, 337-349.

Becker, H. J. (1991). How computers are used in United States schools: Basic data from the 1989 IEA Computers in Education survey. Journal of Educational Computing Research, 7, (4), 385-406.

Billups, A. (2000, September 19). Home-school movement goes global. The Washington Times, B1, B2.

Blumenstyk, G. (2001a). Temple U. lowers the axe on its distance education venture. The Chronicle of Higher Education [On-line]. Available: http://www.chronicle.com/daily/2001/07/2001070901u.htm 
Blumenstyk, G. (2001b). Temple U. Shuts Down For-Profit Distance-Education Company. The Chronicle of Higher Education, 47, (48), 029-030.

Bohrer, K. (1998). Analysis of contingencies and metacontingencies in a private sector workplace. Cambridge, MA: Cambridge Center for Behavioral Studies.

"Brownian Motion," Microsoft® Encarta® Online Encyclopedia 2001

[On-line]. Available:

http://encarta.msn.com/find/Concise.asp?z=1\&pg=2\&ti=761565039

Brunner, C. \& MacMillan, K. (1994). Beyond test scores: Other ways to measure your technology program. Electronic Learning, 14, 22-23.

Burt, R. S. (1987). Social contagion and innovation: Cohesion versus structural equivalence. American Journal of Sociology, 92,1287-1355.

Carlson, R. O. (1965). Adoption of Educational Innovation. Eugene, OR: Center for the Advanced Study of Educational Administration, University of Oregon.

Carlson, S. (2000). Campus survey finds that adding technology to teaching is a top issue. The Chronicle of Higher Education, 47, (9), A46.

Catania, A.C. \& Harnad, S. (eds.) (1988) The Selection of Behavior. The Operant Behaviorism of BF Skinner: Comments and Consequences. New York: Cambridge University Press.

Cervini, E. (2001). Virtual universities are a flop, warns web pioneer. The Age.com, (Feb 28). [On-line]. Available:

http://www.theage.com.au/education/home/education_news/2001/02/28/FFX3IBOGOJC. html 
Clayton, M. C., Mawhinney, T. C., Luke, D. E., \& Cook, H. G. (1997). Improving the management of overtime costs through decentralized controls: Managing an organizational metacontingency. Journal of Organizational Behavior Management, 7, (2), $77-98$.

Coleman, J. S., Katz, E., \& Menzel, H. (1957). The diffusion of an innovation among physicians. Sociometry, 20, 253-270.

Cooper, J.M., \& Bull, G. (1997). Technology and teacher education: Past practice and recommended directions. Action In Teacher Education, 19, 97-106.

Crandall, J., Jacobson, J., \& Sloane, H. (1997). What works in education. Cambridge, MA: Cambridge Center for Behavioral Studies.

Cross, D. E. (2001). For whom does the NET work? Black Issues in Higher Education, 18, (15), 104-105.

Crump, R.E. (1928). Correspondence and Class Extension Work in Oklahoma. Unpublished Doctoral Dissertation, Teachers College, Columbia University.

De Moll, C. (2000) Do try this at home! ComputerUser, 19, (10), 20-22.

Downs, G.W., Jr. \& Mohr, L. B. (1976). Conceptual issues in the study of innovations. Administrative Science Quarterly, 21, 700-714.

ECornell Press Release (2000). [On-line]. Available: http://www.ecornell.com/press/september14.jsp

Falba, C. J., Strudler, N. B., Bean, T. W. (1999). Choreographing change one step at a time: Reflections on integrating technology into teacher education courses. Action in Teacher Education, 21, (1), 61-76. 
Feeney, D. R. (1997). Creative life-style management through online and realtime application of the behaviorological education practices of precision teaching. In Ledoux (Ed.). Origins \& Components of Behaviorology. Canton, NY ABCs.

Fick, A. (1855). Annalen der Physik, Leipzig, 170, 59.

Flynn, G. L., Yalkowsky, S. H., \& Roseman, T. J. (1974). Mass Transport Phenomena and Models: Theoretical Concepts. Journal of Pharmaceutical Science., 63 (4), 479-510.

Ford, B. J. (2000). The earliest days of the microscope. Yearbook of Science and the Future 2000, ISBN 0-85229-702-5, Chicago: Encyclopedia Britannica, (pp. 192-209).

Foreman, J. (2001). Trading mules for tractors: The pros and cons of adopting a course management system. The Technology Source, January/February 2001. [On-line]. Available: http://horizon.unc.edu/TS/default.asp?show=article $\&$ id $=825$

Foreman, J., \& Widmayer, S. (2000). How online course management systems affect the course. Journal of Interactive Instruction Development, 13, (2), 16-19.

Fuller, H. L. (2000). First teach their teachers: Technology support and computer use in academic subjects. Journal of Research on Computing in Education, 32, (4), 511537.

Gagne, M. \& Shepherd, M. (2001). Distance Learning in Accounting: A Comparison Between a Distance and Traditional Graduate Accounting Class. T.H.E. Journal, 28, (9), $58-65$.

Glenn, S. S. (1986). Metacontingencies in Walden Two. Behavior Analysis and Social Action, 7, 1-7. 
Glenn, S. S. (1988). Contingencies and metacontingencies: Toward a synthesis of behavior analysis and cultural materialism. The Behavior Analyst, 11, 161-179.

Glenn, S. S. (1991). Contingencies and metacontingencies: Relations among behavioral, cultural, and biological evolution. In P. A. Lamal (Ed.), Behavior analysis of societies and cultural practices (pp. 125-139). Washington, DC: Hemisphere.

Goldberg, M. W. (1997). CALOS: First Results From an Experiment in Computer-Aided Learning. Proceedings of the ACM's 28th SIGCSE Technical Symposium on Computer Science Education, 11, 48-52. [On-Line]. Available: http://delivery.acm.org/10.1145/270000/268101/p48-

goldberg.pdf?key1=268101\&key2=268101\&CFID=387070\&CFTOKEN=61081412

Green, K. C. (1996). The coming ubiquity of information technology. Change, 28, (2), 24-27.

Hantula, D. A. \& Crowell, C. R. (1994). Intermittent reinforcement and escalation processes in sequential decision making: A replication and theoretical analysis. Journal Of Organizational Behavior Management, 14, (2), 7-37.

Harris, M. (1964). The nature of cultural things. New York: Random House. Harris, M. (1979). Cultural materialism: The struggle for a science of culture. New York: Random House.

Heylighen, F. (1992). "Principles of Systems and Cybernetics: An evolutionary perspective". Cybernetics and Systems '92, R. Trappl (Ed.). World Science, Singapore. (pp. 3-10).

Heylighen, F. (2001): "AUTOCATALYSIS". in F. Heylighen, C. Joslyn \& V. 
Turchin (Eds.). Principia Cybernetica Web [On-line]. Available:

http://pespmc1.vub.ac.be/ASC/Autocatalys.html

Higgins, S. T, \& Katz, J. L. (1998). Cocaine abuse: Behavior, pharmacology, and clinical applications. New York: Academic Press.

Hudson, L., Dietzel R., Sandiford, J. \& Morris, D. (1993). Effectiveness of Satellite Programs for Technical Updating of Vocational Education Teachers. Journal of Health Occupations Education. 8, (2).

Johnson, S. D., Aragon, S. R., Shaik, N. \& Palma-Rivas, N. (2000). Comparative Analysis of Learner Satisfaction and Learning Outcomes in Online and Face-to-Face Learning Environments. Journal of Interactive Learning Research, 11, (1), 29-49.

Johnston, J. M., \& Pennypacker, H. S. (1993). Strategies and Tactics of Behavioral Research 2nd Edition. Hillsdale, NJ: Lawrence Erlbaum Associates.

Jones, G. R. (1997). Cyberschools: An Education Renaissance. Jones Digital Century, Inc., (pp. 58 \& 128).

Karahanna, E., Straub, D., \& Chervany, N. L. (1999). Information technology adoption across time: A cross-sectional comparison of pre-adoption and post-adoption beliefs. MIS Quarterly, 23, (2), 183-214.

Kazdin, A. E. (1994). Behavior modification in applied settings. Pacific Grove, CA: Brooks-Cole.

Kennard, W. E. (2000, January). E-rate: A success story. Paper presented at the meeting of the Educational Technology Leadership Conference Council of Chief State School Officers, Washington, D.C. [On-line]. Available: 
http://www.fcc.gov/Speeches/Kennard/2000/spwek002.txt

Koch, J. V. (1998). How Women Actually Perform in Distance Education. The Chronicle of Higher Education, 45, (3), A60.

Lamal, P. A. (Ed.). (1997). Cultural contingencies: Behavior analytic perspectives on cultural practices. Westport, CT: Praeger.

Lang, M. T. (1973). Computer Extended Instruction in Introductory Calculus Dissertation Abstracts International 34, University Microfilm Abstracts No. 74-5, 271, p. 5662A.

LaRose, R., Gregg, J., \& Eastin, M. (2001). Audiographic Telecourses for the Web: An Experiment. Journal of Computer Mediated Communication, 4, (2) [On-line]. Available: http://www.ascusc.org/jcmc/vol4/issue2/larose.html

Lattal, K.A. \& Perone, M. (Eds.). (1998). Handbook of research on human operant behavior. New York: Plenum.

Lawton, S. B., \& Lawton, W. H. (1979). An autocatalytic model for the diffusion of educational innovations. Educational Administrative Quarterly, 15(1), 19-53.

Leahey, T. H. (1997). History of psychology: Main currents of psychological thought (4th ed.). Upper Saddle River, NJ: Prentice-Hall.

Ledoux, S. L. (1997). Origins \& Components of Behaviorology. Canton, NY ABCs.

Leiner, B. M., Cerf, V. G., Clark, D. D., Kahn, R. E., Kleinrock, L., Lynch, D. C., Postel, J., Roberts, L. G., \& Wolff, S. (2000). A brief history of the internet. [On-line]. Available: http://www.isoc.org/internet/history/brief.html 
Liegland, S. (1999). Pragmatism, science, \& society [Review of the book Objectivity, relativism, and truth: Philosophical papers Volume I]. Journal of the Experimental Analysis of Behavior, 71, 483-500.

Lin, C. \& Davidson, G. (1994). Effects of Linking Structure and Cognitive Style on Students' Performance and Attitude in a Computer-Based Hypertext Environment Proceedings: Selected Research and Development Presentations at the National Convention of the AECT Nashville, Tennessee, (pp. 451-461).

Loder, J. E. (1937). A Study of Aural Learning With and Without the Speaker Present. Master's Thesis, University of Nebraska: Lincoln, Nebraska.

Loveless, T. (1996). Why aren't computers used more in schools? Educational Policy, (10), 4, 448-467.

Lowery, C. T., \& Mattaini, M. A. (1999). The science of sharing power: Native American thought and behavior analysis. Behavior and Social Issues, 9, (1), 3-24.

Mahajan, V., Muller, E., and Bass, F. M. (1990). New product diffusion models in marketing: A review and directions for research. Journal of Marketing, 54, 1, 1-26.

Mawhinney, T. C. (1992). Evolution of organizational cultures as selection by consequences: The Gaia hypothesis, metacontingencies, and organizational ecology. Journal of Organizational Behavior Management, 12, 1-26.

Mawhinney, T. C. (1999). Cumulatively large benefits of incrementally small intervention effects: Costing metacontingencies of chronic absenteeism. Journal of Organizational Behavior Management, 18, (4), 83-95.

McCollum, K. (1997). A professor divides his class in two to test value of on-line 
instruction. The Chronicle of Higher Education, 43, (24), A23.

McKee, J. (2000). The Riddled Chain: Chance, Coincidence, and Chaos in

Human Evolution. Rutgers, NY: Rutgers University Press.

MIT OpenCourseWare Fact Sheet. (2001). [On-line]. Available:

http://web.mit.edu/newsoffice/nr/2001/ocw-facts.html

Moore, B. (2001). Taking stock of teacher technology use. Multimedia Schools, $\underline{8,(1), 26-31 .}$

Morris, E. K., \& Zarcone, T. J. (1999). Review of Cultural contingencies:

Behavior analytic perspectives on cultural practices. Behavior and Social Issues, 9, 1/2, 81-93.

National Center for Education Statistics. (1997a). 1997 digest of educational statistics. Washington, DC: U.S. Government Printing Office.

National Center for Education Statistics. (1997b). The condition of education: 1997. Washington, DC: U.S. Government Printing Office.

Navarro, P. \& Shoemaker, J. (1999). The Power of Cyberlearning: An Empirical Test.

Journal of Computing in Higher Education, 11, (1), 29-54.

Ndahi, H. (1999). Utilization of distance learning technology among industrial and technical teacher education faculty. Journal of Industrial Teacher Education, 36, (4), 21-37.

Neal, E. (1998). A Critical Response to Jerald G. Schutte's Virtual Teaching in Higher Education. [On-line]. Available: http://www.csuohio.edu/uctl/anti.html 
Nielsen, J. (1995). Alertbox for September 1995: Kill the 53-Day Meme. [Online]. Available: http://www.useit.com/alertbox/9509.html

Nielsen, J. (1996). Multimedia and HyperText: The Internet and Beyond. San Francisco, CA: Morgan Kaufmann Publishers.

Olsen, F. (1999). Faculty wariness of technology remains a challenge, computing survey finds. The Chronicle of Higher Education, 46, (10), A65, A66.

O’Neill, J. (November 4, 1999). For profit Temple spin-off will offer online courses. The Philadelphia Inquirer [On-line]. Available: http://www.temple.edu/news/online.html

Pelgrum, W. J., Janssen, R. I., \& Plomp, T. (Eds.).(1993). Schools, teachers, students, and computers: A cross national perspective: IEA CompEd Study.

Perley, J., \& Tanguay, D. M. (1999). Accrediting on-line institutions diminishes higher education. The Chronicle of Higher Education, 46, 10, B4, B6.

Phipps, R., \& Merisotis, J. (1999). What's the Difference? A Review of Contemporary Research on the Effectiveness of Distance Learning in Higher Education. Host name: Washington, DC: The Institute for Higher Education Policy [On-line]. Available: http://www.ihep.com/PUB.htm

Rai, A. (1998). Researching the organizational diffusion of information technology innovation. Information Resources Management Journal, 11, (3), 3-4.

Ray, B. D. (2001). FACT SHEET IIIc. Home Education Research [On-line]. Available: http://www.nheri.org/98/research/fact3b.html

Redmon, W. K, \& Agnew, J. L. (1991). Organizational behavior analysis in the 
United States: A view from the private sector. In P. A. Lamal (Ed.), Behavior analysis of societies and cultural practices (pp. 125-139). Washington, DC: Hemisphere.

Redmon, W. K. \& Wilk, L. A. (1991). Organizational behavior analysis in the United States: Public sector organization. In P. A. Lamal (Ed.), Behavior analysis of societies and cultural practices (pp. 107-123). Washington, DC: Hemisphere.

Riley, R. W. (1998). Technology for every classroom. Teaching Pre K - 8, 29, (2), $8-9$.

Rogers, E. M. (1986). Communication technology: The new media in society. New York, NY: The Free Press.

Rogers, E. M. (1995). Diffusion of Innovations, 4th Edition. New York, NY: The Free Press. Rogers, E. M., Geoghegan, W.H., Marcus, J., \& Johnson, L. (1996). In response: Four viewpoints. Change, 28, (2), 29-31.

Rogers, E. M., \& Shoemaker, F. F. (1971). Communication of Innovations: A Cross-Cultural Approach. New York, NY: The Free Press. Rogers, M. \& Oder, N. (2001). Bush won't move E-rate to DOE. Library Journal, 126, (6), 16-18.

Russell, T. L. (1999). The no significant difference phenomenon. Chapel Hill, NC: Office of Instructional Telecommunications, North Carolina State University.

Russell, T. L. (2000). The no significant difference phenomenon: A comparative research annotated bibliography on technology for distance education. Raleigh, NC: North Carolina State University.

Sato, M. (1995). Buddhism and Japanese culture: A behavioral analysis. Paper presented at the meeting of the Association for Behavior Analysis: An International 
Organization. Washington, DC.

Schmitt, D. R. (1998). The introductory class in higher education: Some old problems and new considerations. The Behavior Analyst, 21, (2), 281-288.

Schroeder, S. (Ed.). (1990). Ecobehavioral analysis and developmental disabilities: The twenty-first century. New York, NY: Springer-Verlag.

Schulman, A. (1999). Learning in an online format versus an in-class format: An experimental study. T.H.E. Journal, 26, (11), 54-56.

Schutte, J. G. (1996). Virtual Teaching in Higher Education: The New Intellectual Superhighway or Just Another Traffic Jam? California State University, Northridge. [Online]. Available: http://www.csun.edu/sociology/virexp.htm

Shermer, M. (2001). The evolution wars. Skeptic, 8, (4), 67-70.

Sidman, M. (1960). Tactics of Scientific Research: Evaluating Experimental Data in Psychology. New York, NY: Basic Books.

Skinner, B. F. (1938). The behavior of organisms: An experimental analysis. New York, NY: Appleton-Century.

Skinner, B. F. (1959). Cumulative record. New York, NY: Appleton-Century.

Skinner, B. F. (1981). Selection by consequences. Science, 213, 501-504.

Smith, E. E. \& Shen, C. (1992). The Effects of Knowledge of Results Feedback of Captioning on Listening Comprehension of English as a Second Language in Interactive Videodisc System. Proceedings of Selected Research and Development Presentations at the AECT National Convention, (pp. 718-742).

Stromberg, E. L. (1952). College for Television Home Study. American 
Psychologist, 7, 507-509

Thompson, K. R., \& Luthans, F. (1990). Organizational culture: A behavioral perspective. In B. Schneider (Ed.), Organizational climate and culture (pp. 319-344). San Francisco, CA: Jossey-Bass.

Thorman, J. H. \& Amb, T. (1974). The video tape presentation versus the "live" presentation: Better, worse or the same? Moorhead State College: Moorhead, MN.

Tornatzky, L. G., \& Klein, K. J. (1982). Innovation Characteristics and Innovation Adoption-Implementation: A Meta-Analysis of Findings. IEEE Transactions on Engineering Management, Feb 1982. New York, NY.

Ulman, J. D. (1998). Toward a more complete science of human behavior:

Behaviorology plus institutional economics. Behavior and Social Issues, 8, (2), 195-218.

Vachris, M. A. \& Bredon, G. (1999). Teaching principles of economics without 'chalk and talk': The experience of CNU online. Journal of Economic Education, 30, (3), 292-307.

Valente, T. W. (1994). Network models of the diffusion of innovations. Creskill, NJ: Hampton Press.

VanderMeer, A. W. (1950). Relative Effectiveness of Instruction by Films Exclusively, Films Plus Study Guides, and Standard Lecture Methods. Technical Report No. SDC 269-7-130. U. S. Navy Training Devices Center: Port Washington

Watkins, C. L. (1997). Project Follow Through: A case study on the contingencies influencing instructional practices of the educational establishment. Cambridge, MA: Cambridge Center for Behavioral Studies. 
Wegner, S., Holloway, K., \& Garton, E. (1999, November). The effects of Internet-based instruction on student learning. ALNMagazine [On-line]. Available: http://www.aln.org/alnweb/journal/Vol3_issue2/Wegner.htm

Weingand, D. E. (1984). Telecommunications and the Traditional Classroom: A Study of the Delivery of Education. University of Wisconsin, Madison, WS.

Weiss, M. J. (2001). Online America. American Demographics, 23, (3), 53-61.

Wellin, E. (1955). Water boiling in a Peruvian town. In Benjamin D. Paul (ed.), Health, Culture, and Community. Russell Sage Foundation, New York, NY.

Willis, J., Thompson, A., \& Sadera W. (1999). Research on technology and teacher education: current status and future directions. Educational Technology Research and Development, 47, (4), 29-45.

Woelfel, N. \& Tyler, I.K. (1945). Radio and the School. Tarrytown-on-Hudson, N.Y: World Book Co.

Young, J. (2001). MIT professors propose a costly effort to put all course materials online. The Chronicle of Higher Education Website. [On-line]. Available: http://chronicle.com/free/2001/03/2001030101u.htm 


\section{Vita}

Dr. David R. Feeney

449 Ravine Street, Langhorne PA 19047

DavidFeeney@aol.com

215-750-0458 home

215-204-2727 office

\section{DEGREES}

- Doctorate: Educational Psychology

West Virginia University, November 13, 2001. Contact: Dan Hursh, Ph.D

- Master of Arts: Educational Psychology

West Virginia University, 1995. Contact: Lawrence Fraley, Ed.D.

- $\quad$ Bachelor of Science: Philosophy

Ball State University, 1988. Contact: Jerome Ulman, Ph.D.

\section{EMPLOYMENT}

August 1999 to Present

Director of Digital Education, FOX School of Business \& Management, Temple University.

- Director, FOXOnline MBA, http://foxonline.temple.edu

- Office, classroom, and online coach for FOX School of Business faculty, staff, and students.

- Producer, Digital Concierge solutions events via wireless laptop.

- Producer, FOX STUDENT COMMUNITY

- Producer, My FOX Community on Blackboard.com

- Producer, Fox eNews public digital education listserv

- Analyses of measures of learning change in face to face vs. online sections of ACCOUNTING 401 (Fall 1999), with Dr. Eric Press.

July 1998 to August 1999

Distance Education Project Director, On-Line Learning Program, Temple University

- Faculty development and teacher-training for Temple online \& Laptop Learning faculty.

- Administration, Temple University Organizational Studies degree website.

- Course Manager, Women in American History distance course with Norton Connect online writing intensive server system.

- Design, setup and maintenance of On-Line Learning Lab for online teachers.

- $\quad$ Producer, America Online marketing program and website for Temple Online Learning Program

- Evaluation team for institutional adoption of WebStudy and Blackboard course management systems.

- $\quad$ Elearning program management at Temple Main Campus, Temple Fort Washington, Temple Ambler, Eagle Lodge, TU Center City, Executive MBA, Online MBA.

- $\quad$ Producer, Behavior2000 public listserve archive.

\section{IMPACT}

- Since March 25, 1999, Temple University has adopted more than 2800 Blackboard courses, making Temple Blackboard one of the largest installations of Blackboard in higher education.

- $\quad$ FOX School of Business has adopted more than 900 Blackboard courses, $30 \%$ of all courses in the Temple Blackboard system. 


\section{Endnotes}

i See http://www.fcc.gov/Reports/tcom1 996.txt

${ }^{\text {ii }}$ See http://news.cnet.com/news/01005-200-315893.html, http://dispatches.azstarnet.com/feat ures/class.htm

${ }^{\text {iii }}$ See

http://company.blackboard.com/do cs/Bbeduventures.pdf

${ }^{\text {iv }}$ See http://www.temple.edu/factbook

${ }^{v}$ See http://www.temple.edu

${ }^{\text {vi }}$ See

http://ww2.lafayette.edu/ allanr/bi blio.html

vii The database management system used in Temple Blackboard 5.0 is not designed to track course deletions. In each version of Temple Blackboard used (4.0, 5.0, 5.5), a course is created, the CREATION, COURSE ID, COURSE NAME, and other data are logged. However, in Blackboard 5.0 and 5.5, if a course is deleted, the original record for that course is removed. There is no $\log$ of course deletion dates, course ID deleted, or course name deleted, as if such courses were never created. An alternative logging tactic was needed to log and keep a record of every course ever created, regardless of subsequent deletion. The investigator solved this problem by taking regular "snapshots" of logged data. Beginning in April 1999, each new data snapshot was compared to the author's "master log" started on March 25, 1999. From each new data snapshot of Blackboard course data, only newly created courses were added to the original master $\log$. This results in a cumulative list of every course ever created in Temple University Blackboard course management system. Blackboard representatives have verified that the Blackboard 5.0 product does not track course deletions.

viii The Temple Blackboard system administrator is the computer services technician responsible for the day-to-day functioning of the Temple Blackboard server. While all data used in this study are available to the public via a web browser, public data views are not in tab-delimited or spreadsheetready format, but embedded in HTML pages. The Temple Blackboard system administrator has authority to query the database of Temple Blackboard for fields of select interest to the author, substantially reducing preparation of data for analysis \& charting.

${ }^{\text {ix }}$ See http://isc.temple.edu

${ }^{\mathrm{x}}$ See http://oll.temple.edu

${ }^{\mathrm{xi}}$ See http://directory.temple.edu/search/

xii The full-time faculty of School of Tourism and Hospitality report to the Dean of the Fox School of

Business. All such courses were included in the total courses for the Fox School of Business under the THM code. See http://www.temple.edu/sthm

xiii The count of Fox full time and part time faculty was done on $7 / 20 / 2001$. Numbers of full and part-time faculty per department are accurate only for the duration of Fall 2001 semester, but were used as a divisor for the entire 898 days of Temple Blackboard operation. Faculty counts dating back to $3 / 25 / 1999$ were not available at the time of completion of this study. While it is certain that faculty counts for prior semesters are different (lower), both the Fox School of Business Dean's Office and Fox department chairs verify that the number of faculties from semester to semester has changed little since Summer, 1999.
${ }^{\text {xiv }}$ Publication date of BITS N PCS Spring 2000 verified by Sue Banka, Bits N PCs Senior News Editor, sbanka@temple.edu, 215204-5555. See http://foxonline.temple.edu/drf/evi dence/tubitsnpcs

${ }^{\mathrm{xv}}$ See

http://www.temple.edu/factbook/cd s00/cdsi.html

${ }^{\text {xvi }}$ See

http://www.temple.edu/factbook/de scription.html 